Andrews University

Digital Commons @ Andrews University

2018

\title{
A Study Of Collaborative Skills Of Graduates Of A National, Faith- Based, Leadership Development Program
}

Eileen Kooreman

Andrews University, kooreman@andrews.edu

Follow this and additional works at: https://digitalcommons.andrews.edu/dissertations

Part of the Higher Education Commons, and the Leadership Studies Commons

\section{Recommended Citation}

Kooreman, Eileen, "A Study Of Collaborative Skills Of Graduates Of A National, Faith-Based, Leadership Development Program" (2018). Dissertations. 1655.

https://digitalcommons.andrews.edu/dissertations/1655

https://dx.doi.org/10.32597/dissertations/1655

This Dissertation is brought to you for free and open access by the Graduate Research at Digital Commons @ Andrews University. It has been accepted for inclusion in Dissertations by an authorized administrator of Digital Commons@ Andrews University. For more information, please contact repository@andrews.edu. 


\title{
ABSTRACT
}

\section{A STUDY OF COLLABORATIVE SKILLS OF GRADUATES OF A NATIONAL, FAITH-BASED, LEADERSHIP DEVELOPMENT PROGRAM}

\author{
by
}

Eileen Kooreman

Chair: Erich Baumgartner 


\title{
ABSTRACT OF GRADUATE STUDENT RESEARCH
}

Dissertation

\author{
Andrews University \\ School of Education
}

\section{Title: A STUDY OF COLLABORATIVE SKILLS OF GRADUATES OF A NATIONAL, FAITH-BASED, LEADERSHIP DEVELOPMENT PROGRAM}

Name of researcher: Eileen Kooreman

Name and degree of faculty chair: Erich Baumgartner, Ph.D.

Date completed: January 2018

Collaboration is often cited as a long-term benefit of participation in leadership development programs. Successful collaboration requires unique leadership skills, which rely on trust and influence rather than authority and position. Collaboration takes place over the passage of time. Evaluation of leadership development programs that focus on outcomes after the passage of time is rare making it difficult to confirm if a relationship between the collaborative skills taught and measurable collaboration activity exists.

This study was able to draw on the alumni of the DeVos Urban Leadership Initiative, a national faith-based leadership development program that maintains on-going relationships with its graduates. Alumni from a ten-year period were surveyed using a pre-existing instrument called the Collaborative Leadership Self-Assessment and a collaboration activity measurement designed for the study. An analysis of the effect of 
the collaborative leadership skills and demographics of the participants on collaboration activity was conducted using, Pearson correlation, multiple regression analysis, and oneway analysis of variance.

All of the collaborative leadership skills had a significant relationship to reported collaboration activity. The ability of the leader to bring clarity to a shared vision and create action plans to mobilize people had the strongest relationship to collaboration activity. Leaders who showed a willingness to share power and influence also had a strong relationship to collaboration activity. Analysis of demographic segments of the study participants showed there was a significant difference between men and women with men reporting collaboration more often than women. There was also a significant difference based on education level. Alumni who had no college degree reported more collaboration activity than those who had a graduate degree. 
Andrews University

School of Education

\title{
A STUDY OF COLLABORATIVE SKILLS OF GRADUATES \\ OF A NATIONAL, FAITH-BASED, LEADERSHIP \\ DEVELOPMENT PROGRAM
}

\author{
A Dissertation \\ Presented in Partial Fulfillment \\ of the Requirements for the Degree \\ Doctor of Philosophy
}

by

Eileen Kooreman

January 2018 
CCopyright by Eileen Kooreman 2018 All Rights Reserved 


\title{
A STUDY OF COLLABORATIVE SKILLS OF GRADUATES OF A NATIONAL, FAITH-BASED, LEADERSHIP DEVELOPMENT PROGRAM
}

\author{
A dissertation \\ presented in partial fulfillment \\ of the requirements for the degree \\ Doctor of Philosophy
}

by

Eileen Kooreman

APPROVAL BY THE COMMITTEE:

Chair: Erich Baumgartner

Member: Jay Brand

Member: Edwin Hernandez

External: Graham McKeague
Dean, School of Education Robson Marinho 


\section{TABLE OF CONTENTS}

LIST OF TABLES ............................................................................. vi

LIST OF FIGURES …........................................................................ viii

LIST OF ABBREVIATIONS .................................................................... ix

ACKNOWLEDGEMENTS ....................................................................

Chapter

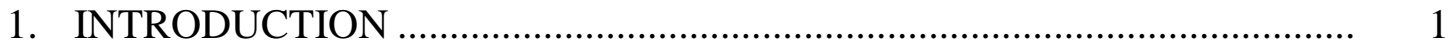

Background of the Problem ...................................................................... 1

Statement of the Problem......................................................................... 5

Purpose of the Study ............................................................................ 6

Research Questions ...................................................................... 7

Significance of the Study .................................................................... 7

Theoretical Framework ............................................................................. 8

Research Design............................................................................. 10

Delimitations of the Study ............................................................. 10

Limitations of the Study................................................................ 10

Definition of Terms........................................................................... 11

Organization of the Study ................................................................ 13

2. LITERATURE REVIEW ................................................................. 14

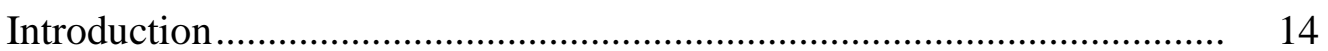

Youth At-Risk ......................................................................... 15

Working with At-Risk Youth............................................................... 19

The Power of Collaboration .................................................................... 22

The Six Skills of a Collaborative Leader................................................... 26

Leadership Development Programs ........................................................ 32

Evaluation of Leadership Development Programs ................................. 34

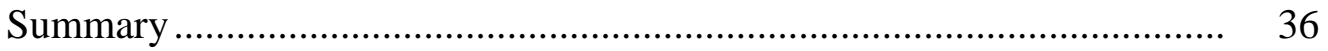

3. METHODOLOGY ............................................................................ 37

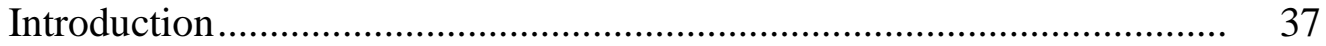

Research Questions ........................................................................ 37

Research Context ........................................................................... 38

Selection of Participants ......................................................... 39 
Curriculum Content and Delivery Format .................................... 40

Post-Training Support for Collaboration ......................................... 42

Type of Research ............................................................................. 44

Population and Sample ............................................................. 45

Correlation Design .............................................................. 45

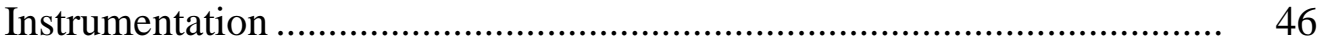

Collaborative Leadership Self-Assessment ..................................... 49

The Youth Ministry Collaboration Activity Scale ............................. 50

Cooperation ........................................................................ 52

Coordination .................................................................. 52

Collaboration................................................................. 52

Definition of Variables ................................................................... 53

Hypotheses .............................................................................. 55

Reliability/Validity ...................................................................... 58

Data Collection Procedures................................................................ 60

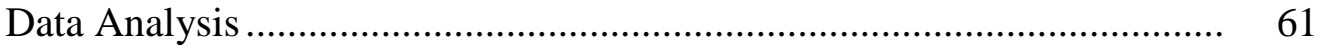

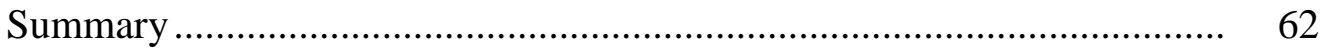

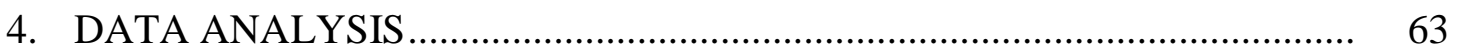

Participants Description .................................................................... 63

Demographics of the Population ........................................................ 64

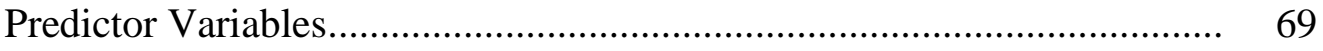

Dependent Variable YMCAS ........................................................ $\quad 70$

Hypotheses Testing .............................................................................. 73

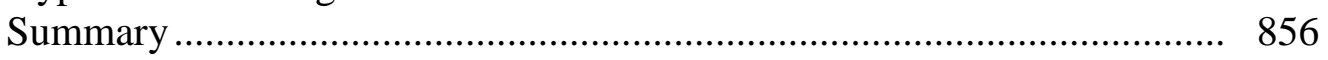

5. SUMMARY, CONCLUSIONS, AND RECOMMENDATIONS.................. 87

Summary ..................................................................................... 87

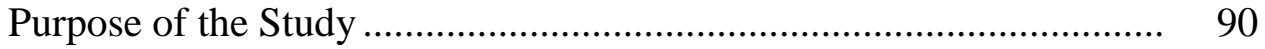

Leadership Program Evaluation...................................................... 90

Design of the Study................................................................ 96

Findings and Discussion ................................................................... 98

Collaborative Leadership Self-Assessment ................................... 98

Collaboration Activity Scale ............................................................ 99

Collaboration Activities .............................................................. 99

Frequency Reports ......................................................... 100

Research Question One ........................................................... 102

Research Question Two ............................................................ 105

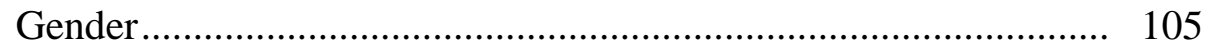

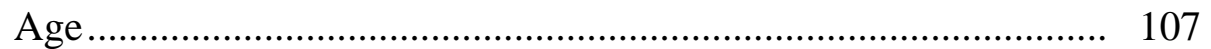

Education Level .................................................................... 108

Ethnicity ....................................................................... 109

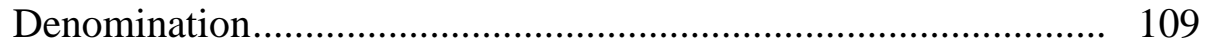

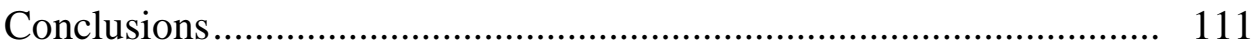

Recommendations for DVULI......................................................... 112 
Recommendation for Further Research

Appendix

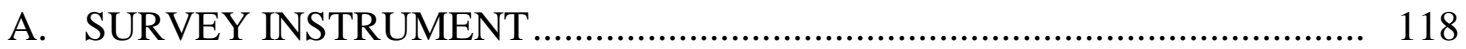

B. YOUTH MINISTRY COLLABORATION ACTIVITY SCALE ................... 128

C. DVULI PROGRAM LOGIC MODEL ................................................... 130

D. DVULI COLLABORATIVE LEADERSHIP SKILLS INTEGRATION ....... 138

E. PERMISSION TO USE SURVEY ....................................................... 142

F. ALTERNATE VIEW OF DATA (GROUPING BY COOPERATION, COORDINATION, AND COLLABORATION WITH ACTIVITY COUNT) .................................................................... 145

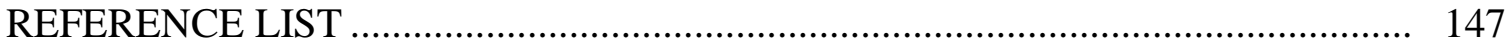

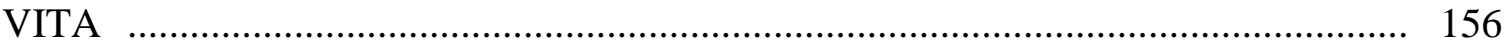




\section{LIST OF TABLES}

1. Top Stressors Reported by Urban Youth Workers ......................................... 20

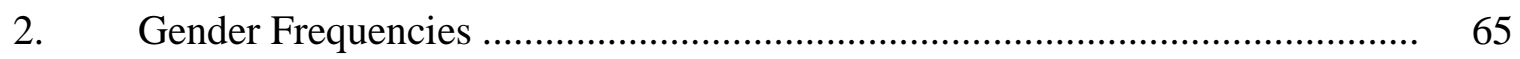

3. Age Frequencies................................................................................... 65

4. Level of Education Frequencies..................................................................... 66

5. Racial and Ethnic Heritage Frequencies ...................................................... 67

6. Denomination or Faith Tradition Frequencies ................................................. 68

7. Collaborative Leadership Skills descriptive results ......................................... 69

8. YMCAS descriptive statistics ……………………………………............ 71

9. Correlation of Self-Reflection with Collaboration Activity ............................. 73

10. Correlation of Building Trust with Collaboration Activity ............................. 74

11. Correlation of Developing People with Collaboration Activity ...................... 74

12. Correlation of Assessing the Environment with Collaboration Activity .......................................................................................... 74

13. Correlation of Creating Clarity-Visioning and Mobilizing with

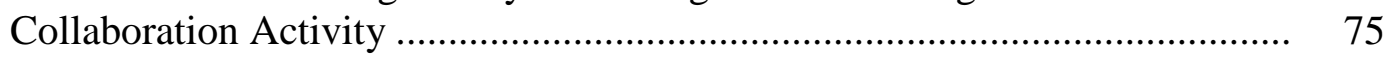

14. Correlation of Sharing Power and Influence with Collaboration Activity

15 Regression Model of Collaboration Skills as Predictor of Collaboration Activity ........................................................................... 78

16. One-Way Analysis of Variance of Collaboration Activity by Gender

17. Group Statistics for Men and Women ...................................................... 80

18. One-Way Analysis of Variance of Collaboration Activity by Age .................. 81 
19. Group Statistics for Age Groupings.......................................................... 81

20. One-Way Analysis of Variance of Collaboration Activity with Education Level ....................................................................................... 82

21. Group Statistics for Education Level ........................................................ 82

22. One-Way Analysis of Variance of Collaboration Activity with Ethnicity ............................................................................................. 83

23. Group Statistics for Ethnicity .................................................................. 84

24. One-Way Analysis of Variance of Collaboration Activity with

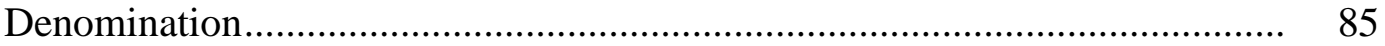

25. Group Statistics for Denomination ……………........................................... 85

26. DeVos Urban Leadership Theory of Change..................................................... 91 


\section{LIST OF FIGURES}

1. Multilevel Outcome of Leadership Development...................................... 5

2. DVULI Logic Model Goal 4........................................................... 94 


\section{LIST OF ABBREVIATIONS}

$\begin{array}{ll}\text { CLSA } & \text { Collaborative Leadership Self-Assessment } \\ \text { DVULI } & \text { DeVos Urban Leadership Initiative } \\ \text { YMCAS } & \text { Youth Ministry Collaboration Activity Scale }\end{array}$ 


\section{ACKNOWLEDGMENTS}

No one completes a dissertation project alone. I had many family, friends, and colleagues who helped and encouraged me along the way. While there are too many individuals to name them all, I would like to mention a few.

I'd like to give thanks to God whose heart's desire is to see his people love each other and work together in community to demonstrate his Kingdom here on earth. After focusing on this topic for the past seven years, I've become even more passionate about the unity and diversity of the body of Christ and still believe in our God-given ability to overcome our differences.

I'd also like to acknowledge the incredible leaders I have gotten to know over the past 20 years through the DeVos Urban Leadership Initiative. To have met so many amazing people totally committed to sharing the transformative message of the Gospel and discipling urban youth to be leaders in their communities is truly an honor. They see their work as an urgent, God-given, mandate; a call on their life, and often work tirelessly and sacrificially to reach as many young people as possible. They may not be making headlines, but their quiet steady persistence is making a difference one life at a time.

I'd like to thank the faculty and staff at Andrews University for guiding this process. My dissertation committee and Erich Baumgartner, as my committee chair provided advice and feedback. Janet Ledesma as my faculty advisor was invaluable in helping me navigate the overall dissertation process. Laura Luchies at the Calvin Center for Social Research also provided much needed assistance with statistical analysis. 
Ginny VanderHart and my colleagues at the DeVos Urban Leadership Initiative provided moral support, participated in many discussions about direction, and read many drafts of this work in progress. I believe we have a shared joy in the mission of the DeVos Urban Leadership Initiative and I'm so thankful to work with such a group of passionate and gifted people.

Lastly, I can't say enough about the support I received from my loving husband Jack. This goal was more of a stretch than either of us ever thought it would be. There were so many times when I wanted to quit. Jack, my dearest companion for over 38 years, thank you for standing by me, for spending endless evenings and weekends alone while I was hunkered over a computer, and never doubting that I could finish. 


\section{CHAPTER 1}

\section{INTRODUCTION}

\section{Background of the Problem}

Urban communities of poverty face many problems: dilapidated housing, hunger, violence, drugs, pollution, poor medical care, broken education systems, broken justice systems, and budget deficits. All of these problems are complex and systemic, making it unlikely that the intervention of any individual organization or program will bring about long-term impact and change on its own (Kania, Hanleybrown, \& Juster, 2014; Kania \& Kramer, 2011; Winer \& Ray, 1994).

Collaborative approaches to solving community-based problems have become increasingly common in the fields of education, health care, environmental justice, juvenile justice, and youth intervention programming. The last several decades have brought attention to the idea that cross-sector collaboration is an important facet in problem solving when socially complex problems are present. Cross-sector solutions include bringing together government, business, non-profit, and faith-based organizations who see the community as a place where people's lives are woven together (Kania \& Kramer, 2011; London, 2011; Pillsbury, Goddard-Truitt, \& Littlefield, 2009; Woodland \& Hutton, 2012).

Since the 1980s there have been a growing number of leadership development programs which focus on developing leaders that embrace collaborative solutions. 
Collaborative solutions can help prevent fragmentation among community stakeholders, prevent duplication of effort, prevent a sense of competition for resources, and provide cultural competence for the diverse context of the problem (Edwards \& Turnbull, 2013; Kennedy, Carroll, \& Francoeur, 2013; Van De Valk \& Constas, 2011; Wolff, 2010; Woodland \& Hutton, 2012). Many leadership development programs provide collaborative leadership skill building for the individual leader. These programs also aim to lay the groundwork for future collaboration by fostering relationships and networking among the program participants as part of their learning journey.

Participants are selected for leadership training based on their involvement with a particular field or issue. For example, a community experiencing a high level of health issues related to obesity, asthma, or HIV might establish a leadership development program for health workers associated with various agencies within the community that aim to prevent or treat those conditions. The objective is for leaders participating in a leadership development environment together to grow and learn as individuals in their field, while creating a bond with each other that fosters the opportunity to look for solutions together (Black \& Earnest, 2009; Van De Valk, 2008).

In 1998, the Richard and Helen DeVos Foundation piloted a national evangelical faith-based leadership development program for adult leaders who work with urban atrisk youth. The DeVos Urban Leadership Initiative (DVULI) exists "to make a positive impact on the lives of disadvantaged, urban youth by investing in their leaders" (DeVos Urban Leadership Initiative, 2017d, 2017f). The 15-month training program equips urban youth leaders with personal values (e.g. life-work balance, mutual accountability) and the leadership skills needed to stay in ministry for the long-haul and to sustain long-term 
outreach with youth in urban communities of poverty. The training includes a heavy emphasis on the practical advantages of collaboration and relationship building and the Biblical mandate to work alongside other churches and community-based youth outreach programs (DeVos Urban Leadership Initiative, 2017c, 2017g).

The overarching goal of DVULI is to bring together a small but diverse group of Christian leaders from the same community who share a common passion. That passion is sharing the transformational message of the Christian faith with young people. Then, using leadership development as a holistic model, mentoring and discipling youth to young adulthood. The diversity of each DVULI cohort ideally reflects the community in ethnicity, gender, age, years of ministry experience, and denominational background (Burke, Galvin, O'Donnell, VanderHart, \& VanPatten, 1997).

To achieve this goal, the program has a rigorous selection process to determine who will participate. The selected 10 to 12 leaders attend two-day workshops, week-long national conferences, and group dialogues. They complete reading and homework assignments, meet with mentors on a monthly basis, and do reflective journaling over a period of 15 months. The training takes place in five cities concurrently each year beginning in January. As a cohort of learners, participants create a learning community that focuses on personal leadership values, organizational skills, leadership replication skills, and collaboration skills (Burke et al., 1997).

Over the years, there have been many powerful stories of leadership transformation from the graduates of the DeVos program. An outside evaluation of the program done by Andrews University in 2008 showed promising results in many areas of personal leadership skills as self-reported by graduates. Yet it is hard to evaluate whether 
these leaders are having a broader impact on their communities (VanderWaal et al., 2008).

According to the literature, there is a shortage of evaluation tools to measure the long-term outcomes of leadership development programs (Black \& Earnest, 2009; Bourda, 2014; Hannum, Martineau, \& Reinelt, 2007). Individual participants form social relationships while learning. Observed results are development of influential relationships and mutual purpose resulting from shared frameworks for problem solving. This interaction leads to transformation of the individual leader and impacts the organization and the community. Overall, evaluation is difficult because the desired outcomes are multileveled. Outcomes involve both a change in thinking and changed behavior at three levels: individual, organizational, and community (Black \& Earnest, 2009). Figure 1 shows Black and Earnest's theory that leadership development includes not only how the individual is impacted but whether that change has any influence in his/her organization and community of practice.

Furthermore, existing studies have been criticized for not taking into consideration broad-based outcomes such as developing a high value for partnership and collaboration. Contemporary leadership literature suggests thinking about mindsets, culture, partnerships, and the interdependency of leaders when conducting evaluation (Bourda, 2014; Edwards \& Turnbull, 2013; Van De Valk \& Constas, 2011). For programs like DVULI, the challenge becomes how to measure whether collaborative leadership skills being taught are leading to actual collaboration and partnership for graduates in the years beyond completing the program. 


\section{Theoretical Model of Leadership}

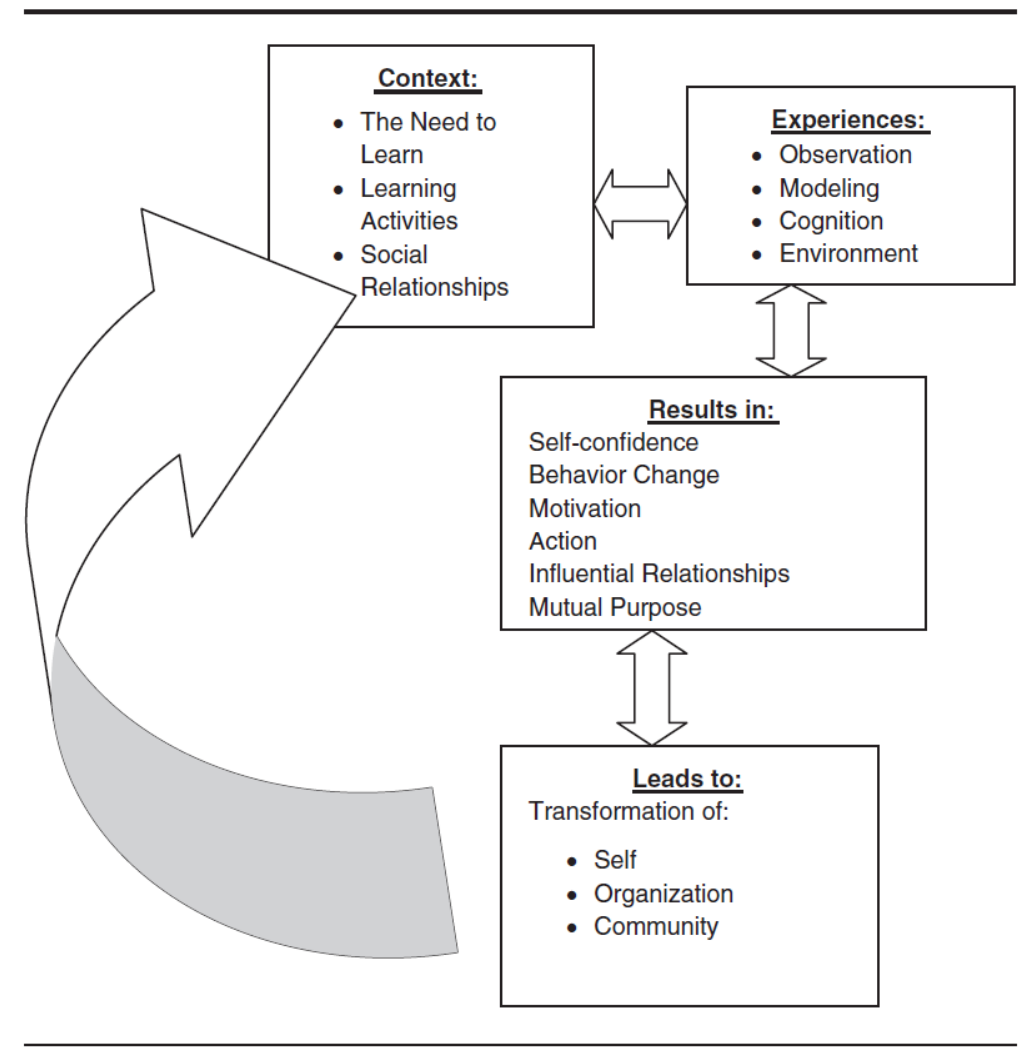

Figure 1. Multilevel Outcome of Leadership Development. Adapted from "Measuring the outcomes of leadership development programs," by A. M. Black, and G. W. Earnest, (2009), Journal of Leadership \& Organizational Studies, 16(2), p. 185.

\section{Statement of the Problem}

Since the 1980s, a body of research has emerged on the evaluation of leadership development programs. Many evaluation studies of leadership development programs have been able to measure the individual skills of leaders and/or the ability of the leader to implement new strategies or improve their organization in some tangible way.

However, it has been far more challenging to determine whether graduates of these programs adopt a long-term value for inter-organizational collaboration and incorporate 
collaboration into their routine work (Black and Earnest, 2009; Bourda, 2014; Edwards \& Turnbull, 2013; Keating, 2011; Kennedy et al., 2013; Van De Valk \& Constas, 2011). Collaborative leadership is a term that was first connected to the practice of leading across organizational departments (O'Leary, Choi, \& Gerard, 2012). Later scholars began to study the skills that a leader would need to be a successful collaborator. Approximately 25 to 30 different skills and personal qualities have been identified in the literature (Chrislip \& Larson, 1994; Huxham \& Vangen, 2005; Jameson, 2007; O'Leary et al., 2012). Leadership development programs differ in their approach on which skills they include based on their assessment of the problem they are trying to solve and the capacity of the leaders with whom they work.

DVULI's program designers incorporated collaborative skills they believed to be particularly relevant to Christian leaders working with youth in under-resourced communities of poverty. Knowledge together with action based on that knowledge demonstrates skill. As such, the problem addressed in this study was to determine if there is sufficient evidence as to whether the collaborative skills being taught in the curriculum of DVULI are producing the desired action of collaboration.

\section{Purpose of the Study}

Successful collaboration requires unique leadership skills, which rely on trust and influence rather than authority and position. The purpose of this study was to determine if a relationship exists between six collaborative leadership skills taught by DVULI and collaboration activities as reported by alumni of the program who graduated over a tenyear period. 
The DVULI program Logic Model includes six collaborative leadership skills that are thought to be uniquely at play in collaboration settings. Using a pre-existing survey called the Collaborative Leadership Self-Assessment developed by the Turning Point Leadership Development National Excellence Collaborative (hereafter called Turning Point) and a self-designed measurement of collaboration activity, this study explored whether those six collaborative leadership skills are predictors of collaboration activity for participants who are at least one year beyond graduation from the DVULI program.

\section{Research Questions}

The study was guided by two research questions:

1. Is there a significant relationship between the collaborative leadership skills assessed in the Collaborative Leadership Self-Assessment (CLSA) and the collaboration activities reported by DVULI graduates on the Youth Ministry Collaboration Activity Scale (YMCAS)?

2. Is there a significant difference between the collaboration activity reported on the YMCAS based on gender, age, ethnicity, denominational background, and level of education?

\section{Significance of the Study}

This study provided an opportunity to learn more about whether the six collaborative leadership skills the DVULI program focuses on have a relationship to actual collaboration activity with others (Turning Point, 2006a; Van De Valk, 2008). The study provided DVULI with information that can be used to make adjustments to program curriculum content and activities based on collaboration and assist in the ongoing effort to support alumni of the program with collaboration. 
In addition, this study adds to the limited number of studies on post-training collaboration activity by graduates of leadership development programs. As such, it may also be of interest to funders and other stakeholders who are supporting, designing or evaluating leadership development programs.

\section{Theoretical Framework}

The conceptual framework for this study is supported by a body of literature in several different areas that are addressed in the literature review in Chapter 2. One area is leadership development programs that exist specifically to bring together like-minded leaders. The desired outcome of bringing leaders together in a learning environment is to create motivation to work together to solve problems that cannot be solved when acting alone (Black \& Earnest, 2009; Edwards \& Turnbull, 2013; Van De Valk \& Constas, 2011).

Another area is that of collaborative leadership skills. According to Crislip and Larson (1994), leaders who work in collaboration require a unique set of skills. Collaborative leaders do not lead from a position of authority, they lead from the middle. They bring peers together, convince them to take action, contribute their power and resources to solve problems, and use their influence to keep them at the table.

Developing collaborative leadership skills provides a scaffold that helps the leader to move from having a narrow focus on one's own organization to a broader focus on results for the larger population. In addition, learning and practicing collaborative leadership skills together in a training environment unites the leaders around a common purpose and leads to the initiation of collaboration together. The literature identified 
numerous skills as assets to collaborative leaders (Chrislip, 2002; O'Leary et al., 2012; Pillsbury et al., 2009; Turning Point, 2006a).

Turning Point conducted an extensive review of research on collaborative leadership. Turning Point determined that while there are many leadership skills a community leader must employ, six unique skills must be developed in order for leaders to be successful at collaboration: Self-Reflection, Building Trust, Developing People, Assessing the Environment, Creating Clarity-Visioning and Mobilizing, and Sharing Power and Influence (Turning Point, 2006a).

Turning Point and DVULI were developed around the same time period based on similar scholarly research. Many such leadership development programs work from a program Theory of Change together with a program Logic Model to identify assumptions that undergird the design of the program and depict the logical relationships between a program's inputs, activities, outputs that are produced by the activities, and changes or benefits that result from the program (Cooksy, Gill, \& Kelly, 2001). DVULI incorporates the same six skills identified by Turning Point into their curriculum content and their program implementation process in alignment with the program Theory of Change (Burke et al., 1997).

Using the Logic Model as an evaluation tool, this study examined the six collaborative leadership skills identified by Turning Point and incorporated into the DVULI program to determine if they have a predictive relationship to collaboration for alumni of DVULI. 


\section{Research Design}

A correlation research design was chosen for this study because the research questions involve understanding the relationship of the dependent variable collaboration activity - to the independent variables - the six skills of collaborative leaders. Quantitative correlation studies involve sampling a single group of individuals to measure the association between two or more variables (Creswell, 2012). This quantitative correlation study used an existing survey called the Collaborative Leadership Self-Assessment (CLSA) developed by the Turning Point Leadership Development National Excellence Collaborative. The survey is a self-assessment, containing 64 questions about established collaborative practices.

In addition to the CLSA, this study includes a Youth Ministry Collaboration Activity Scale (YMCAS) which asked 10 questions about collaboration activities performed by participants and demographic questions for the purpose of describing the study participants. The survey was sent electronically to alumni of DVULI who completed the training over a ten-year period from 2006 through 2015.

\section{Delimitations of the Study}

This study was delimited to alumni of DVULI who participated in the program from the years 2006 through 2015. Only graduates of DVULI were included in the research, rather than a broad number of leaders from the community who are working through non-profits with a focus on at-risk youth.

\section{Limitations of the Study}

The challenge of a self-assessment surveys is that responses are limited by the truthfulness of participants in the survey process. As program participants, they learned 
that the program places a high value on building relationships and partnerships with other leaders in the community. Respondents may have felt an expectation that they value collaboration within their community. Also, the topic was explained in the email introduction to the survey. It is possible that leaders who are collaborative were more likely to choose to complete the survey. Results will only be applicable to the DVULI program and cannot be generalized to other leadership development programs.

\section{Definition of Terms}

Urban: As defined by DVULI refers to densely populated communities of poverty. At the time of the study, the DeVos Initiative had conducted the leadership training in 34 cities/metro areas in the United States which have such urban areas.

At-risk youth: This is a frequently used term for which there is no agreed upon definition in the literature. The DVULI uses the term to describe youth who are "at-risk" of reaching adulthood unprepared for college, work, and life due to environmental, social and family conditions that hinder their personal development (Burke et al., 1997).

Leadership Development Programs: Programs that share a common goal to impact not just individual leaders but also complex social issues that involve organizations and communities where those leaders have influence (Edwards \& Turnbull, 2013).

Community of Practice: A group of people committed to supporting each other's learning in order to achieve individual and collective excellence in the particular field of practice (Wenger, 1998). 
Collaboration: This study used a simplified definition suggested by Michael Winer and Karen Ray. "Collaboration is a process that gets people to work together in new ways" (Winer \& Ray, 1994, p. ix).

Collaborative Leadership: The practices of leaders in collaboration which engage others in a process for working together by convening, facilitating, and sustaining their interaction together (Chrislip, Larson, \& American Leadership Forum, 1994).

Collaborative Leadership Skills: Key leadership behaviors identified in the literature as being essential to successful collaboration.

The following skills are identified as "six key elements unique to the practice of leading a collaborative process" by Turning Point (Turning Point, 2006a, p. 3).

Self-reflection: Collaborative leaders understand their own values, attitudes, and behaviors as they relate to their own leadership and how their leadership impacts others. They can describe their strengths and weaknesses realistically and recognize how their emotions impact relationships and group dynamics.

Building Trust: Collaborative leaders are able to create safe places for building shared purpose and action. They understand the communication processes that allow people to safely say what is on their mind. They are inclusive of all stakeholders and endeavor to find common ground among them. They are transparent about their own motives and assumptions.

Developing People: Collaborative leaders are committed to developing other leaders through mentoring and coaching focusing on the interest of others at times even over self-interest. 
Assessing the Environment: Collaborative leaders recognize the importance of assessing and understanding the context for change before acting on any intervention to solve problems. They encourage people to act on information rather than assumptions.

Creating Clarity-Visioning and Mobilizing: This leadership skill involves defining shared values and engaging people in positive action. It includes being able to facilitate process, create a framework and plan for action, and the ability to communicate the vision.

Sharing Power and Influence: Collaborative leaders recognize and use their personal power responsibly, share power with others, and encourage others to act together for change. They use influence to impact others and allow others to influence their own actions.

\section{Organization of the Study}

This study is organized into five chapters. The first chapter outlines an introduction to the study. The second chapter reviews the relevant literature related to the environment of leaders serving at-risk youth, collaboration as a leadership tool, the design of leadership development programs, and the evaluation of leadership development programs. The third chapter describes the methods used to conduct the research. The results and analysis of the research are outlined in Chapter 4, and Chapter 5 summarizes the findings, draws conclusions and makes recommendations for further research. 


\section{CHAPTER 2}

\section{LITERATURE REVIEW}

\section{Introduction}

The purpose of this literature review is to examine the scholarship that informed this study. It will address five topics related to the overall focus of this study. The first topic establishes the leadership context of the participants in DVULI who work with atrisk youth through Christian organizations in urban communities of poverty.

The second topic explores what current literature has to say about collaboration as an approach to addressing community level problems such as at-risk youth. In addition, since the participants of DVULI work within Christian churches and non-profit organizations, it explores the Biblical values for collaboration.

The third topic discusses the unique capacities or skills a collaborative leader requires. It also focuses on the six collaborative leadership skills that were identified by Turning Point and their incorporation into the DVULI training.

The fourth topic focuses on the field of leadership development programs. This section looks at the philosophical foundation and the Theory of Change behind leadership development programs that have collaboration as an expected outcome. It also explains the Theory of Change behind DVULI using its Logic Model and identifies how the program incorporates curriculum content and activities related to the six collaborative leadership skills examined in this study. 
The final topic examines the scholarship related to evaluation of leadership development programs and the challenges of determining broader effects of such programs on participants after they graduate. It presents the pros and cons of various approaches to evaluation and provides rationale for the quantitative approach of this study.

\section{Youth At-Risk}

In the mid-1990s the family of Richard and Helen DeVos, wealthy Christian philanthropists, decided to focus foundation funding on the issue of at-risk youth in urban centers in the United States. The foundation conducted two years of research using individual interviews and focus groups. Over a hundred individuals and organizations that worked with urban at-risk youth participated in the discovery phase. In 1998, they piloted a leadership development program called the DeVos Urban Leadership Initiative with the mission, "To make a positive impact on the lives of disadvantaged, urban youth by investing in their leaders" (DeVos Urban Leadership Initiative, 2017f).

In an article titled "Best Youth Ministry Ever," a youth minister named Rick Mast (2011) explained that his observation of young people in his youth ministry brought about an important discovery. Youth needed to be seen as "nomads" in life. According to Mast, youth embraced change. Many traveled extensively, sometimes around the globe, by the time they graduated high school. They had innumerable choices in fashion, music, movies, sports, extracurricular activities, and forms of communication. Mast's leadership and understanding of young people saw them as hungry for new experiences. This understanding enabled him to engage and equip youth for life as Christian believers in a society where they constantly navigated exciting waters. 
One cannot draw those same conclusions for impoverished youth growing up in urban communities of poverty. According Putnam (2015), a Harvard social scientist, in his recent book Our Kids, the gap between young people that have, and those that have not, has been widening over the past 30 years. Putnam illustrates with stories and empirical analysis that, instead of opportunities, more and more lower-income children are growing up without the benefit of supportive families, schools, communities, and churches (Putnam, 2015).

Labeled at a young age as "at-risk" by virtue of the household they were born to and the neighborhoods where they live, young people growing up in urban conditions of poverty do not have the opportunity to travel extensively and access the innumerable choices and opportunities witnessed by Mast. In fact, some spend their entire childhood without leaving the area within a few blocks of their home. Instead, their lives are often dictated by daily survival and the basic safety and health issues most people take for granted (Main, 2005).

Prior to the 1990s, social policy approaches to poverty focused on the negative physical and social conditions that influenced people's behavior. Communities of poverty were assessed by their "needs" and interventions were designed based on those points of greatest need (Cohen, Piquero, \& Jennings, 2010; Hankins \& Walter, 2012; Lerner et al., 2005). Assessing a community by its needs became an established model for determining solutions for societal-level problems.

To conduct a quality needs assessment, one would determine the gaps between current conditions and the ideal condition. Once the needs are identified, interventions can be designed to be brought into the community to solve the problems (Kretzmann \& 
McKnight, 1993). The term "at-risk" emerged in the 1980s from needs assessment studies of students in the educational system (Altschuld, 2010).

Research on the effectiveness of the needs assessment model and negative predictors have not been conclusive. Researchers have not been able to show, for example, that certain negative factors have a causal link to adverse outcomes for young people (Edwards, Mumford, \& Serra-Roldan, 2007). This is born out in everyday experience. In spite of the same risk factors being present, one child may follow the predicted path for failure and one may rise above his or her circumstances.

Asset-based community development posits that while a needs assessment does tell part of the story, too often those negative images are seen as the whole story of a community. Once communities begin to be addressed through deficit-oriented policies and programs, services to the community begin to be seen as the answer to all of its problems. Residents (and children) soon begin to see themselves as people with special needs that can only be met by outsiders who bring their services to bear on the community. As consumers of services, residents then lose incentive for being producers in their own communities; thus, a cycle of poverty is born and the negative risk factors become a self-fulfilling prophecy (Kretzmann \& McKnight, 1993).

Kretzmann and McKnight (1993) contrast the community needs assessment with a community asset assessment using a technique called Asset Mapping. It is their contention that viewing a community as a place with endless needs denies the basic wisdom that regards problems as a complexity of interwoven symptoms and a breakdown of the community's own ability to solve problems. 
The asset-based approach is the philosophical underpinning of DVULI's approach to leadership development for practitioners in urban youth outreach programs. Assetbased youth development, also referred to as positive youth development, or community youth development has emerged from this field of thought (Edwards et al., 2007; Lerner et al., 2005; Pittman, Irby, Tolman, Yohalem, \& Ferber, 2011; Taylor et al., 2005).

DVULI curriculum incorporates one of the most well-known models for asset based youth development called "40 Developmental Assets" from the Search Institute (Lerner \& Benson, 2003). The framework identifies 40 assets that contribute to the healthy development of a child. The number of assets that are present in a child's life is related to the degree of resiliency to overcome obstacles that child develops (Edwards et al., 2007; Lerner et al., 2005).

The first 20 assets focus on positive experiences the child receives from people and institutions present in his/her life. Assets include things such as support, empowerment, boundaries and expectations, and constructive use of time. These factors are delivered in the context of community through families, schools, neighborhoods, peers, congregations, workplaces, and programs (Benson et al., 2006). The more developmental assets at play in a young person's life, the more likely that young person is to succeed at school and at life. It is key to note that no one family, program, or institution can possibly provide all of the 40 assets for a child. As such, with the assetbased youth development model, it truly does "take a village," a cross-agency collaborative approach networking families, schools, businesses, churches, and community to nurture a child to adulthood. 
Scales and Leffert (1999) conducted in-depth research on youth and developmental assets. They concluded that faith congregations play an important role in connecting caring adults to youth. On a variety of measures, religiously active and spiritual youth do better than their less involved, less spiritual peers. Religiously active is defined as young people who participate in a religious community one hour or more a week. When young people participated in one hour or more of religious activity they were more likely to experience almost all of the remaining developmental assets. On average, they were $39 \%$ more likely to score higher on all developmental assets than less involved, less spiritual youth (Scales, 2007).

There is growing evidence that youth development programs offered in the context of community are linked to positive behaviors in youth. Participation in such programs is likely to result in a competent, confident and caring individual who is actively engaged in making positive contributions to family and society (Evans \& Kutcher, 2011; Lerner et al., 2005; Thompson \& Lerner, 2000).

\section{Working with At-Risk Youth}

Having established that at-risk youth can benefit from relationships with caring adults through youth outreach programs, it is important to understand the context of the urban youth worker who participates in DVULI. According to a survey conducted by the Fuller Youth Institute in 2006 on risk and resilience of urban youth workers, leaders who work with at-risk youth in the urban setting reported dealing with risk on a day-to-day basis. Table 1 summarizes the most frequently reported chronic stressors (Eriksson, 2007, p. 2): 
Table 1

Top Stressors Reported by Urban Youth Workers

\begin{tabular}{lc}
\hline \multicolumn{1}{c}{ Reported Stressor } & $\begin{array}{c}\% \\
\text { Experiencing } \\
\text { Stressor }\end{array}$ \\
\hline $\begin{array}{l}\text { Felt powerless to change the situation of the people in their community } \\
\text { Felt frustrated by the negative portrayals of their community in the } \\
\text { media }\end{array}$ & $71 \%$ \\
Had difficulty finding time for rest and relaxation & $71 \%$ \\
$\begin{array}{l}\text { Had personally experienced violence } \\
\text { Had experienced direct acts of racism }\end{array}$ & $69 \%$ \\
$\begin{array}{l}\text { Reported low or no salary for their work and personal financial } \\
\text { pressures }\end{array}$ & $67 \%$ \\
\end{tabular}

From: Risk and Resiliency in Urban Ministry: Stress, Spirituality, and Support by Cynthia B. Eriksson, PhD, 2007.

Eriksson's research describes the factors that individual leaders working with urban atrisk youth face. Such leaders are surrounded by extreme circumstances such as poverty, violence, and substance abuse. Often these leaders do not take time for themselves. They place a high value on the relationships they are building with youth sometimes to the neglect of themselves and their own families. Yet, in spite of all of these stress factors, they chose to do what they do because they are passionate about helping youth at-risk. As a result, they even feel that the personal risk is part of the reward (Eriksson, TiersmaWatson, \& Powell, 2007).

Public/Private Ventures, a non-profit, non-partisan social research organization, conducted a similar study that focused on the Big Brothers/Big Sisters program. The study showed that Big Brothers/Big Sister's community-based mentoring program had a 
significant impact on positive outcomes for youth. An unexpected result of the study surfaced that many of the mentors were recruited to the program through community churches. They concluded that most of the youth in the urban context were not being reached by government funded youth programs, but through local churches and religiousbased programming (Trulear, 2000).

Buoyed by what they learned, in 1998, Public/Private Ventures conducted a field demonstration to explore the idea of developing strategies for using faith-based community organizations to impact at-risk youth. They intentionally chose mostly church-based organizations where a high percentage of the program staff and volunteers lived in the community. In the words of the report, "Proximity makes it possible for volunteers to serve during formal program hours as well as informally through encounters on streets and playgrounds, in stores and on stoops" (Trulear, 2000, p. 2).

The findings of this study include an excellent description of the characteristics of organizations that are found to be operating programs with youth in the inner-city. While this study was specifically investigating churches, the description is suitable to faithbased nonprofits and grass roots organizations as well. Leaders from this type of church or organizational setting are typically the focus of recruitment for DVULI.

Trulear (2000) found that most of the organizations were small in capacity. Their definition of small in capacity was, led by part-time or bi-vocational leaders who work simultaneous full-time jobs to provide for themselves and their family. The youth initiatives were "personality driven," meaning that the leadership of a committed individual sustained the program. The organizations and their leaders were not well connected to funding sources available for youth programming from the public sector or 
from private foundations. Sometimes the congregation was not aware of funding opportunities, and sometimes the congregation chose not to apply for funding because they did not want to give the funder the right to tell them how to operate (e.g. no evangelizing).

Trulear (2000) also found that the leaders had little experience with measuring outcomes or program evaluation. Leaders also made an intentional decision to focus on youth-related issues at the expense of a more general focus on community problems. Trulear found that leaders working with youth had to say no to other problems they could have been addressing, because the issue of working with high-risk youth was just too labor intensive.

The study found that because these church-based leaders were focused on youth they often benefitted from networking with each other and collaborating in the community. They saw the community as the primary source of social interaction with the youth. As a result, the leaders adopted a "parish mentality" and an understanding that if they were to be successful in reaching young people they needed to be seen as a vital part of the neighborhood and a good neighbor (Trulear, 2000).

\section{The Power of Collaboration}

In 2010, The Harwood Institute of Public Innovation did an in-depth study of four informal networks and the roles they played in their community. Scott London, reporting on the study, quotes anthropologist Margaret Mead, "Never doubt that a small group of thoughtful, committed citizens can change the world; indeed, it's the only thing that ever has" (London, 2011, p. 6). London says Mead captures an essential truth about social change: "[I]t begins in the unassuming contexts—in small groups of people who share a 
common passion, who come together after work, on weekends, or over lunch, and who devote their talents and energies to bringing about change" (London, 2011, p. 27).

There are numerous articles and studies about the benefits of collaboration, yet collaboration is a messy and complex business that by its nature operates in the realm of ambiguity and mistrust (Chrislip et al., 1994; Gray, 1989; Hibbert \& Huxham, 2010; Mattessich, Murray-Close, Monsey, \& Amherst H. Wilder Foundation., 2001; Winer \& Ray, 1994). There are possibly more examples of failed collaborations than there are of successful ones, but recognizing the potential of accomplishing more together continues to drive the public sector, private sector, and non-profit sector to build alliances (Chrislip et al., 1994; Kania \& Kramer, 2011; Leavitt \& McKeown, 2013).

Traditional leadership literature might suggest that successful non-profits, including faith congregations, would be able to boast of high quality internal management structures since they must allocate limited resources with efficiency (Hughes, Ginnett, \& Curphy, 2012). However, a study by Grant and Crutchfield (2007) of 12 high impact non-profits, concluded that real change occurred when the non-profit organizations went outside of their own walls and found creative ways to ask for help from others.

According to Kouzes and Posner (2007) in The Leadership Challenge, fostering collaboration requires a climate of trust and a willingness to share resources and information. One might think this would be a natural connection for leaders of Christian organizations. Christian leaders share a belief system based on the Bible and tenants of Christianity. They have a shared mission in transforming the lives of young people and instilling the values of Christianity at a young age as a basis for mentoring youth as 
leaders in the church and developing them as leaders for their communities. A search of books and articles on collaboration between churches and Christian non-profits, however, produced relatively little guidance for this practice.

The Bible highly endorses working together. Scripture is filled with images, symbols, and practices of partnership. In John 17, Jesus prays fervently that his followers will demonstrate unity,

I pray also for those who will believe in me through their (the disciples') message, that all of them may be one, Father, just as you are in me and I am in you. May they also be in us so that the world may believe that you have sent me...May they be brought to complete unity to let the world know that you sent me and have loved them even as you have loved me. John 17:20-23

Unity is modeled after the communal relationship of the Trinity, and its purpose is to point a different way in the context of a divided world.

The President of World Vision, Richard Stearns, goes so far as to suggest that when Jesus left the earth, right after he prayed that prayer found in John 17, he left unfinished business for the church - to establish and build the kingdom of God on earth together. Jesus spent the three years of his ministry talking about the kingdom of God and the new way God expected believers to live in restored relationship with one another. Stearns asks the question, "Is Jesus waiting to return until that happens?" (Stearns, 2013, p. 27).

Phill Butler, Christian author and expert in partnerships and strategic alliances, points out in his book Well Connected, that the imperative to work together is part of God's design for mankind (Butler, 2006). As an international consultant, Butler witnessed what he calls a global partnership movement in many other parts of the world. Unfortunately, that movement is not as evident in the United States. Butler believes that western individualism has affected the Christian church, its theology, and its educational 
paradigms. Divisions in the church place barriers between believers and keep them from working toward a shared mission. In Well Connected, Butler shares stories of partnerships he has seen among believers around the world and from them draws practical principles of collaboration.

According to Butler (2006), God designed men and women to live in harmony in families and in communities just as God lives in unity through the Trinity. "Let $u s$ make man in our image" it says in Genesis 1:26 (italics added for emphasis). Unity and community are a part of God's character. According to the Bible, when sin entered the world, trust and unity among people were destroyed. Christians are to seek reconciliation not just with God and with themselves, but also with others.

To further emphasize the biblical mandate for working together, Butler (2006) suggests Christians consider the following biblical principles. Throughout the Old Testament God's plan of salvation was to reconcile all people and all nations and return them to God's peace (Isa 42:5-7). His people are called to collectively bring peace to whatever city they find themselves in no matter the circumstances (Ps 122:6-9, Jer 29:7, Deut 28:2-6). God urges his people to have compassion for and take care of the poor (Deut 10:18, I Sam 2:8, Ps 9:9, Prov 21:13).

In the New Testament, beginning with the book of Acts, the church is to cross every cultural and ethnic barrier (Acts 2). When they begin to have divisions and follow different teachers, the Apostle Paul calls them back to unity (Eph 2:14 and 4:1-6). His letters to the churches are written to all of the believers in each city with explicit instructions on how they are to love one another and work together as a way of demonstrating the love and power of the gospel to their unbelieving neighbors. 
The church is told that they cannot have a genuine relationship with God unless they are first reconciled to their friends and neighbors. (Matt 5:21-24, 2 Cor 2:5-11). Being a follower of Jesus requires making relationships with others a priority. (Col 3:1217, Rom 12:9-17). Jesus himself prayed on the night before his death for the believers of his day and in the time to come to be united as evidence that God's love can overcome any differences among people and bring them together to point the way to Him (John 17).

The DeVos Urban Leadership Initiative is grounded in these biblical principles. It seeks restoration among Christians who are working in churches and youth-serving organizations and building relationships of trust among its participants with the expectation of working together. Given the philosophical foundation of the Christian leader; the complex, community-based problem of at-risk youth; and the atmosphere that the Christian urban youth leader works in, it is clearly important to address collaboration skills as a tool for leadership.

\section{The Six Skills of a Collaborative Leader}

In order to understand skills that are unique to the collaborative leader, it is important to understand a somewhat recent shift in leadership paradigms. Prior to the 1980s, leadership theories were developed through an industrial or management lens. Leadership training centered on the strengths and traits of the individual, assuming his or her authority to lead was primarily positional. Leaders were effective or could learn to be effective because of their position or title and the authority that went with the title (Day, 2001; Mumford, Zaccaro, Harding, Jacobs, \& Fleishman, 2000).

In the post-industrial era, leadership scholars began to recognize that it is not solely position, but also influence in a wider sphere of relationships that allows a leader 
to be effective (Avolio \& Gardner, 2005; Day, 2001; Greenleaf \& Spears, 2002; Kouzes \& Posner, 2007; Ruben \& Gigliotti, 2016). In a 2001 article by David Day, "Leadership Development: A Review in Context," Day argues that in addition to investing in the individual skills of the leader, good leadership development must take into consideration the social systems and relationships that the leader is a part of and has influence over (Day, 2001).

This idea of leadership through influence is especially necessary in the arena of non-profit management, church, and community leadership where participants of the DVULI serve. Distinctive characteristics of leadership in this setting include the need to navigate an ever changing social and political environment, be creative with fewer resources, get things accomplished with a voluntary workforce, and collaborate with peers and with other organizations either by choice or in response to demands of funders. In fact, non-profit, church, and community leaders often cannot rely on the power of title or authority to get things done; instead they must draw on networks, influence, and relationships. (Chrislip, 2002; Collins \& Collins, 2006; Grant \& Crutchfield, 2007; McIntyre Hall \& Kennedy, 2008; Sinha, 2013).

Collaborative leadership is a term that began to appear in the 1990s to describe the practice of leading across departmental or organizational boundaries (O'Leary et al., 2012). According to O'Leary, earlier studies on collaborative practices were based on examining the collaboration processes among agencies and organizations. While it seems self-evident that collaboration even in an organizational setting would be carried out by individuals, it was not until later that researchers began to study the skills that a leader would need to be a successful collaborator (O'Leary et al., 2012). 
In the late 1990s when DVULI was designed, exciting new scholarship of applied research was being introduced. According to Peter O'Donnell, one of the DVULI program designers, each produced a range of models and approaches including: Peter Senge's Systems Thinking and the learning organization with a particular focus on Team Learning and Dialogue, Etienne Wenger's Communities of Practice, Dee Hock's Chaordic Organization Theory, Margaret Wheatley's work on Complex Adaptive Systems, McKnight and Kretzmann's work on Asset-Based Community Development, and Marvin Weisbord's collaborative planning models, such as Future Search and Harrison Owen's Open Space Planning (O'Donnell, 2017).

Communities began to jump on these approaches as problem solving tools. Soon after, government and foundations seized upon collaboration as a requirement for funding, and that meant it was an important new skill that leaders both wanted and needed (O'Donnell, 2017). It was during this time period that the DVULI and The Turning Point leadership development trainings were birthed, so even though they were developed independently of each other, they have the same collaborative skills embedded into their training.

The DVULI designers conducted a review of a number of other leadership development programs that also bore this out. It is of interest that the designers also came across several failed programs where collaboration was not only a goal but became a forced requirement of participants. As a result, they designed the DVULI training to foster a value for collaboration rather than requiring collaboration of the program participants (Burke et al., 1997; O'Donnell, 2017). 
As a result of the implementation of these collaborative planning models, a body of research about the required skills of an effective collaborator has emerged. Hibbert and Huxham identify having an open and sharing attitude, empathy toward others, practicing good communication skills, the ability to facilitate group processes, building trust, managing conflict, being strategic in designing structures, and understanding complexity (Hibbert \& Huxham, 2010). O'Leary et al. identify being patient, open-minded, goal oriented, listening well, focusing on big picture thinking, having a facilitative leadership style, and managing conflict as collaborative leadership skills (O'Leary et al., 2012). There are numerous others who present a range of leadership skills and qualities that are needed to be a successful collaborator (Chrislip, 1994; Huxham \& Vangen, 2005; Jameson, 2007; Morrison \& Arthur, 2013; Rubin, 2002).

Clearly, depending on which leadership theory one embraces, there are critical skills and capacities that any leader needs to be successful. Many of those skills - good communication skills, the ability to implement change, the ability to manage resources, and conflict management - are needed for all good leaders. Each of the six practices that Turning Point chose to include in the Collaboration Leadership Self-Assessment Survey, however, are skills that specifically enable collaborative leaders to look beyond their own talent and resources to lead. They inspire commitment and action in others and they bring and keep peers together to problem-solve (Turning Point, 2006a).

The ability to engage in Self-Reflection involves an understanding of one's own leadership strengths and weaknesses along with the ability to be open to feedback from others. The questions on the CLSA survey ask respondents to score themselves on a scale of 1 to 7 with 1 being Never, 4 being About Half the Time, and 7 being Always. The 
Self-Reflection subsection contains eleven questions that ask the leader to reflect on his/her awareness of their assumptions and emotions and how they may impact others, their listening skills, and how they intentionally seek feedback from others (Turning Point, 2006b).

Building Trust is the skill of creating safe places for people to express their views without judgment. This section of the CLSA includes ten questions related to establishing the process for collaboration that acknowledges unequal power in relationships and surfaces hidden agendas. It also includes questions about the leader's ability to build relationships individual-to-individual and to model trust by always following through on commitments (Turning Point, 2006b; Winer \& Ray, 1994)

Developing People involves a commitment to identify and build up the leadership strengths of others through mentoring and coaching. This section of the CLSA contains eleven questions. Some of the questions include "I take adequate time doing people development," and "I am committed to developing people from diverse segments of the population," and "I create opportunities for people to assess their leadership skills" (Turning Point, 2006b, p.7). All of the questions aim to raise awareness of the survey respondent around modeling good leadership practices and spending time intentionally developing others in those practices.

Assessing the Environment allows the leader to understand diverse views of the community before attempting to implement change. One of the goals of DVULI is to create a diverse learning cohort with the ability to see the problems of youth growing up in urban communities of poverty from different perspectives. This skill is addressed on the CLSA survey with ten questions that ask about assessment tools for understanding the 
needs of the community, analysis of data related to the community, acting on information rather than assumptions, and using a systems perspective to understand community problems (Turning Point, 2006b).

Creating Clarity-Visioning and Mobilizing involves defining shared values and developing a positive plan of action together. The eleven questions on this portion of the survey focus on not only creating clarity around the shared vision, but also on the leaders' ability to develop conditions for brainstorming and create strategic action plans that mobilize people (Turning Point, 2006b). This is often one of the most challenging skills related to collaboration. Some refer to this as the implementation challenge.

Sharing Power and Influence encourages people, organizations, and communities to accomplish more by openly naming the power each brings to the table. This final section of questions on the CLSA survey focuses on personal power. Power can be used positively to move things forward or negatively to hold things back. In a healthy collaboration, everyone needs to openly claim the power they bring and be open to others pointing out when they are using it negatively. This is one of the reasons creating a trusting safe place is so important (Winer \& Ray, 1994). This section of the CLSA contains eleven questions that ask participants to assess their skill at sharing power and involving others in the process of planning and decision making (Turning Point, 2006b).

Each one of these practices is addressed in DVULI. For example, participants are required to maintain a learning journal as one element of developing the skill of SelfReflection. Diverse cohort members worship, travel, and room together as a way of Building Trust. Developing People is addressed in the core value of Empowerment. Assessing the Environment is introduced in a game called "The Community Maze." 
Creating Clarity-Visioning and Mobilizing is brought out in detail in a week-long conference on Systems Thinking. Sharing Power and Influence is modeled by asking the participants to engage in a learning cohort without using titles such as Minister, Reverend, Doctor, or Pastor, seeing all cohort members as peers. (Please see Appendix D for an extensive list of the six skills and how they are embedded in the DVULI curriculum and programmatic elements.)

The six collaborative leadership skills are not mutually exclusive but support each other. They are addressed by DVULI along with other important leadership skills DVULI believes are critical to navigating leadership in the often uncertain and under-resourced environment of urban youth work.

\section{Leadership Development Programs}

Leadership theory and individual leadership skills are usually taught in a more traditional academic setting. In contrast, leadership development programs generally focus on adult learners who are already in a leadership role. In particular, leadership development programs are delivered over a lengthy period of time, using experiential learning methods, to help participants learn new ways of thinking that can lead to new behaviors and skills. They include the introduction of topics such as role, motivation, and social change theory to help leaders learn and adapt to new scenarios while actually leading (Ardichvili \& Manderscheid, 2008; Van De Valk, 2008).

Leadership development programs that focus on social change are referred to in the literature by a number of different names including leadership development programs, community based leadership programs, change based leadership development programs, and collaborative leadership development programs (Bourda, 2014). This study uses the 
term leadership development programs to indicate programs that share a common goal to impact not just individual leaders but also complex social issues that involve organizations and communities where those leaders have influence. Most leadership development programs operate under the assumption that networking and building partnerships is an important skill for community-based leaders to develop (Black \& Earnest, 2009; Van De Valk \& Constas, 2011).

The W. K. Kellogg Foundation was one of the earliest funders to invest in leadership development programs. Beginning in 1983 in response to the Kellogg Farmer Study, the Kellogg Foundation funded the first organized state-wide leadership development programs focusing on rural farm states. The programs were designed to develop leadership skills in the participants, with the goal of enhancing their knowledge of topics such as food systems, policy-making, and international economic institutions (Carter \& Rudd, 2000; Russon \& Reinelt, 2004).

Since those early years pioneered by Kellogg, literally thousands of leadership development programs have sprung into existence. Many foundations have funded or created leadership development programs in an effort to multiply their impact in particular areas of concern. Some examples include the Annie E. Casey Foundation in their work with children and families (www.aecf.org), the Robert Wood Johnson Foundation in their work in the field of health care (www.rwjf.org), and The Aspen Institute in their work with community development (www.aspeninstitute.org). According to the literature, the theoretical models for most leadership development programs focus on social learning theory, adult learning theory, and multi-disciplinary leadership paradigms of distributed leadership, transformational leadership, relational 
leadership, servant leadership, and team leadership (Chrislip \& Larson, 1994; Hsieh \& Liou, 2016; Morrison \& Arthur, 2013).

\section{Evaluation of Leadership Development Programs}

Current reviews of leadership development programs criticize a lack of clearly defined theories of change and leadership models for many programs. There is also lack of research-based studies on program outcomes (Black \& Earnest, 2009; Freed, Covrig, \& Baumgartner, 2011; Russon \& Reinelt, 2004; Van De Valk \& Constas, 2011).

A 2009 review of established evaluation methods for leadership development programs done by Black and Earnest revealed not only a lack of outcome measurements, but also the challenges of measuring the complexities of leadership at a post-program level (Black \& Earnest, 2009). A dissertation by Bourda surveyed evaluation methods used for collaborative leadership development programs (leadership development programs focused specifically on collaborative outcomes) and found only seven published studies that included evaluation methods (Bourda, 2014).

In 2013, the journal Advances in Developing Human Resources devoted an entire issue to the challenges of evaluating leadership development programs, pointing out that the goal of leadership development programs is really to change or create a mindset toward culture, partnerships, relationships, and interdependency (Edwards \& Turnbull, 2013). Edwards and Turnbull point out that there is limited discussion in the literature regarding evaluating these aspects of leadership behaviors.

One method of evaluation that has been adopted by such programs as a framework for analysis is using Theory of Change with a program Logic Model. A Theory of Change examines program assumptions, sets short, intermediate, and long- 
term goals, and determines the process that is put in place to reach those goals (Harris, 2005). Once a program has an identified Theory of Change in place, a Logic Model can be developed that creates a visual map of the process. A Logic Model depicts the logical relationships between a program's inputs, its activities, the outputs that are produced by the activities, and the changes or benefits that result from the program. In fact, a Logic Model is not static. It should change over time whenever evaluation provides feedback that program outcomes are not being achieved (Cooksy et al., 2001).

In preparation for an evaluation study of DVULI begun by Andrews University in 2006, the DVULI program Theory of Change and Logic Model was updated. The full Theory of Change and Logic Model can be reviewed in Appendix C. Four goals were defined:

- To equip participants for sustained work in youth ministry

- To equip participants to develop healthy and supportive ministry organizations

- To equip participants to reproduce themselves, developing others for leadership with youth

- To equip participants to work with others who share a passion for youth. (VanderWaal, 2005)

This earlier study by VanderWaal et al. (2008) highlighted numerous comments by graduates who indicated they believed the training had helped them to develop stronger partnership and collaboration skills and included recommendations for further research in this area (VanderWaal et al., 2008). The current study evaluated Logic Model goal number four: "The DeVos Urban Leadership Initiative will equip participants to work with others who share a passion for youth," by examining the correlation between 
the six unique skills of collaborative leadership identified by Turning Point and embedded throughout the DVULI curriculum, and collaboration activity reported by alumni.

\section{Summary}

DeVos Urban Leadership Initiative was designed to address the unique challenges faced by youth leaders working with at-risk youth through Christian churches and nonprofits in urban communities of poverty. Leaders who work in these contexts benefit in many ways by collaborating with others who share the same vision.

Leadership develop programs like the DVULI, sometimes referred to as collaborative leadership development programs, effect change by creating a community of learning where leaders are taught various skills identified as necessary for successful collaboration. The DVULI has identified six collaborative leadership skills that it believes lead to greater collaboration: Self-Reflection, Building Trust, Developing People, Assessing the Environment, Creating Clarity-Visioning and Mobilizing, and Sharing Power and Influence, and incorporated them throughout the 15-month training.

Evaluating whether collaborative leadership development programs are effectively fostering a value for collaboration and teaching the skills needed for collaboration is difficult because it involves a change in leader mindset and opportunity to put collaboration into practice. This requires time. This study attempted to evaluate the correlation between the six collaborative leadership skills taught by DVULI and collaboration activity reported by alumni at the post-program level. 


\section{CHAPTER 3}

\section{METHODOLOGY}

\section{Introduction}

The purpose of this study was to determine whether six collaborative leadership skills incorporated into the training program DVULI were significant predictors of collaboration activity among DVULI graduates. The six skills are: Self-Reflection, Building Trust, Developing People, Assessing the Environment, Creating ClarityVisioning and Mobilizing, and Sharing Power and Influence. Chapter 3 will explain the research questions, research context, research design, population and sample, instrumentation, reliability and validity of the instrument, research procedures, treatment of data, and data analysis.

\section{Research Questions}

The two research questions addressed in this study are the following:

1. Is there a significant relationship between the collaborative leadership skills assessed in the Collaborative Leadership Self-Assessment (CLSA) and the collaboration activities reported by DVULI graduates on the Youth Ministry Collaboration Activity Scale (YMCAS)?

2. Is there a significant difference between the collaboration activity reported on the YMCAS based on gender, age, ethnicity, denominational background, and level of education? 


\section{Research Context}

The DeVos Urban Leadership Initiative was developed and piloted in the 1990s as a leadership development program for urban youth workers. One of the principles of leadership development incorporated throughout the program is "to develop a shared vision with others who have a passion for youth and to work with others to determine 'what kinds of things can we do better together than alone?"' (Burke et al., 1997, p. 10).

The stated aims and rationale of the program:

By investing in emerging leaders who share the belief that Jesus Christ is the foundation for sustainable change in a young person's life, the DeVos Urban Leadership Initiative hopes to strengthen the scope and effectiveness of urban youth ministry in local communities. Through high-quality, relevant leadership training, the program creates a learning environment that builds trust among participants, develops skills and helps participants develop a shared vision in how to most effectively address the needs of their community's at-risk youth.

An effective urban leadership ministry means reaching out to kids who are at risk. The DeVos Urban Leadership Initiative involves an intensive "building up" of emerging urban leaders who are already committed to their work but want to build their capacity to help kids become positive influences in their families and in their communities. Through support and training, program participants may increase effectiveness and capacity in their ministries, and initiate partnership with other community leaders. (DeVos Urban Leadership Initiative, 2017f)

The DVULI incorporates curriculum and activities to develop collaborative leadership throughout the 15-month program and clearly states that the goal of collaboration is one of the outcomes it expects to achieve by offering the training to those who are doing outreach with youth (Burke et al., 1997).

There are a number of ways that collaboration is designed to be a focus of the training delivery: applicants are selected who are already participating in or are open to cross-ministry partnerships, curriculum content and delivery format center on the skills of a collaborative leader, and post-training support is provided for collaboration. 


\section{Selection of Participants}

According to program documents and materials, the selection process for identifying and recruiting participants has been developed and refined over the past 20 years by City Coordinators. The DVULI hires a part-time contractor in each city to manage the selection process at the local level. The DVULI training is offered in five U.S. cities every year beginning in January. Each city cohort contains a maximum of 1012 participants. Participants must be working (paid full-time, part-time, or volunteer) in a leadership position with a Christian church or agency that serves urban at-risk youth.

City Coordinators are required to attend four additional trainings where they gain an understanding of the goals and the process that is used to select the cohort members and to deliver the curriculum. They also participate in the DVULI training along with the rest of the selected cohort. City Coordinator trainings address how to market DVULI in their city and recruit applicants, how to prepare the selected participants for the preworkshop assignments and the workshops, how to provide an orientation for the required mentors, and how to assist the participants with completion of the written strategic plan required to complete the program (DeVos Urban Leadership Initiative, 2017a).

The recruiting process has been uniquely developed to span the diverse demographics found in every U.S. city. DVULI employs a number of methods to intentionally recruit cohorts that are diverse in ethnicity, age and years of ministry experience, gender, denomination and Christian tradition, both church and non-profit organizations, geographical location within the city, education, and any other diversity that may exist. The goal of recruiting a diverse cohort is to build trust and provide the opportunity to share knowledge among youth serving individuals who in most circumstances do not cross paths on a day-to-day basis. 
In order to receive an application for the program, a youth worker must be nominated by someone who knows of their work with youth. Once they complete the application, the applications are reviewed by a team of local stakeholders and DVULI staff. Fifteen to 17 applicants are chosen to be interviewed. The interviews are conducted by a panel of five that consists of one DVULI staff member and four local ministry leaders from the city, including the City Coordinator. Candidates are asked about their experiences with collaboration in the interview process and told that if they are accepted into the program, there will be an expectation that they collaborate with others after completing the training.

The 10-12 leaders selected, participate in a fully-funded series of 5 two-day trainings and two week-long conferences that take place at retreat centers away from home. Cohort members room together, learn together, and have planned fun together during free time. No other family and friends are permitted at the training events. The purpose for this is to build inter-group relationships and create a safe place for them to be transparent with each other while learning.

\section{Curriculum Content and Delivery Format}

The training curriculum is specifically designed for adult learners. It is a mix of theory and practice taught by experienced urban practitioners who have been trained as facilitators to not only teach new skills but to draw on the diverse experience of the leaders in the training cohort. Collaboration is introduced at the very first workshop. The concept of interdependence and the value of collaboration is woven throughout each and every training and reading assignment. 
The first two workshops focus on the individual leader; strengths, leadership style, personal call, core values, communication skills, and on an assessment of their ministry organization. These workshops foster the skill of self-reflection and the value of feedback from others as avenues for leadership growth.

The next four workshops focus on community building skills; community youth development, planning, systems thinking, and resource networking. Collaborative skills addressed in these workshops include the importance of assessing the environment, understanding and developing people for leadership, creating clarity through shared vision, mobilizing people through principles of social change, and sharing power and personal influence.

Workshops have required pre-reading and practical application assignments. All of the participants are required to have a program mentor. The mentor receives training on the goals and expectations of the DVULI and guides their mentee toward personal objectives that the trainees set at the beginning of the program. DVULI staff connects to the youth leader's pastor or supervisor and provides an orientation about the training. The supervisor is made aware that collaboration is a goal of the program. They receive updates on the curriculum content throughout the year as it is being taught.

Several other components of the program build on collaborative leadership skills. DVULI staff make at least one site visit to the participant to learn more about their ministry context. Participants are required to keep a reflective journal on what they are learning. In between the training workshops, the city cohort meets to share, pray, and dialogue about common themes they are experiencing in their learning journey. At the end of the training program, each participant creates a written document called a 
Breakthrough Plan that identifies their personal growth, their action steps for implementing change within their ministry, and a plan for developing others for leadership in youth ministry in their city. The Breakthrough Plan is presented to their peers for feedback at the final workshop. The final workshop is used as a platform to identify common threads or themes that could possibly lead to opportunities to partner together going forward.

\section{Post-Training Support for Collaboration}

Collaboration is identified and simulated throughout the curriculum, but participants are not required to work collaboratively in their ministry context during the training program. Once opportunities for partnership are identified at the final workshop, DVULI supports a transfer of learning about collaboration to real-life cross ministry collaboration. Alumni receive ongoing support and encouragement to develop projects together that will lead to sharing what they learned with other emerging youth leaders in their city. They are provided with "training toolkits" to facilitate the transfer of their learning to other leaders. They are encouraged to develop networks of support for youth leaders in the city or develop capacity for more effective youth ministry in the city in some other way. The DeVos foundation provides small seed grants for collaboration projects.

The DVULI considers its alumni to be its most valuable asset toward developing community-wide youth outreach and a high value for developing youth as assets and leaders for their communities. In an effort to continue to support alumni in post-training collaboration, the DVULI program provides several interventions. They return to the city to recruit and train a second, third, and sometimes fourth cohort of participants to try and 
develop a larger community of youth serving practitioners who are like-minded about working together and share a common language around youth development.

DVULI provides a City Liaison for each city. This City Liaison is an alumni or staff of the program who is a champion of collaboration and has the skills and ability to invest in other leaders. The City Liaison stays in regular contact with all of the city alumni, maintains an updated list of contact information and acts as a coach for those who continue on in youth ministry. The liaison encourages partnership and provides other leadership and capacity building resources as needed.

The DVULI provides post-training opportunities for continued education and learning for its alumni based on demonstrated needs. Examples of these trainings include techniques for fundraising in the urban context, volunteer recruitment and retention training, models of youth discipleship, and other topics that youth ministry leaders benefit from. They also provide scholarships to conferences and trainings of other national youth ministry organizations.

Based on reported experiences of the city liaison working with alumni and on the applications for collaboration grants, DVULI has seen successful efforts of collaboration in many cities. Yet, others have moderate or very little collaboration activity. To date the only measure for alumni collaboration has been the collaboration grants and anecdotal stories from the city liaisons.

This study was initiated in an effort to understand whether the collaboration curriculum and activities built into the program are leading to actual collaboration activity. It is possible that DVULI alumni are collaborating with others in their community (non-DVULI alumni) in ways that are not being reported. It is also possible 
that alumni are involved in little or no collaboration after the program. This study designed a Youth Ministry Collaboration Activity Scale that could be used to examine the relationship between the curriculum and activities offered through the DVULI and collaboration activity post-training.

\section{Type of Research}

Research is helpful to practitioners by providing descriptions of what is happening, an idea of what to anticipate, and prescriptions for how to react. According to Creswell a quantitative research design is useful for studying the behavior and actions of humans by allowing the researcher to quantify behaviors with numbers in order to test or verify theories. Quantitative methods are commonly used for identifying factors that influence an outcome, evaluating the usefulness of an intervention, or understanding the best predictors of outcomes (Creswell, 2014).

A correlation research design was the best design for this study because the research questions involved understanding the relationship of the dependent variable collaboration activity - and the independent variables - the six skills of collaborative leaders - after the passage of time, a minimum of at least one year after completing the DVULI (Creswell, 2014). Successful collaboration involves using complex skills as a leader (Chrislip \& Larson, 1994; Huxham \& Vangen, 2005). Collaborative skills are taught as part of the DVULI training, but successful collaboration can only be measured after a period of time has passed allowing the leader to put those collaborative skills into practice. This study chose the period of one year or longer. Correlation research can identify if a relationship exists between collaborative leadership skills and youth worker engagement in collaboration activity on a routine basis. 
The weakness of correlational research is primarily that it cannot be used to show cause and effect, only that a relationship exists between the variables (Creswell, 2012). Even if the results showed a strong relationship, they cannot necessarily be attributed to the DVULI training. Other variables known or unknown could contribute to that result. For example, if unsuccessful collaboration were attempted in the past, a DVULI alumni could have a bias against collaboration, or if collaboration is not supported by the alumni's ministry or leadership, they may not be encouraged to engage in working with others.

\section{Population and Sample}

A population is a group of people who share the same characteristic. Quantitative researchers choose a target population from a sample of people who are available and meet criteria of the shared characteristic (Creswell, 2014). For this study, the shared characteristic was that each person had completed the DVULI training and one year had passed providing them the opportunity to collaborate with other youth leaders or youthserving organizations after completion of the program. The most recent alumni to meet this criterion was the 2015 cohort which would have completed their training in March of 2016.

\section{Correlation Design}

Creswell recommends a minimum of 30 participants for a correlational study that relates variables (Creswell, 2014). This study purposefully chose to include a ten-year span of alumni. A study by the National Network of Youth Ministries stated that youth leaders who were connected to a professional network averaged 9.2 years in youth ministry (National Network of Youth Ministries, 2015). An assumption was made that 
going back more than ten years would likely include alumni that are no longer engaged in youth ministry. The sample included all alumni who began the training program from 2006 through 2015 and successfully completed the program; a total of 582 people fit this criterion and the DVULI had active email addresses for 541 alumni. Written permission was received from DVULI to survey all alumni. Alumni from 2006 through 2015 were chosen because it was thought that a group within the previous ten years was likely to still be engaged in youth ministry. Ending with 2015 allowed for at least one year post graduation (by 2017) to become engaged in collaboration.

\section{Instrumentation}

This study examined the predictability of engagement in collaboration activities using an online survey. The survey was made up of three components: the Collaborative Leadership Self-Assessment questionnaire (CLSA), a Youth Ministry Collaboration Activities Scale (YMCAS) and demographic variables. Analysis was conducted using descriptive, correlation, regression analysis, and one-way analysis of variance. The study attempted to determine which variables from these categories were strong predictors of collaboration activity.

While it is generally acknowledged that collaboration is important in addressing community-wide problems, there is no established method for evaluating collaboration (Cross, Dickmann, Newman-Gonchar, \& Fagan, 2009; Dedrick \& Greenbaum, 2011; Frey, Lohmeier, Lee, \& Tollefson, 2006; Granner \& Sharpe, 2004; Thomson, Perry, \& Miller, 2009). According to Dedrick \& Greenbaum (2011), part of the challenge is that there are multiple definitions of collaboration. Some see collaboration as part of an organizational culture, some view it as an individual leadership skill, and still others 
identify various levels of collaboration ranging from basic information-sharing to networking to formal coordination of projects.

In addition to the complexity of definitions, there is a lack of standard measures which evaluate the collaborative activities undertaken by the individual or by the organization and what the outcomes of those activities are. Desired activities and outcomes are defined by the field of practice and the goal or mission of the collaboration. For example, measures of collaboration among K-12 educators would be different from measures of collaboration among health care professionals (Frey et al., 2006; Granner \& Sharpe, 2004; Woodland \& Hutton, 2012). Most of the measures that have been published are related to fields where collaboration has long been established as an important skill: health care, education, the mental health field, and other health and human service fields (Frey et al., 2006; Granner \& Sharpe, 2004).

In 2004, Granner and Sharpe conducted a review of published measurement tools for assessing partnerships and collaborations:

The largest numbers of measures were identified for assessing individual and group characteristics, with impact and outcome measures being the least numerous. Published measures often lacked information regarding validity and reliability, with internal consistency reliability being the most commonly reported statistic. Some measures were well defined, but others lacked conceptual clarity. (Granner \& Sharpe, 2004, p. 514)

In 2013, Advances in Developing Human Resources dedicated a special issue to evaluating leadership development for more broad-based community outcomes. They highlighted innovative methods of evaluation addressing mindset, culture, partnerships, and interdependency while also noting a lack of techniques for measuring collective leadership outcomes (Edwards \& Turnbull, 2013). 
A search was conducted but no measurement instrument for collaboration among church-based and Christian non-profit youth serving organizations was found. Research was conducted on the web and through library databases of peer reviewed journals and dissertations using search terms of various forms of collaboration, partnership, and collective impact in the areas of early childhood care, positive youth development, opportunity youth, youth serving organizations, and community youth development. While this is a strong area of interest among service providers, research exploring the outcomes of collaboration did not produce well defined models (Chien, Blasberg, Daneri, Halle, King, M., Fisher, \& Dwyer, 2013; Dedrick \& Greenbaum, 2011; Thomson et al., 2009).

In a review of evaluation practices by collaborative leadership development programs, a dissertation by Bourda (2014) reported that many of the studies incorporated the key collaborative leadership skills identified by a program called Turning Point. Turning Point was developed "to better define, describe, and build the skills of collaborative leadership for public health practitioners" (Turning Point, 2006a). According to Turning Point program materials, after reviewing research and literature on collaborative leadership, six collaborative leadership competencies were identified which became the foundation for a comprehensive training program launched in 2003. Dr. Carl Larson, professor at the University of Denver and co-author of Collaborative Leadership (Chrislip \& Larson, 1994) provided consultation on the research and design of the training (Turning Point, 2006a) 


\section{Collaborative Leadership Self-Assessment}

The Collaborative Leadership Self-Assessment (CLSA) questionnaire was

designed by Turning Point as a pre- and post-test to the program. Six partner agencies served as pilot sites to test the CLSA questionnaire. Feedback from workshop participants helped in the development and revision process. The training and the CLSA questionnaire were finalized in 2003. The questionnaire was further validated through the ongoing work of the Center for Excellence in Leadership (Jameson, 2007; Turning Point, 2006a).

As mentioned, Turning Point identified "six key elements unique to the practice of leading a collaborative process: Self-Reflection, Building Trust, Developing People, Assessing the Environment, Creating Clarity-Visioning and Mobilizing, Sharing Power and Influence" (Turning Point, 2006a). The DeVos Urban Leadership Initiative, developed around the same period of time and based on similar research, has these same skills embedded throughout the training. Each of the skills is key, but they are not mutually exclusive; they support each other. (See appendix D for a description of each of the six skills and a detailed outline of how those skills are currently incorporated into delivery of the DeVos Urban Leadership training.)

The six skills assessed in the CLSA are part of the curriculum and activities of the DVULI training. If a relationship is established to collaboration activity, the DVULI could make use of the assessment for participants of the program to both determine areas for potential growth and to evaluate individual growth after completion of the leadership training program.

In the CLSA questionnaire, participants were asked to rate the frequency of behaviors in each of the six areas on a 7-point Likert scale with continuous points from 1 
to 7 where $1=$ Never and $7=$ Always. For example, sample CLSA Questions under the category of Self Reflection include the following:

Please indicate how often you exhibit each of the behaviors listed below with (1) Never, (2) Rarely, (3) Sometimes, (4) About half the time, (5) Often, (6) Most of the time, (7) Always

1. I recognize the effect of my emotions on work performance

2. I recognize the effect of my emotions on relationships

3. I can describe my strengths realistically

4. I can describe my weaknesses realistically

5. I work to understand others' perspectives

\section{The Youth Ministry Collaboration Activity Scale}

The CLSA focuses on self-assessment in key areas of collaborative leadership skills but does not provide any information about actual collaboration activities or a measurement of collaboration. Since an existing measure of collaboration activities related to faith-based youth service providers did not exist, this study developed a relevant Youth Ministry Collaboration Activity Scale (YMCAS).

DVULI has a working relationship with Calvin College's Center for Social Research (CCSR) which administrates an ongoing evaluation for all training participants. The research project was designed in cooperation with CCSR to develop the questions to measure collaboration activity. Questions were created by inviting a focus group of urban youth leaders to come together to brainstorm typical ways leaders like themselves might work together with others across the city. Some of the focus group participants were DVULI alumni and others were graduates of a local version of leadership training called 
the Grand Rapids Initiative for Leaders which was developed by DVULI alumni and is also based on the DVULI program content. Therefore, all participants were familiar with the curriculum and activities on collaboration used by the DVULI. As experienced youth workers, they were also familiar with the typical collaboration activities that a youth worker might participate in.

The DVULI uses collaboration materials developed by the Wilder Foundation as part of their curriculum (Mattessich et al., 2001; Winer \& Ray, 1994). Wilder identifies three stages of collaboration. The first and most basic is cooperation, which is simply sharing information to prevent duplication of services, the second is coordination where organizations work together each taking on specific roles and responsibilities to coordinate activity. The third is collaboration as the Wilder Foundation truly defines it. This most complex stage involves creating a new entity for a separate mission or agenda (Mattessich et al., 2001). Using the definitions of these stages as a guide, the group came up with a lengthy list of potential activities for each stage.

After the focus group, the list of potential activities were reviewed. Duplicate activities were eliminated and activities that were similar in nature were combined. The result was a final list of ten activities that described an array of potential activities a youth worker working in a faith-based, youth-serving organization might participate in while working with others in their community. The final list of questions was submitted to the same focus group as a pilot to get feedback and approval on clarity of phrasing for each activity and to be sure that in combining activities a unique activity was not left out. The following list of activities was approved by the focus group: 


\section{Cooperation}

1. Communicated with youth leaders outside of my own organization for personal connections, encouragement, or support.

2. Communicated with youth leaders outside of my own organization to discuss a specific concern, issue, or event.

3. Posted an event on a calendar that people outside my organization can access.

4. Participated in a youth leader network in my city.

5. Shared information about training or funding opportunities with youth leaders outside of my own organization.

\section{Coordination}

6. Worked with youth leaders outside of my own organization to implement events or trainings.

7. Directed youth to other programs in my community.

8. Received approval from my organization to work with other youth-serving organizations.

\section{Collaboration}

9. Worked with another organization to establish a new entity that achieves a common goal.

10. Received full commitment and resources from my organization to work with other youth-serving organizations.

For each activity selected, participants were asked how many times they had performed this activity in the prior 12 months. The final survey used for this study included the Collaborative Leadership Self-Assessment, the Youth Ministry 
Collaboration Activities Scale, and demographic information about the participants which was used to describe the population sample.

\section{Definition of Variables}

The independent variables included the demographic questions and six subscales of leadership skills identified in the Collaborative Leadership Self-Assessment Survey.

Gender: Gender is the sex of the participant collected in the survey.

Participants Age: Participants were asked to indicate their current age and also included the option of Prefer Not To Answer.

Level of Education: The survey asked study participants to quantify their level of education from the options; Less Than High School, High School Graduation, Some College, 2-Year Degree, 4-Year Degree, Professional Degree, Doctorate, and Prefer Not To Answer.

Racial and Ethnic Heritage: Six options were listed and participants were asked to check all that apply. An open space was provided for other options not listed and participants were given the option of Prefer Not To Answer.

Denomination or Faith Tradition: An open-ended space was provided for participants to include church denomination or faith tradition.

The following independent predictor variables identified as "six key elements unique to the practice of leading a collaborative process" by the Turning Point Leadership Development National Excellence Collaborative were used in this study (Turning Point, 2006c, p. 3).

Self-reflection: Collaborative leaders understand their own values, attitudes, and behaviors as they relate to their own leadership and how their leadership impacts others. 
They can describe their strengths and weaknesses realistically and recognize how their emotions impact relationships and group dynamics.

Building Trust: Collaborative leaders are able to create safe places for building shared purpose and action. They understand the communication processes that allow people to safely say what is on their mind. They are inclusive of all stakeholders and endeavor to find common ground among them. They are transparent about their own motives and assumptions.

Developing People: Collaborative leaders are committed to developing other leaders through mentoring and coaching focusing on the interest of others at times even over self-interest.

Assessing the Environment: Collaborative leaders recognize the importance of assessing and understanding the context for change before acting on any intervention to solve problems. They encourage people to act on information and data rather than assumptions.

Creating Clarity-Visioning and Mobilizing: This leadership skill involves defining shared values and engaging people in positive action. It includes being able to effectively facilitate process, create a framework and plan for action, and the ability to communicate the vision.

Sharing Power and Influence: Collaborative leaders recognize and use their personal power responsibly, share power with others, and encourage others to act together for change. They use influence with others and allow others to influence their own actions. 
Each of these six variables are addressed in the CLSA with 10 or 11 questions per section for a total of 64 questions. They were identified by the Turning Point Leadership Development National Excellence Collaboration using literature reviews, individual interviews, focus groups, expert panel debates, and attendance at leadership development programs (Turning Point, 2006c). The full survey can be found in Appendix A.

The dependent variable is the Youth Ministry Collaboration Scale developed for this study. It included 10 inter-organizational activities that those working in Christian youth-serving organizations might perform. The option of comparing groups using the questions related to the three stages of collaboration was explored; but using factor analysis, it was determined that all of the questions loaded together. Therefore, the correlation analysis was performed using one count of all activities reported by study participants. The survey questions for the Youth Ministry Collaboration Activity Scale can be found in Appendix B.

\section{Hypotheses}

To answer the research questions 1 and 2, the following hypotheses were examined using the 95\% confidence level $($ Alpha $=.05)$.

Hypothesis $\mathrm{H}_{0} 1$ : Self-Reflection is not a significant predictor of collaboration activity among alumni of the DVULI who graduated between 2006 and 2015.

Hypothesis $\mathrm{H}_{\mathrm{a}} 1$ : Self-Reflection is a significant predictor of collaboration activity among alumni of the DVULI who graduated between 2006 and 2015.

Hypothesis $\mathrm{H}_{0} 2$ : Building Trust is not a significant predictor of collaboration activity among alumni of the DVULI who graduated between 2006 and 2015. 
Hypothesis $\mathrm{H}_{\mathrm{a}}$ 2: Building Trust is a significant predictor of collaboration activity among alumni of the DVULI who graduated between 2006 and 2015.

Hypothesis $\mathrm{H}_{0} 3$ : Developing People is not a significant predictor of collaboration activity among alumni of the DVULI who graduated between 2006 and 2015.

Hypothesis $\mathrm{H}_{\mathrm{a}}$ 3: Developing People is a significant predictor of collaboration activity among alumni of the DVULI who graduated between 2006 and 2015.

Hypothesis $\mathrm{H}_{0} 4$ : Assessing the Environment is not a significant predictor of collaboration activity among alumni of the DVULI who graduated between 2006 and 2015.

Hypothesis $\mathrm{H}_{\mathrm{a}} 4$ : Assessing the Environment is a significant predictor of collaboration activity among alumni of the DVULI who graduated between 2006 and 2015.

Hypothesis $\mathrm{H}_{0} 5$ : Creating Clarity-Visioning and Mobilizing is not a significant predictor of collaboration activity among alumni of the DVULI who graduated between 2006 and 2015.

Hypothesis $\mathrm{H}_{\mathrm{a}}$ 5: Creating Clarity-Visioning and Mobilizing is a significant predictor of collaboration activity among alumni of the DVULI who graduated between 2006 and 2015.

Hypothesis $\mathrm{H}_{0} 6$ : Sharing Power and Influence is not a significant predictor of collaboration activity among alumni of the DVULI who graduated between 2006 and 2015 . 
Hypothesis $\mathrm{H}_{\mathrm{a}} 6$ : Sharing Power and Influence is a significant predictor of collaboration activity among alumni of the DVULI who graduated between 2006 and 2015.

Hypothesis $\mathrm{H}_{0} 7$ : The amount of collaboration activity reported among alumni of the DVULI who graduated between 2006 and 2015 is not significantly different for men than for women.

Hypothesis $\mathrm{H}_{\mathrm{a}}$ 7: The amount of collaboration activity reported among alumni of the DVULI who graduated between 2006 and 2015 is significantly different for men than for women.

Hypothesis $\mathrm{H}_{0} 8$ : There is no significant difference between collaboration activity reported among alumni of the DVULI who graduated between 2006 and 2015 based on age.

Hypothesis $\mathrm{H}_{\mathrm{a}} 8$ : There is a significant difference between collaboration activity reported among alumni of the DVULI who graduated between 2006 and 2015 based on age.

Hypothesis $\mathrm{H}_{0} 9$ : The amount of collaboration activity reported among alumni of the DVULI who graduated between 2006 and 2015 will not be significantly different based on education level grouped in three categories by No College Degree, College Degree, and Graduate Degree.

Hypothesis $\mathrm{H}_{\mathrm{a}}$ 9: The amount of collaboration activity reported among alumni of the DVULI who graduated between 2006 and 2015 will be significantly different based on education level grouped in three categories by no college degree, college degree, and graduate degree. 
Hypothesis $\mathrm{H}_{0} 10$ : There is no significant difference between collaboration activity reported among alumni of the DVULI who graduated between 2006 and 2015 and reported ethnicity.

Hypothesis $\mathrm{H}_{\mathrm{a}} 10$ : There is a significant difference between collaboration activity reported among alumni of the DVULI who graduated between 2006 and 2015 and reported ethnicity.

Hypothesis $\mathrm{H}_{0} 11$ : There is no significant difference between collaboration activity reported among alumni of the DVULI who graduated between 2006 and 2015 and denominational background.

Hypothesis $\mathrm{H}_{\mathrm{a}} 11$ : There is a significant difference between collaboration activity reported among alumni of the DVULI who graduated between 2006 and 2015 and denominational background.

\section{Reliability/Validity}

The CLSA survey was designed for the Turning Point Leadership Development National Excellence Collaborative which was funded by the Robert Wood Johnson Foundation. Written permission was received from the Robert Wood Johnson Foundation via e-mail to use the Turning Point survey and to convert the survey from paper to an electronic format. Several organizations who had used the survey internally and three other dissertation studies that had used the CLSA were identified but no comparison data from any other source was found.

The following statement is provided on the website of the Robert Wood Johnson Foundation providing evidence of the survey's reliability and validity:

The Robert Wood Johnson Foundation prides itself on providing reliable and objective information that meets the highest standards for scientific integrity and 
adheres to our principles. Much of the research and evaluation work we fund and disseminate includes results from surveys and polls. These activities must be carried out adhering to the highest standards for the design, conduct, and reporting of the studies. RWJF standards are consistent with American Association for Public Opinion Research (AAPOR). The guidelines apply to polls and surveys purchased directly by RWJF or by a grantee or contractor using RWJF funds. (RWJF, 2012)

Reliability estimators such as inter-rater or test-retest for the CLSA were also unavailable since the program ended in 2009. A search of the internet surfaced numerous organizations that incorporated the survey into their programs as a self-evaluation for leaders: Northwoods Coalition for Stronger Communities, Tamarack Institute City Match The Public Health Foundation The Build Initiative and Delaware Academy of School Leadership are examples of a few of those organizations. The survey was also available online at Researchgate.net, an open source website for researchers. Its consistent use over time implies a degree of reliability across researchers.

This study did establish internal consistency for the CLSA. Internal consistency is a measure of how well related but different items measure the same thing. Cronbach's alpha is a common measure of internal consistency used by researchers (Creswell, 2012). When all of the items are highly related, it can be interpreted that they are measuring the same thing. A value of .8 or greater is taken to indicate good internal consistency (Creswell, 2012). The Cronbach's alpha coefficient for the six collaborative leadership skills was Self-Reflection (11 items), .83; Building Trust (10 items), .89; Developing People (11 items), .90; Assessing the Environment (11 items), .90; Creating ClarityVisioning and Mobilizing (10 items), .95; Sharing Power (11 items), .90; and the coefficient for all 64 items was .97 .

The Youth Ministry Collaboration Activities Scale is original to this study. During data analysis, it was thought that perhaps the dependent variables could be 
grouped as three variables related to levels of collaboration and compared. To determine how many factors existed among the ten items in the scale, an exploratory factor analysis was conducted. The results showed that only one factor had an eigenvalue greater than one. That factor had an eigenvalue of 5.73. Each of the ten items loaded onto the one factor in the .43 to .68 range. The next highest value was .86 . Therefore, it was determined that all ten items could actually be considered together as one construct or variable. Cronbach's alpha for the YMCAS was .92, suggesting high internal consistency.

As confirmation, Pearson correlation analysis was also performed with the collaboration activities grouped into three categories. Activities 1-5 were recoded as the dependent variable Cooperation, activities 6-8 recoded as dependent variable Coordination, and activities 9 and 10 recoded as dependent variable Collaboration. Results were the same as using the total activity count. The output table from the resulting analysis can be found in Appendix F.

\section{Data Collection Procedures}

Graduates of DVULI from 2006 through 2015 were invited to participate in the study. There were a total of 582 graduates during the stated time period, 541 had active email addresses. Alumni email addresses were obtained with permission from the internal database of the DVULI program. Participation was voluntary and participants were not compensated in any way. A pre-survey email was sent to 541 alumni on a Monday letting them know the nature of the study. The pre-survey email suggested they whitelist the email address that the survey would be coming from to prevent it from going to a spam 
folder and asked them to watch for the email in their inbox in the next few days. The actual survey went out on Tuesday; it was successfully sent to 541 alumni.

The body of the email accompanying the survey contained a link to the survey and explained the purpose of the study. When the link was selected, an informed consent form appeared and agreement was required in order to participate in the study.

Participants were informed that participation was voluntary, that they could choose not to answer any of the questions, and that they had the option to end the survey at any time without penalty. They were also informed of risks involved in participation.

The survey was open for a four-week period. Each week CCSR sent an update with a list of completed surveys, surveys started but not completed, and surveys that remained unopened. The researcher followed up with all individuals who had started the survey or who had not completed the survey with a reminder each week stating that they could still participate by completing the survey.

At the close of the four-week period, 269 surveys were completed, approximately a 50\% return rate. The Survey data was retained on the Qualtrics website server at CCSR. Data transferred from the survey site has been saved in an encrypted format at the Calvin Center for Social Research and will be stored for not less than three years. Only the researcher and staff at the Calvin Center for Social Research have access to the data collected by this study.

\section{Data Analysis}

After data were collected, SPSS Statistics 22 was used to analyze relationships between the variables. Preliminary analysis was performed with descriptive statistics to describe the data. Pearson correlation analysis and analysis of variance were performed to 
describe the relationship between variables and regression analysis was performed to determine which variables, if any, may predict collaboration activities.

\section{Summary}

The purpose of this study was to examine the relationships between the six collaborative leadership skills, demographic factors, and reported collaboration activity. This chapter provided a summary of the design of the survey instrument, a description of how the DVULI graduates for the sample were chosen, how the survey was administered, and the quantitative methods used to perform the analysis. The results follow in Chapter 4. 


\section{CHAPTER 4}

\section{DATA ANALYSIS}

The purpose of this study is to determine whether six collaborative leadership skills identified by Turning Point and taught by DVULI are significant predictors of collaboration activity among DVULI graduates. This chapter presents the results of the statistical analysis relevant to the study. The chapter includes demographic statistics of the sample population, a description of the variables, and results of the hypotheses testing.

This study followed a quantitative correlation design and thus inferential statistics were used to analyze the relationship between the independent and dependent variables (Creswell, 2014). Results are presented in both table format and brief discussion.

\section{Participants Description}

The participants in this study were graduates of DVULI, a 15-month leadership development program designed for Christian youth leaders who work with urban at-risk youth. Following IRB approval and with institutional approval, current email information was obtained from the DeVos Urban Leadership Initiative for alumni in the selected years. Alumni from a ten-year span entering the program from 2006 through 2015 were selected to receive the survey. The ten-year period was chosen to include more current leaders because they would more likely still be in youth ministry. It was also important to allow for at least one year beyond graduation to have passed so the alumni had an 
opportunity to practice collaboration in their ministry context after completion of the program (year 2015).

The survey consisted of 64 questions from a pre-existing survey called the Collaborative Leadership Self-Assessment (CLSA); 10 questions from the Youth Ministry Collaboration Activity Scale (YMCAS) developed for this study; and five demographic questions relating to gender, age, level of education, racial and ethnic heritage, and denominational tradition. The CLSA was used by permission of the Robert Wood Johnson Foundation (Turning Point, 2006b).

There were a total of 558 alumni, 17 emails were undeliverable, 2 people opted out, and 269 people submitted the survey representing a $48 \%$ response rate. In reviewing the 269 responses, it was discovered that some people started the survey but did not finish it completely, including a number who skipped the questions on the YMCAS portion of the survey. It was decided to eliminate any incomplete responses from the study. The final number of valid responses was 215 , or $38.5 \%$ of the total.

\section{Demographics of the Population}

Study participants reported their gender as $58.3 \%$ male and $41.2 \%$ female (Table

2). The majority of respondents $(67.1 \%)$ reported being between ages 30 and 49 (Table $3)$. 
Table 2

Gender Frequencies

\begin{tabular}{lcc}
\hline Gender & Frequency & $\%$ \\
\hline Male & 119 & 58.3 \\
Female & 84 & 41.2 \\
Prefer not to answer & 1 & 0.5 \\
Missing & 11 & \\
\hline
\end{tabular}

$N=215$

Table 3

Age Frequencies

\begin{tabular}{|c|c|c|}
\hline How Old Are You? & Frequency & $\%$ \\
\hline $25-29$ & 13 & 6.3 \\
\hline $30-34$ & 27 & 13.0 \\
\hline $35-39$ & 41 & 19.8 \\
\hline $40-44$ & 33 & 15.9 \\
\hline $45-49$ & 38 & 18.4 \\
\hline $50-54$ & 18 & 8.7 \\
\hline $55-59$ & 15 & 7.2 \\
\hline $60-64$ & 16 & 7.7 \\
\hline 65 or older & 4 & 1.9 \\
\hline Prefer not to answer & 2 & 1.0 \\
\hline Missing & 8 & 3.7 \\
\hline
\end{tabular}


Level of education is represented in Table 4. Respondents were asked to identify their level of education with choices beginning with not having graduated from high school through doctoral degree. All but 5 participants had some college education.

Table 4

Level of Education Frequencies

\begin{tabular}{lcc}
\hline Level of Education & Frequency & $\%$ \\
\hline Less than high school & 1 & 0.5 \\
High school graduate & 3 & 1.4 \\
Some college & 36 & 16.7 \\
2 year degree & 13 & 6.0 \\
4 year degree & 63 & 29.3 \\
Professional degree & 76 & 35.3 \\
Doctorate & 13 & 6.0 \\
Prefer not to answer & 1 & 0.5 \\
Missing & 9 & 4.2 \\
\hline$N=215$ & &
\end{tabular}

Because recruiting an ethnically diverse cohort is important to DVULI, it was desirable to determine if ethnic heritage had an impact on collaboration activity. For the purpose of this study the question was worded as follows:

What is your racial and ethnic heritage? Check all that apply.

American Indian or Alaska Native

Asian or Asian American

Black or African American

Hispanic or Latino/Latina

Native Hawaiian or Pacific Islander

White or Caucasian

Other (please specify)

Prefer not to answer 
Table 5 shows reported ethnicities. Since some participants chose more than one answer from those listed, responses total more than $N=215$. The results are $46 \%$ reported being Black or African American, 28.8\% reported being White or Caucasian, 19.1\% selected Hispanic or Latino, 2.3\% chose Asian or Asian American, 1.4\% chose Native American, .5\% chose Hawaiian or Pacific Islander, $2.3 \%$ chose other and $1.4 \%$ responded Prefer Not To Answer.

Table 5

Racial and Ethnic Heritage Frequencies

\begin{tabular}{lcc}
\hline Racial and Ethnic Heritage & Frequency & $\%$ \\
\hline Native American & 3 & 1.4 \\
Asian or Asian American & 5 & 2.3 \\
Hispanic or Latino & 41 & 19.1 \\
Hawaiian or Pacific Islander & 1 & 0.5 \\
Black or African American & 99 & 46.0 \\
White or Caucasian & 62 & 28.8 \\
Other & 5 & 2.3 \\
Prefer not to answer & 3 & 1.4 \\
\hline$N=215$ & &
\end{tabular}

DVULI believes that denominational tradition plays a part in shaping the culture or language of faith and has the potential to determine whether believers are willing to partner with youth leaders from other Christian or secular organizations for the common good. Since the Protestant Reformation 500 years ago, the Protestant church has endured many splits and divisions. According to the Association of Religion Data Archives, today 
there are thousands of self-identified denominations (Association of Religion Data Archives, 2017).

Rather than present survey participants with an extensive list of denominations to choose from, this study asked participants an open-ended question, "What is your denomination or faith tradition?" Some chose not to respond (13\%), another $41.1 \%$ said they were non-denominational. The remaining $45.9 \%$ gave a variety of responses. Those responses were grouped into seven categories based on an analysis of 400 families of religious groups found on the website of the Association of Religion Data Archives (2017) . Based on that description, the next largest reported denominational groups were Baptists with $15.4 \%$, and Pentecostals at $11.7 \%$ as presented in Table 6.

Table 6

Denomination or Faith Tradition Frequencies

\begin{tabular}{lcc}
\hline Denomination or faith tradition & Frequency & $\%$ \\
\hline No answer & 29 & 13.1 \\
Non-denominational & 88 & 41.1 \\
Baptist & 33 & 15.4 \\
Pentecostal & 25 & 11.7 \\
Reformed & 16 & 7.5 \\
Methodist/Pietist & 12 & 5.6 \\
Holiness & 9 & 4.2 \\
Roman Catholic & 2 & .9 \\
Disciple of Christ/Restoration & 1 & .5 \\
\hline$N=215$ & &
\end{tabular}




\section{Predictor Variables}

The predictor variables are the six skills of collaborative leadership: Self-

Reflection; Building Trust; Developing People; Assessing the Environment; Creating Clarity-Visioning and Mobilizing; and Sharing Power and Influence. Participants had the highest mean scores for Sharing Power and Influence and the lowest mean score for Assessing the Environment. Means and standard deviations of the six collaboration skills are shown in Table 7 . Results are based on a scale of 1 to 7 where $1=$ Never, $2=$ Rarely, $3=$ Sometimes, $4=$ Half the Time, $5=$ Often, $6=$ Most of the Time and $7=$ Always. Participants ranked their use of the skills at 4 or higher for all the skills.

\section{Table 7}

Collaborative Leadership Skills descriptive results

\begin{tabular}{lccccc}
\hline & $N$ & Mean & $S D$ & Min & Max \\
\hline Sharing Power & 205 & 5.77 & .79 & 3.00 & 7.00 \\
Building Trust & 206 & 5.56 & .88 & 2.20 & 7.00 \\
Developing People & 206 & 5.48 & .97 & 2.73 & 7.00 \\
Self-reflection & 207 & 5.40 & .69 & 3.36 & 6.82 \\
Creating Clarity & 206 & 4.83 & 1.2 & 1.00 & 7.00 \\
Assess Environment & 207 & 4.81 & 1.1 & 2.10 & 7.00 \\
\hline
\end{tabular}

No population comparison data were found based on research of other organizations who have employed the CLSA. According to instructions on the survey, the self-assessment is to be used to trigger personal reflection about these key behaviors associated with collaborative practices. Turning Point suggests an average of 6.1-7.0 for 
each subset of skills indicates an excellent score, 4.1 to 6.0 indicates a strong score, 2.1 to 4.0 is an opportunity for growth and 1.0 to 2.0 is an important area for behavior change (Turning Point, 2006b). DVULI participants assessed themselves in a range from 4.81 to 5.77 on all of the skills indicating they believe they are strong in practices related to all six collaboration skills.

\section{Dependent Variable YMCAS}

The data for responses to the ten questions on the YMCAS needed to be cleaned. If the participants responded 'yes' to the activity, they were asked how many times in the prior 12 months they performed that activity. Some participants gave responses in a range, for example 6 to 10 times. In those instances, the middle number of the range was chosen. If the range was an even number, the lower number was chosen (e.g. for 5-10 became 7 and 1-2 became 1). Some participants wrote in a term such as a few or often. If the term was quantifiable it was given a number (monthly became 12) but if not, the response was eliminated (a few or often were removed). Using the cleaned data, Table 8 presents the frequency counts for those who answered yes to each of the ten questions and the $\mathrm{N}$, mean, and standard deviation for the number of times those who answered yes reported doing that activity in the prior twelve months. 
Table 8

YMCAS descriptive statistics

\begin{tabular}{|c|c|c|c|c|c|}
\hline & Freq & $\%$ & $\mathrm{~N}$ & Mean & S.D \\
\hline Answered No to all questions & 15 & 7.0 & 215 & & \\
\hline $\begin{array}{l}\text { 1. Communicated with youth leaders outside of } \\
\text { my organization for personal connections, } \\
\text { encouragement, or support. }\end{array}$ & 8 & 3.7 & 207 & 15.69 & 33.25 \\
\hline $\begin{array}{l}\text { 2. Communicated with youth leaders outside of } \\
\text { my organization to discuss a specific concern, } \\
\text { issue, or event. }\end{array}$ & 10 & 4.7 & 208 & 10.02 & 19.62 \\
\hline $\begin{array}{l}\text { 3. Posted an event on a calendar that people } \\
\text { outside my organization can access. }\end{array}$ & 16 & 7.4 & 212 & 7.88 & 27.27 \\
\hline $\begin{array}{l}\text { 4. Participated in a youth leader network in my } \\
\text { city. }\end{array}$ & 14 & 6.5 & 210 & 2.86 & 4.59 \\
\hline $\begin{array}{l}\text { 5. Shared information about training or funding } \\
\text { opportunities with youth leaders outside of my } \\
\text { organization. }\end{array}$ & 24 & 11.2 & 209 & 6.69 & 14.82 \\
\hline $\begin{array}{l}\text { 6. Worked with youth leaders outside of my } \\
\text { organization to implement events or trainings. }\end{array}$ & 21 & 9.8 & 210 & 3.60 & 6.40 \\
\hline $\begin{array}{l}\text { 7. Directed youth to other programs in my } \\
\text { community. }\end{array}$ & 19 & 8.8 & 206 & 9.98 & 18.85 \\
\hline $\begin{array}{l}\text { 8. Received approval from my organization to } \\
\text { work with other youth-serving organizations. }\end{array}$ & 23 & 10.7 & 204 & 3.46 & 8.65 \\
\hline $\begin{array}{l}\text { 9. Worked with another organization to establish } \\
\text { a new entity that achieves a common goal. }\end{array}$ & 21 & 9.8 & 205 & 2.13 & 4.58 \\
\hline $\begin{array}{l}\text { 10. Received full commitment and resources } \\
\text { from my organization to work with other youth- } \\
\text { serving organizations. }\end{array}$ & 44 & 20.5 & 207 & 3.43 & 9.08 \\
\hline
\end{tabular}


Once the data were cleaned, a decision needed to be made regarding treatment of the dependent variable(s). Should the ten activities be treated as individual independent variables? Should they be grouped by the level of complexity based on cooperation, coordination, and collaboration, or should they be treated as on variable based on the count of all activities reported by each participant in the prior year?

To answer this question, factor analysis was conducted on the YMCAS responses. The results of factor analysis indicated only one factor seemed to be at play determined by an eigenvalue greater than one. This factor had an eigenvalue of 5.73. Each of the ten items loaded onto the one factor in the $.43-.68$ range. The next highest value was .86 . Logically it makes sense that is a participant who is reporting a highly complex level of collaboration activity, it is likely they would not stop performing less complex collaboration activities.

Based on the scree plot and the eigenvalues provided by the factor analysis, it was determined that all ten items should be considered together as one construct or variable. Cronbach's alpha, a measure for internal consistency, was .92 for the ten items.

To test the results of the factor analysis which indicated that all ten of the questions in the YMCAS loaded onto one factor, the data were disaggregated and the questions grouped as three variables representing three categories of cooperation (questions 1-5), coordination (questions 6-8) and collaboration (questions 9 and 10). These categories were used with the focus group in the design of the survey. The correlation results were the same which strengthens the factor analysis results indicating the questions co-varied as one variable. 


\section{Hypotheses Testing}

The hypotheses described in Chapter 3 were analyzed using statistical procedures. These procedures included Pearson's r correlation, multiple linear regression, one-way analysis of variance, and factorial one-way analysis of variance. The hypotheses test results are reported in the following paragraphs.

The first six hypotheses were created to answer research question one which asked: Is there a significant relationship between the six collaborative leadership skills and the collaboration activity reported by DVULI graduates? To test each hypothesis, a Pearson correlation analysis was conducted using a 95\% confidence level for the null hypothesis. The mean for each skill subset was used in the analysis. The dependent variable used a total count of all collaboration activity reported by each participant. Tables 9-14 present results for correlation with each of the collaborative skills.

Table 9

Correlation of Self-Reflection with Collaboration Activity

\begin{tabular}{llc}
\hline & Self-Reflection & CollabActivity \\
\hline Self-Reflection & Pearson Correlation & $.19^{* *}$ \\
& Sig. (2-tailed) & .01 \\
$N$ & 207 & \\
$* *$ Correlation is significant at the 0.01 level (2-tailed).
\end{tabular}


Table 10

Correlation of Building Trust with Collaboration Activity

\begin{tabular}{llc}
\hline & Building Trust & CollabActivity \\
\hline Building Trust & Pearson Correlation & $.23 * *$ \\
& Sig. (2-tailed) & .01 \\
$N$ & 206 & \\
& & \\
$* *$ Correlation is significant at the 0.01 level (2-tailed).
\end{tabular}

Table 11

Correlation of Developing People with Collaboration Activity

\begin{tabular}{llcc}
\hline & & Developing People & CollabActivity \\
\hline Developing People & Pearson Correlation & $.25^{* *}$ \\
& Sig. (2-tailed) & .00 \\
& $N$ & 206 & \\
& &
\end{tabular}

**Correlation is significant at the 0.01 level (2-tailed).

Table 12

Correlation of Assessing the Environment with Collaboration Activity

\begin{tabular}{|c|c|c|c|}
\hline & & AssesEnvironment & CollabActivity \\
\hline \multirow[t]{3}{*}{ AssessEnvironment } & Pearson Correlation & & $.23 * *$ \\
\hline & Sig. (2-tailed) & & .00 \\
\hline & $N$ & 207 & \\
\hline
\end{tabular}


Table 13

Correlation of Creating Clarity-Visioning and Mobilizing with Collaboration Activity

\begin{tabular}{llcc}
\hline & & Create Clarity & CollabActivity \\
\hline CreateClarity & Pearson Correlation & & $.34^{* *}$ \\
& Sig. (2-tailed) & .00 \\
$N$ & 206 & \\
\hline
\end{tabular}

**Correlation is significant at the 0.01 level (2-tailed).

Table 14

Correlation of Sharing Power and Influence with Collaboration Activity

\begin{tabular}{llcc}
\hline & & SharePower & CollabActivity \\
\hline SharePower & Pearson Correlation & & $.29 * *$ \\
& Sig. (2-tailed) & & .00 \\
& $\mathrm{~N}$ & 205 & \\
\hline
\end{tabular}

**Correlation is significant at the 0.01 level (2-tailed).

Hypothesis $\mathrm{H}_{0} 1$ : Self-Reflection is not a significant predictor of collaboration activity among alumni of the DVULI who graduated between 2006 and 2015 .

Hypothesis $\mathrm{H}_{\mathrm{a}} 1$ : Self-Reflection is a significant predictor of collaboration activity among alumni of the DVULI who graduated between 2006 and 2015.

With a $p$ value of .007 which is less than .05 , the null hypothesis is rejected. It can be concluded that there is a significant correlation between Self-Reflection and collaboration activity among alumni of the DVULI who graduated between 2006 and $2015(r=.19, \mathrm{p}<.01)$. 
Hypothesis $\mathrm{H}_{0} 2$ : Building Trust is not a significant predictor of collaboration activity among alumni of the DVULI who graduated between 2006 and 2015 .

Hypothesis $\mathrm{H}_{\mathrm{a}}$ 2: Building Trust is a significant predictor of collaboration activity among alumni of the DVULI who graduated between 2006 and 2015.

With a $p$ value of .01 which is less than .05 , the null hypothesis is rejected. It can be concluded that there is a significant correlation between Building Trust and collaboration activity among alumni of the DVULI who graduated between 2006 and $2015(r=.23, \mathrm{p}<.01)$.

Hypothesis $\mathrm{H}_{0} 3$ : Developing People is not a significant predictor of collaboration activity among alumni of the DVULI who graduated between 2006 and 2015.

Hypothesis $\mathrm{H}_{\mathrm{a}} 3$ : Developing People is a significant predictor of collaboration activity among alumni of the DVULI who graduated between 2006 and 2015.

With a $p$ value of .00 which is less than .05 , the null hypothesis is rejected. It can be concluded that there is a significant correlation between developing people and collaboration activity among alumni of the DVULI who graduated between 2006 and $2015(r=.25, p<.01)$.

Hypothesis $\mathrm{H}_{0} 4$ : Assessing the Environment is not a significant predictor of collaboration activity among alumni of the DVULI who graduated between 2006 and 2015.

Hypothesis $\mathrm{H}_{\mathrm{a}} 4$ : Assessing the Environment is a significant predictor of collaboration activity among alumni of the DVULI who graduated between 2006 and 2015. 
With a $p$ value of .00 which is less than .05 , the null hypothesis is rejected. It can be concluded that there is a significant correlation between visioning and mobilizing and collaboration activity among alumni of the DVULI who graduated between 2006 and $2015(r=.23, \mathrm{p}<.01)$

Hypothesis $\mathrm{H}_{0} 5$ Creating Clarity-Visioning and Mobilizing is not a significant predictor of collaboration activity among alumni of the DVULI who graduated between 2006 and 2015.

Hypothesis $\mathrm{H}_{\mathrm{a}}$ 5: Creating Clarity-Visioning and Mobilizing is a significant predictor of collaboration activity among alumni of the DVULI who graduated between 2006 and 2015.

With a $p$ value of .00 which is less than .05 , the null hypothesis is rejected. It can be concluded that there is a correlation between Creating Clarity-Visioning and Mobilizing and collaboration activity among alumni of the DVULI who graduated between 2006 and $2015(r=.34, p<.00)$.

Hypothesis $\mathrm{H}_{0} 6$ : Sharing Power and Influence is not a significant predictor of collaboration activity among alumni of the DVULI who graduated between 2006 and 2015.

Hypothesis $\mathrm{H}_{\mathrm{a}} 6$ : Sharing Power and Influence is a significant predictor of collaboration activity among alumni of the DVULI who graduated between 2006 and 2015.

With a $p$ value of .00 which is less than .05 , the null hypothesis is rejected. It can be concluded that there is a correlation between sharing power and influence and 
collaboration activity among alumni of the DVULI who graduated between 2006 and $2015(r=.29, p<.00)$.

Correlation explains the degree of linear association between two variables but does not explain if multiple variables work together to predict the outcome. A multiple regression analysis was performed to reveal more about the relationship of the independent (predictor) variables - the six collaborative leadership skills together - to the dependent variable, the collaboration activity reported. Table 15 presents the results of the regression analysis.

Table 15

Regression Model of Collaboration Skills as Predictor of Collaboration Activity

\begin{tabular}{lcccc}
\hline \multicolumn{1}{c}{ Collaborative Skill } & $B$ & $t$ & $p$ & Sig \\
\hline Constant & .224 & .131 & -.360 & .896 \\
SelfReflection & -.021 & -.056 & .709 & .955 \\
BuildTrust & .102 & .307 & .125 & .759 \\
DevPeople & .031 & .103 & .157 & .918 \\
AssessEnviron & -.054 & -.211 & & .833 \\
CreateClarity & .622 & 2.769 & & .006 \\
SharePower & .487 & 1.357 & & .176 \\
\hline
\end{tabular}

$R^{2}=.13 ; F_{(6,197)}=4.84, p<.001$

A significant regression equation was found $\left(F_{(6,197)}=10.40, p<.001\right)$ with an $R$ of $.359, R^{2}$ of .129 and adjusted $R^{2}$ of .102 . When controlling for the effects of the other five variables, only Creating Clarity-Visioning and Mobilizing has a significant association $(p=.006)$ with collaboration activity. 
According to the regression analysis, the model summary explains that the multiple correlation coefficient $(R)$, using all six predictors simultaneously, is .36 and the adjusted $R^{2}$ is .13 meaning that $13 \%$ of the variance in collaboration activity can be explained by the model $F=4.84$ and is statistically significant, $p<.001$. This indicates that the predictors combined together significantly predict collaboration activity.

The coefficient table shows if each of the independent variables (skills) is significantly contributing to the equation for predicting collaboration activity. In this study, we can conclude that only Creating Clarity-Visioning and Mobilizing is significantly contributing to collaboration; however, all six collaboration skills do need to be included in the model in order to obtain this result.

Research question two asked: Is there a significant difference between the collaboration activity reported on the YMCAS based on gender, age, education level, ethnicity, and denominational background? Hypotheses 7 through 11 tested this question.

Hypothesis $\mathrm{H}_{0} 7$ : The amount of collaboration activity reported among alumni of the DVULI who graduated between 2006 and 2015 is not significantly different for men than for women.

Hypothesis $\mathrm{H}_{\mathrm{a}}$ 7: The amount of collaboration activity reported among alumni of the DVULI who graduated between 2006 and 2015 is significantly different for men than for women.

Tables 16 and 17 show results of a one-way analysis of variance which was conducted to compare the effect of Gender on Collaboration Activity. There was a 
significant effect of Gender on Collaboration Activity at the $p<.05$ level, $\left[F_{(2,201)}=3.66\right.$, $p=.03]$ therefore the null hypothesis is rejected. The mean collaboration activity count

Table 16

One-Way Analysis of Variance of Collaboration Activity by Gender

\begin{tabular}{lrrrcc}
\hline & $S S$ & $d f$ & \multicolumn{1}{c}{$M S$} & $F$ & $p$ \\
\hline Between Groups & 62.73 & 2 & 31.36 & 3.66 & .03 \\
Within Groups & 1724.70 & 201 & 8.58 & & \\
Total & 1787.43 & 203 & & & \\
\hline
\end{tabular}

Table 17

Group Statistics for Men and Women

\begin{tabular}{lcccc}
\hline Gender & $n$ & Mean & SD & SEM \\
\hline Male & 119 & 9.81 & 2.91 & .27 \\
Female & 84 & 5.79 & 2.96 & .32 \\
\hline
\end{tabular}

for men was $6.81(S D=2.91)$ and the mean collaboration activity count for women was $5.79(S D=2.96)$ indicating that men reported significantly more collaboration activity than women.

Hypothesis $\mathrm{H}_{0} 8$ : There is no significant difference between collaboration activity reported among alumni of the DVULI who graduated between 2006 and 2015 and age.

Hypothesis $\mathrm{H}_{\mathrm{a}} 8$ : There is a significant difference between collaboration activity reported among alumni of the DVULI who graduated between 2006 and 2015 and age. Table 18 presents results of the analysis of age with collaboration activity. 
Age was reported as a continuous variable in response to the question, What is Your Age. A one-way analysis of variance was conducted to compare the effect of age on Collaboration Activity by grouping the ages into 4 categories. Results are shown in tables 18 and 19. There was no significant effect of age on Collaboration Activity at the $p<.05$ level, $\left[F_{(201,3)}=.43, p=.73\right]$; therefore, the null hypothesis cannot be rejected. This result suggests that there is no correlation between age and collaboration activity.

Table 18

One-Way Analysis of Variance of Collaboration Activity by Age

\begin{tabular}{lrrrrr}
\hline & \multicolumn{1}{c}{$S S$} & $d f$ & $M S$ & $F$ & $p$ \\
\hline Within Groups & 1784.02 & 201 & 8.88 & & \\
Between Groups & 11.56 & 3 & 3.85 & .43 & .73 \\
Total & 1795.58 & 204 & & & \\
\hline
\end{tabular}

Table 19

Group Statistics for Age Groupings

\begin{tabular}{lcccc}
\hline Age & $n$ & Mean & $S D$ & SEM \\
\hline age $20-34$ & 40 & 6.08 & 3.13 & .50 \\
age $35-44$ & 74 & 6.38 & 2.88 & .33 \\
age $45-54$ & 56 & 6.41 & 3.20 & .43 \\
age 55 and older & 35 & 6.86 & 2.64 & .45 \\
Total & 205 & 6.41 & 2.97 & .21 \\
\hline
\end{tabular}

Hypothesis $\mathrm{H}_{0} 9$ : The amount of collaboration activity reported among alumni of the DVULI who graduated between 2006 and 2015 is not significantly different by 
Education level grouped in three categories of No College Degree, College Degree, and Graduate Degree.

Hypothesis $\mathrm{H}_{\mathrm{a}}$ 9: The amount of collaboration activity reported among alumni of the DVULI who graduated between 2006 and 2015 is significantly different by Education level grouped in three categories of No College Degree, College Degree, and Graduate Degree. Tables 20 and 21 present results of education level with collaboration activity.

Table 20

One-Way Analysis of Variance of Collaboration Activity with Education Level

\begin{tabular}{lrrrrc}
\hline & \multicolumn{1}{c}{ SS } & df & MS & F & p \\
\hline Between Groups & 55.85 & 2 & 27.93 & 3.25 & .04 \\
Within Groups & 1734.23 & 202 & 8.59 & & \\
Total & 1790.08 & 204 & & & \\
\hline
\end{tabular}

Table 21

Group Statistics for Education Level

\begin{tabular}{lcccc}
\hline Level & $n$ & Mean & $S D$ & SEM \\
\hline No College Degree & 40 & 7.40 & 2.92 & .46 \\
College Degree & 76 & 6.43 & 2.92 & .34 \\
Graduate Degree & 89 & 5.98 & 2.94 & .31 \\
Total & 205 & 6.42 & 2.96 & .21 \\
\hline
\end{tabular}

One-way analysis of variance was used to test for group differences. Table 20 shows the results of the ANOVA at $\alpha=0.05$, which indicate that there are significant differences among the groups by level of education. $\left(F_{(2,202)}=3.253, p=.041\right)$. The null 
hypothesis is rejected. This result suggests there is a difference in collaboration by education level but does not identify between which groups.

Table 21 shows the mean and standard deviation of collaboration activity reported by group. Performing a post hoc comparison using the Bonferroni correction for testing multiple hypothesis (Morgan, Leech, Gloeckner, \& Barrett, 2013) revealed there is a significant difference between those with no college degree and those with a graduate degree $(p=.035)$.

Hypothesis $\mathrm{H}_{0} 10$ : There will be no significant difference between collaboration activity reported among alumni of the DVULI who graduated between 2006 and 2015 and reported ethnicity.

Hypothesis $\mathrm{H}_{\mathrm{a}} 10$ : There is a significant difference between collaboration activity reported among alumni of the DVULI who graduated between 2006 and 2015 and reported ethnicity. Tables 22 and 23 show results comparing ethnicity.

Table 22

One-Way Analysis of Variance of Collaboration Activity with Ethnicity

\begin{tabular}{lrrrrr}
\hline & \multicolumn{1}{c}{$S S$} & $d f$ & $M S$ & $F$ & $p$ \\
\hline Between Groups & 3.65 & 3 & 1.22 & .14 & .94 \\
Within Groups & 1798.10 & 202 & 8.90 & & \\
Total & 1801.75 & 205 & & & \\
\hline
\end{tabular}


Table 23

Group Statistics for Ethnicity

\begin{tabular}{lcccc}
\hline & $n$ & Mean & $S D$ & SEM \\
\hline Black & 92 & 6.28 & 2.97 & .31 \\
other & 15 & 6.27 & 3.28 & .85 \\
Hispanic & 37 & 6.57 & 3.07 & .50 \\
White & 62 & 6.53 & 2.87 & .36 \\
Total & 206 & 6.41 & 2.96 & .21 \\
\hline
\end{tabular}

A one-way analysis of variance was conducted to compare the effect of Ethnicity on Collaboration Activity by grouping Ethnicities into 4 categories. There was no significant effect of Ethnicity on Collaboration Activity at the $p<.05$ level, $[F(3,202)=$ $.14, \mathrm{p}=.94]$; therefore, the null hypothesis cannot be rejected. This result suggests that there is no correlation between ethnicity and collaboration activity.

Hypothesis $\mathrm{H}_{0} 11$ : There is no significant difference between collaboration activity reported among alumni of the DVULI who graduated between 2006 and 2015 and denominational background.

Hypothesis $\mathrm{H}_{\mathrm{a}}$ 11: There is a significant difference between collaboration activity reported among alumni of the DVULI who graduated between 2006 and 2015 and denominational background. Tables 24 and 25 show results comparing denomination.

While denominations likely do have an impact on mindset toward collaboration, understanding current trends in how people self-identify related to denominational affiliation made it difficult to evaluate. Recent work in sociology has challenged 
traditional categories for Protestants. Steensland et al. make a case for grouping denominations into two dominant religious traditions: mainline Protestantism and evangelical Protestantism (Steensland, Park, Regnerus, Robinson, W. Bradford Wilcox, \& D.Woodberry, 2000).

Table 24

One-Way Analysis of Variance of Collaboration Activity with Denomination

\begin{tabular}{lrrrrr}
\hline & \multicolumn{1}{c}{$S S$} & \multicolumn{1}{c}{$d f$} & \multicolumn{1}{c}{$M S$} & $F$ & $p$ \\
\hline Between Groups & 15.03 & 1 & 15.03 & 1.77 & .19 \\
Within Groups & 1536.69 & 181 & 8.49 & & \\
Total & 1551.72 & 182 & & & \\
\hline
\end{tabular}

Table 25

Group Statistics for Denomination

\begin{tabular}{lcccc}
\hline & $n$ & Mean & SD & Std. Error Mean \\
\hline Nondenominational & 88 & 6.78 & 2.94 & .31 \\
Any Denomination & 95 & 6.21 & 2.89 & .30 \\
Total & 183 & 6.49 & 2.92 & .22 \\
\hline
\end{tabular}

Using these categories, a one-way analysis of variance was conducted to compare the effect of Denominational Affiliation on Collaboration Activity by grouping responses into 2 categories. There was no significant effect of Denomination on Collaboration Activity at the $p<.05$ level, $\left[\mathrm{F}_{(1,181)}=1.77, p=.19\right]$; therefore, the null hypothesis is not rejected. This result suggests there is no correlation between Denomination and collaboration activity. 


\section{Summary}

The purpose of this study was to examine the relationship between the six collaboration skills taught by DVULI and youth ministry collaboration activity for alumni who participated in the program from 2006 through 2015. Additionally, demographic factors were considered for influence of collaboration activity. Data was collected through an online survey and analyzed using Pearson's r correlation analysis, multiple regression analysis, and one-way analysis of variance to answer the research questions of this study.

Results of the Pearson correlation showed that each of the collaborative skills had a significant positive relationship with collaboration activity. Regression analysis of the model showed that all six collaborative skills together were predictors of collaboration activity with Creating Clarity-Visioning and Mobilizing as the single significant predictor when controlling for the effect of the other five skills. Results also indicated differences in collaboration activity based on gender and education level. The discussion of findings, conclusion and recommendations for this research will be discussed in Chapter 5. 


\section{CHAPTER 5}

\section{SUMMARY, CONCLUSIONS, AND RECOMMENDATIONS}

\section{Summary}

Addressing the challenges of urban youth growing up in communities of poverty is a systems-level problem. Young people do not grow up in programs but in families, schools, churches, and neighborhoods. It takes diverse perspectives and crossorganizational cooperation to bring about significant change for youth at the systemslevel. Consequently, interest in partnering together and the ability to work collaboratively is an important skill for leaders working with urban at-risk youth. (Chrislip \& Larson, 1994; Huxham \& Vangen, 2005; Kania \& Kramer, 2013; Lerner et al., 2005; Pittman et al., 2011).

For young people in crisis, transformational change centers on developing competency and resiliency in the context of their everyday lives. When caring adults and youth-centered programs have a shared vision and work together in collaboration, the result can be a higher level of impact on youth. Collaboration has the potential to bring about healthier communities where young people and their families can thrive (Edwards et al., 2007; Lerner \& Benson, 2003; Trulear, 2000; Wheeler, 2006).

Leaders often do not seek out collaboration because collaboration is not easy. Collaboration takes longer. It is more complicated. It has more risk and a higher potential for failure than working alone. All of these factors mean more can go wrong and results 
may be out of the control of the leader. There is also the very real possibility that hidden agendas and strong egos will sabotage efforts at collaboration (Abele, 2011; Chrislip \& Larson, 1994; Gray, 1989; Huxham \& Vangen, 2005; Wheeler, 2006).

Still, the benefits of collaboration when faced with system-level problems outweigh the risks. When collaboration is successful, it can reduce duplication of services and have a broader impact than any one agency can provide. Collaboration has the potential to help under-resourced communities leverage their existing assets. It brings a stronger voice to issues and is inclusive of voices that normally are not heard. Collaboration also provides a network of support and comradery for leaders who share a passion and reduces the sense of isolation for those who work together (Abele, 2011; Chrislip \& Larson, 1994; Huxham \& Vangen, 2005).

Christian churches and other community-based Christian institutions have a role to play in collaborative solutions for at-risk young people as well, and their mandate lies even deeper than that of secular agencies. They share a belief system based on the biblical tenants of Christianity which highly value partnership, unity, and community with others. Consider these biblical principles. Throughout the Old Testament, God's plan of salvation was to reconcile all people and all nations and return them to God's shalom (Isa 42:5-7). His people are called to collectively bring peace to the city (Ps 122:6-9, Jer 29:7, Deut 28:2-6). God urges his people to have compassion for the poor (Deut 10:18, I Sam 2:8, Ps 9:9, Prov 21:13).

In the New Testament, beginning with the book of Acts, the church is to cross every cultural and ethnic barrier (Acts 2). When the new believers begin to have divisions and follow different teachers, the Apostle Paul calls them back to unity (Eph 2:14 and 
4:1-6). His letters to the churches are written to all of the believers in each city with explicit instructions on how they are to love one another and work together as a way of demonstrating the love and power of the gospel to their unbelieving neighbors.

The church is told that they cannot have a genuine relationship with God unless they are first reconciled to their friends and neighbors. (Matt 5:21-24, 2 Cor 2:5-11). Being a follower of Jesus requires making relationships with others a priority. (Col 3:1217, Rom 12:9-17). Jesus himself prayed on the night before his death for the believers of his day and in the time to come to be united as evidence that God's love can overcome any differences among people and bring them together to point the way to Him (John 17).

The biblical foundation for working together is clear, however, disagreements continue to divide the church. Christian leaders with a desire to work with youth share a compelling passion yet barriers still exist that keep them from working together. Most work in isolation instead of collaboratively engaging together in a shared mission of community-wide outreach to youth (Butler, 2006; Fleischmann, 2014; Stearns, 2013).

The DeVos Urban Leadership Initiative is a leadership training program designed for Christian leaders working with at-risk youth in urban communities of poverty. The program is grounded in biblical principles and has as one of its goals to encourage interdependence among leaders who are working in churches and youth-serving organizations and to build relationships of trust among program participants with the expectation that its graduates will see the value of practicing collaboration after the completion of the program.

Research done in the development phase for the DVULI program surfaced four critical areas of need that are common among leaders working in the context of urban youth 
ministry. The program was designed to address those four areas. Table 26 shows each problem area for urban youth ministry and the corresponding change strategy employed by the program to address it.

\section{Purpose of the Study}

DeVos Urban Leadership Initiative incorporates training around six collaborative leadership skills to achieve the goal of developing leaders equipped to partner with others who share their passion for working with urban at-risk youth. The six skills include: Self-

Reflection, Building Trust, Developing People, Assessing the Environment, Creating Clarity-Visioning and Mobilizing, and Sharing Power and Influence. Using a preexisting survey called the Collaborative Leadership Self-Assessment (Turning Point, 2006b) and a measurement scale of collaboration activity, this study was designed to evaluate whether those six collaborative leadership skills are actual predictors of collaboration activity for participants who are at least one year beyond graduating from the program.

\section{Leadership Program Evaluation}

Since the 1980s, numerous leadership development programs have been developed with the intention of increasing networking, cooperation, promoting social capital, coalition building, and/or collaboration among like-minded individuals in a shared field. While these terms may seem different, they have an important ingredient in common, they all require the ability of the leader to develop and sustain relationships with peer leaders. This study used the term collaboration to mean "a process that gets people to work together in new ways" (Meehan \& Reinelt, 2007; Winer \& Ray, 1994). For the Christian youth worker, that could be as simple as going from working in 
Table 26

DeVos Urban Leadership Theory of Change

Problem Change Strategy

1. High burnout rates that result in high turnover. A tendency to work inefficiently without long-term holistic goals that address the complexity of urban ministry
Equip leaders individually to help them stay in youth ministry for long-term influence with youth. Help them develop a value for self-care and spiritual disciplines including: accountability, balance, empowerment, interdependence, and leverage

Foster skills to develop sustainable ministry practices. Provide knowledge of tools and skills to navigate complex urban environment. These include asset mapping, networking, planning, youth development, and systems thinking

Build an understanding of the value of empowering others as leaders for urban youth ministry. Help leaders see developing the gifts of others as one of their primary responsibilities as a leader

Encourage leaders to work with others serving at-risk youth. Develop a high value for collaboration with others who share their passion and vision.

(VanderWaal, 2005, p. 2) 
complete isolation to reaching out for friendship and support to other youth workers outside of their organization.

Much of the evaluation of leadership development programs has centered on development of skills and assessment of the individual leader before and after participating in the training. It has been much harder to evaluate whether those programs have made a long-term impact at the community level on the problems they were interested in solving. There has been criticism that, in fact, existing evaluation methods are not adequate to show that leadership development programs can claim the outcome of enhanced networking or collaboration after completion of the program (Black \& Earnest, 2009; Bourda, 2014; Hannum et al., 2007; Russon \& Reinelt, 2004; Van De Valk \& Constas, 2011). One of the features of the DVULI training is maintaining long-term connections with alumni of the program, which provided a unique opportunity to evaluate outcomes related to collaboration a year or more after participants complete the training.

While evaluation of DVULI alumni in the long-term may be an advantage, program evaluation can also be valuable in other ways. Developing performance measurement systems can help provide feedback to program administrators for ongoing decisions about program content and activities (Mark, 2005; Taplin \& Clark, 2012). There are a number of different approaches that have been shown to provide useful program evaluation for leadership development programs (Hannum et al., 2007).

This study used the program Theory of Change and Logic Model as the basis for creating the evaluation tool. The term Theory of Change emerged in the 1990s as a means to evaluate community initiatives. (Harris, 2005; Weiss, 1998) A program Theory of 
Change explains the assumptions behind an intervention and how it is expected to create long-term results. According to the Center for Theory of Change:

Theory of Change is essentially a comprehensive description and illustration of how and why a desired change is expected to happen in a particular context. It is focused in particular on mapping out or "filling in" what has been described as the "missing middle" between what a program or change initiative does (its activities or interventions) and how these lead to desired goals being achieved. (www.theoryofchange.org)

The Theory of Change related to collaboration for DVULI is to reduce the sense of isolation in an effort to "encourage leaders to work with others in serving at-risk youth. Develop a high value for collaboration with others who share their passion and vision." (See Table 26).

The program Logic Model depicts the logical relationships between a program's inputs, its activities, the outputs that are produced by the activities, and the changes or benefits that result from the program. It is developed by first identifying the desired longterm goals and then working back from these to map the inputs and activities thought to be needed for the outcome to occur. A Logic Model is not static. It should change over time whenever evaluation provides feedback that the intended outcomes of the program are not being achieved (Cooksy et al., 2001).

The program's Logic Model, provides the tactical details for implementing the Theory of Change. Combining the DVULI Theory of Change and Logic Model, this study explored whether the assumptions behind the training, the activities provided, and the outputs led to the desired program results related to collaboration. An infographic of the DVULI Logic Model related to collaboration as an outcome is shown in Figure 2.

Focus groups in the development phase of DVULI identified a sense of isolation and lack of support as one of the challenges of working with at-risk urban youth (Burke 


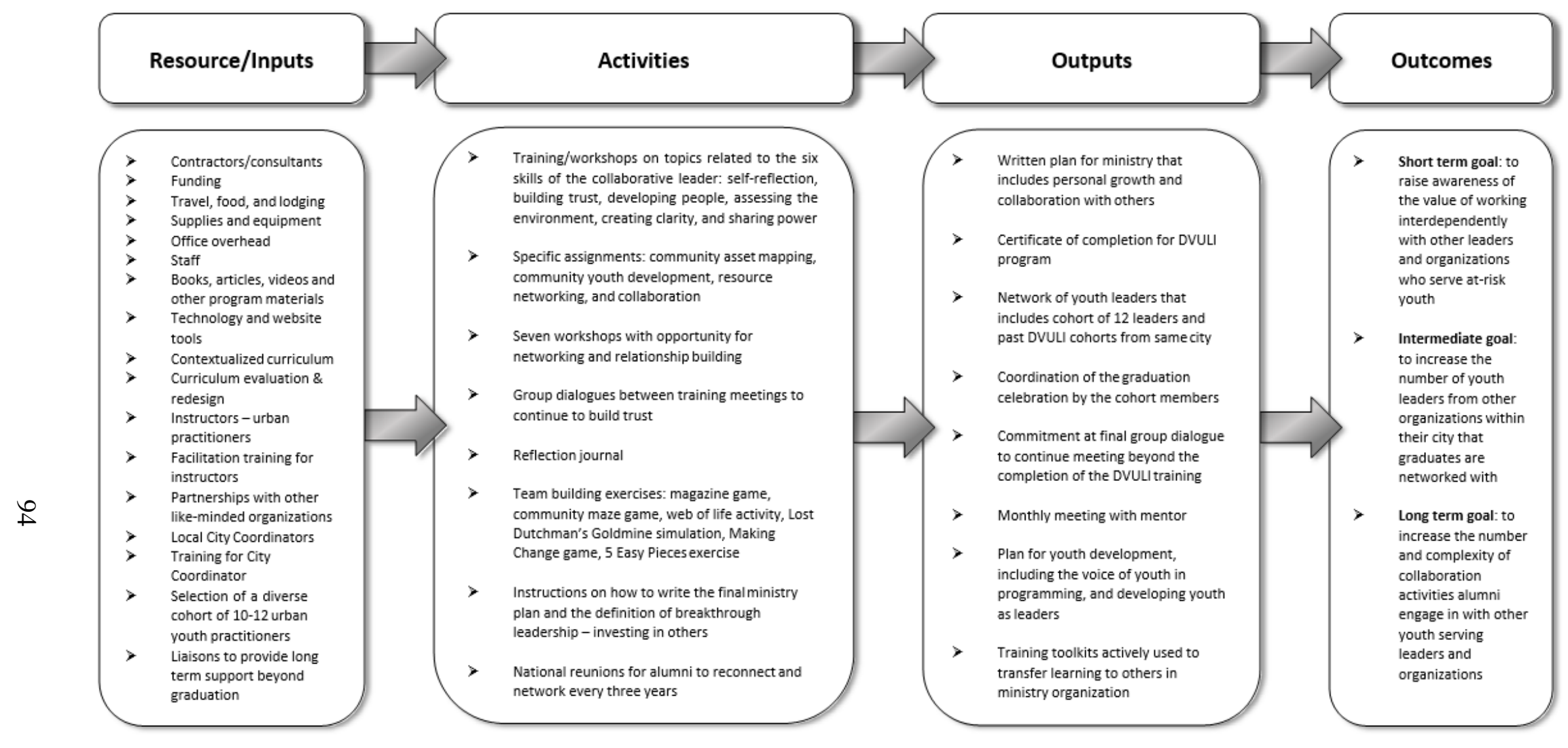

Figure 2. DVULI Logic Model Goal 4. "The DeVos Urban Leadership Initiative will equip participants to work with others who share a passion for youth." 
et al., 1997). To address the challenge, DVULI helps leaders build relationships and encourages them to work with others who share their passion and vision. Working collaboratively also addresses the overarching mission of DVULI to help leaders expand their capacity for serving youth. The DVULI does this by incorporating six collaborative leadership skills into the training program with the intended outcome of collaboration activity. The six skills and their definitions include the following.

Self-Reflection: Collaborative leaders understand their personal values, attitudes, and behaviors as they relate to their own leadership and how their leadership impacts others. They can describe their strengths and weaknesses realistically and recognize how their emotions impact relationships and group dynamics.

Building Trust: Collaborative leaders are able to create safe places for building shared purpose and action. They understand the communication processes that allow people to safely say what is on their mind. They are inclusive of all stakeholders and endeavor to find common ground among them. They are transparent about their own motives and assumptions.

Developing People: Collaborative leaders are committed to developing other leaders through mentoring and coaching focusing on the interest of others at times even over self-interest.

Assessing the Environment: Collaborative leaders recognize the importance of assessing and understanding the context for change before acting on any intervention to solve problems. They encourage people to act on information rather than assumptions.

Creating Clarity-Visioning and Mobilizing: this leadership skill involves defining shared values and engaging people in positive action. It includes being able to facilitate 
process, create a framework and plan for action, and the ability to communicate the vision.

Sharing Power and Influence: Collaborative leaders recognize and use their personal power responsibly, share power with others, and encourage others to act together for change. They use influence to others and allow others to influence their own actions.

This study investigated whether the collaborative leadership skills selected are predictors of collaboration activity reported by graduates of the program who have had at least one year to undertake collaboration activity in their routine leadership practices.

\section{Design of the Study}

A correlation research design was chosen for this study because the research questions involved understanding the relationship of the dependent variable collaboration activity - to the independent variables: the six skills of collaborative leaders (Creswell, 2014). Successful collaboration involves using complex skills as a leader (Chrislip \& Larson, 1994; Huxham \& Vangen, 2005). Practicing collaborative leadership skills is not a one-time event; it is a process developed over time. Successful collaboration can only be measured after a period of time has passed, allowing the leader to put those skills into practice (Chrislip \& Larson, 1994; Getha-Taylor \& Morse, 2013; O'Leary et al., 2012). Correlation research can identify if the collaborative leadership skills being taught by DVULI are a predictor of routine collaboration activity for the youth leader who has completed the DVULI training.

An online survey was created with three parts. Part 1 was the Collaborative Leadership Self-Assessment (CLSA) created by a leadership development program called 
Turning Point. Turning Point was designed around the same time as DVULI and drew from some of the same research. The CLSA evaluated the six collaborative leadership skills: Self-Reflection, Building Trust, Developing People, Assessing the Environment, Creating Clarity-Visioning and Mobilizing, Sharing Power and Influence. These skills served as the independent variables in the study. The collaborative skills section of the survey contained a subset of 10 or 11 questions for each of the skills for a total of 64 questions. The participants were asked to evaluate themselves on a seven-point scale that included (1) Never, (2) Rarely, (3) Sometimes, (4) About Half the Time, (5) Often, (6) Most of the Time, and (7) Always.

The dependent variable, collaboration activity, was more difficult to measure. There were no existing measurement scales for collaboration activities performed by Christian urban youth leaders. Using a focus group of graduates from DVULI and a local affiliate program, an original measurement scale called the Youth Ministry Collaboration Activity Scale (YMCAS) was developed for this study. The activity scale contained ten questions that ranged from very simple forms of collaboration, such as meeting with other youth workers, to more complex ways of working together, such as coordinating events together. If a participant responded yes, to an activity, then a follow up question appeared asking them how many times they had performed that activity in the prior twelve months. The YMCAS is Part 2 of the survey.

The final section of the survey included demographic questions to provide general background information which were thought may also influence collaboration. The questions included gender, age, level of education, ethnicity, and denominational background. 
A sample population was purposefully chosen to include only alumni who participated in the training from 2006 to 2015. The ten-year span was chosen because it was thought that those alumni would likely still be serving in youth ministries. The year 2015 was chosen as the latest entry year to allow for at least one year after graduation before taking the survey. Institutional permission was granted to send the survey to all alumni of the DVULI program. A total of 541 alumni were sent the survey and 269 $(50 \%)$ responded. After eliminating a number of surveys that had missing answers, the final number of surveys included in the study is $215(38 \%)$.

\section{Findings and Discussion}

Chapter 4 described the findings of this study. This section explores the meaning of the findings and relationship to the literature.

\section{Collaborative Leadership Self-Assessment}

The CLSA developed by the Turning Point Leadership program provided data on how the DVULI alumni assessed themselves on the six collaborative skills. Participants were asked to answer 10 or 11 questions on each skill area. Their responses were averaged for each subset providing a mean score for each study participant. According to Turning Point, a score of 6.1 to 7 is an excellent score; 4.1 to 6 is a strong score; 2.1 to 4 is an opportunity for growth; and 1 to 2 indicates it is important to change behavior (Turning Point, 2006b).

Given the standards provided by Turning Point, DVULI alumni ranked themselves with strong scores in each of the six collaborative leadership skills. The reported means were Self-Reflection 5.40; Building Trust 5.56; Developing People 5.48; 
Assessing the Environment 4.81; Creating Clarity-Visioning and Mobilizing 4.83; and Sharing Power and Influence 5.77.

In some ways, this is not surprising. Since the DVULI training emphasizes these skills, alumni would recognize that these skills are desirable and would be likely to assess themselves generously, perhaps even based on their intent rather than on their actions. This is a common outcome of self-assessment surveys. Each subset allowed for openended comments at the end of the section and many participants left comments that the survey itself was a helpful reminder of the important skills needed for collaboration. According to Creswell, this is why scoring strongly on a self-assessment doesn't tell the whole story. Evaluation needs to measure more than the perception of the alumni (Creswell, 2014).

\section{Collaboration Activity Scale}

The first area of interest was related to the YMCAS which identified the ways and frequency at which alumni participated in specific collaboration activities related to youth ministry. Participants surveyed were asked to answer yes or no as to whether or not they had performed ten different activities.

\section{Collaboration Activities}

1. Communicated with youth leaders outside of my organization for personal connections, encouragement, or support.

2. Communicated with youth leaders outside of my organization to discuss a specific concern, issue, or event.

3. Posted an event on a calendar that people outside my organization can access.

4. Participated in a youth leader network in my city. 
5. Shared information about training or funding opportunities with youth leaders outside of my organization.

6. Worked with youth leaders outside of my organization to implement events or trainings.

7. Directed youth to other programs in my community.

8. Received approval from my organization to work with other youth-serving organizations.

9. Worked with another organization to establish a new entity that achieves a common goal.

10. Received full commitment and resources from my organization to work with other youth-serving organizations.

\section{Frequency Reports}

If a participant responded that they had performed a collaboration activity, they were asked how many times they performed that activity in the prior year. A high percentage of alumni, 93\%, reported they had participated in some collaboration activity in the previous twelve months. The two activities with the highest average number of times performed were "Communicated with youth leaders outside of my organization for personal connections, encouragement, or support" $(M=15.69, S D=33.25)$ and "Communicated with youth leaders outside of my organization to discuss a specific concern, issue, or event" $(M=10.02, S D=19.62)$. The high standard deviations reflect a wide variation in answers. This result reflects collaboration literature which says sharing information is one of the easiest ways to begin building trusting relationships toward working together (Mattessich et al., 2001; Winer \& Ray, 1994). 
One of the lowest reported activities was "Participated in a youth leader network in my city" ( $M=2.86, S D=4.59)$. Over the past 20 years, the DVULI has encouraged alumni to join or start their own networks for leaders working with youth in each city. They have provided small grants for learning communities as a catalyst for forming networks. The low level of reported leaders participating in a youth leader network indicated that this might be an area of continued opportunity for growth and investment by DVULI. However, some research has found that there is as much power in informal networks. Leaders who catalyze conversations around community change often use informal networks rather than established institutions to mobilize action (London, 2011).

The lowest mean score for collaboration activity was "Worked with another organization to establish a new entity that achieves a common goal" $(M=2.13, S D=$ 4.58). This result was not surprising. Establishing a new entity with a separate mission would be one of the most challenging and complicated ways of collaborating with others (Mattessich et al., 2001; Winer \& Ray, 1994). It was encouraging to see that some people did report collaboration activity at that most complex level within the prior year.

Questions 6, 8, and 9 on the YMCAS were all related to receiving permission and support from the ministry organization to work collaboratively with others. These questions had a low average of between $M=3.43$ and $M=3.6$ which may imply that alumni experience barriers to collaboration from within their organizational culture and/or from leadership of their church or non-profit. These barriers may include a lack of permission to work with other agencies, lack of leadership role models who value collaboration, or lack of positive experiences of collaboration. 
What follows is an explanation of how the analysis of data generated by the survey instrument was used to provide answers to the two research questions proposed for this study.

\section{Research Question One}

The first research question explored the relationship between the collaborative leadership skills and reported collaboration activity. Question one asked: Is there a significant relationship between the collaborative leadership skills assessed in the Collaborative Leadership Self-Assessment (CLSA) and the collaboration activities reported by DVULI graduates on the Youth Ministry Collaboration Activity Scale (YMCAS)?

In order to quantitatively analyze whether the collaboration skills were influencing collaboration activity, a correlation analysis was performed using the collaboration skills as the independent variables and the measure of collaboration activity as the dependent variable. A Pearson correlation analysis was performed using the mean of the six skill subsets. Correlations can vary from -1.0 (a perfect negative correlation) to 1.0 (a perfect positive correlation) with 0.0 meaning that there is no correlation (Creswell, 2012). Creating Clarity-Visioning and Mobilizing stood out from the others as having the strongest positive relationship with collaboration activity $(r=.34, p<.00)$.

As hypothesized, all six of the skills had a positive correlation to the outcome of collaboration activity. There was some variation in the strength of the relationships that are useful to consider. Self-Reflection had the weakest correlation $(r=.19, p=.01)$. Building Trust $(r=.21, \mathrm{p}=.01)$, Developing People $(r=.23, p=.01)$, Assessing the Environment $(r=.26, p=.01)$ and Sharing Power and Influence $(r=.29, p<.01)$ had 
similar and slightly higher correlations. Creating Clarity-Visioning and Mobilizing ( $r=$ $.34, p<.01)$ had the highest correlation.

Self-Reflection on the CLSA is defined as, collaborative leaders understand their own values, attitudes, and behaviors as they relate to their own leadership and how their leadership impacts others. They can describe their strengths and weaknesses realistically and recognize how their emotions impact relationships and group dynamics.

Self-Reflection is an area that the DVULI training spends a large proportion of time on. The first workshop focuses on the participant as a leader, uncovering their personality profile, skills, leadership style, writing a personal mission statement, understanding how feedback is best given and received, introducing the concept of journaling and the practices of a reflective practitioner. The second training event focuses on core values of accountability and work-life balance and includes live case studies of leaders who failed because they were not practicing these values. These two training events on the individual as a leader encompass six of the total 18 full days of training.

According to Chrislip (2002), a framework for collaboration begins when leaders convene to solve problems and motivate others to participate. One possible explanation for the low correlation of the skill of Self-Reflection to collaboration activity is that SelfReflection as an overall characteristic of a good leader takes place before collaboration begins but may not necessarily lead to collaboration.

Henri Nouwen (1995) provides a ministry parallel for this in an article he wrote on the biblical passage of Luke 6. In that passage, Jesus spent the night in prayer. When day came, he appointed the apostles; and after spending time with them in community, he 
headed out with them to teach and to heal those who were sick or disabled. Jesus went from solitude (reflection) to community to ministry. In Nouwen's words:

So often in ministry I have wanted to do it by myself. If it didn't work, I went to others and said, 'Please!' searching for a community to help me. If that didn't work, maybe I'd start praying. But the order that Jesus teaches is the reverse. It begins with being with God in solitude; then it creates a fellowship, a community with whom the mission is being lived; and finally this community goes out together to heal and to proclaim good news. (Nouwen, 1995, p. 1)

It is in community that Christians have the opportunity to engage with other believers, recognizing each other's gifts and seeing each other's humanity. It is in times alone when a wise leader reflects on what they have learned about their strengths and weaknesses and searches to discern God's will for their life. As Nouwen points out, selfreflection takes place in solitude with God before spending time in community or when retreating from time spent with others. It is possible that while DVULI alumni value SelfReflection it had the lowest correlation with collaboration activity because it does not in itself lead to working together in community.

Creating Clarity-Visioning and Mobilizing along with Sharing Power and Influence were the strongest predictors of collaboration activity. Also, Creating ClarityVisioning and Mobilizing was the only skill that proved to be a significant predictor toward collaboration activity in the regression model.

This skill resulted in the highest predictor of collaboration activity because it requires the leader to bring clarity to the vision and to have the ability to lead people to action around the vision. Reviewing the questions on the survey related to this skill, it becomes evident that most of the questions were about the ability to mobilize people.

- I create a framework for action using systems thinking.

- I facilitate stakeholder teaming to develop strategic action plans. 
- I build an action plan with time lines and assigned responsibilities that enable the community vision to be achieved.

- I facilitate achieving buy-in to the action plans and next steps.

- I follow up on action plans to ensure completion.

The questions related to this skill-set ask, can the leader both facilitate a shared vision - and then go on to create and implement an action plan, garner buy-in among stakeholders, and follow through to completion? The collaborative leader is able to set aside ego, promote the strengths of others, and keep coming back to the table in spite of failure and challenges; all characteristics identified in the questions for the skill sub-set of Creating Clarity-Visioning and Mobilizing (Chrislip \& Larson, 1994; Gray, 1989; Kouzes \& Posner, 2007).

\section{Research Question Two}

The second research question explored the potential influence of several demographic variables that were thought to possibly have an impact on collaboration. This question asked, Is there a significant difference between the collaboration activity reported on the YMCAS based on gender, age, ethnicity, denominational background, and level of education? One-way analysis of variance was performed on each demographic variable with the collaboration activity count as the dependent variable. A factorial ANOVA was also performed with all of the demographic categories as independent variables to check for interactions between and within groups.

\section{Gender}

To test whether there is any difference in collaboration activity between men and women, one-way analysis of variance was performed. The average collaboration activity 
count for men was $6.81(S D=2.91)$ and the average collaboration activity count for women was $5.79(S D=2.96)$. The ANOVA showed that there was a significant effect of gender on collaboration activity $\left[F_{(2,201)}=3.66, p=.03\right]$ indicating that men reported significantly more collaboration activity than women.

In most sectors of public life, women are now more visible in leadership roles. There have been many studies about the differences between men and women in leadership style. Most suggest women are more likely to have a collaborative leadership style. In general, women in leadership are naturally relational, they are less competitive and less self-promoting, and they are better at developing others (Duff, 2013; Gipson, Pfaff, Mendelsohn, Catenacci, \& Burke, 2017; Misner \& Morgan, 2000).

Historically, the church has been very slow to accept women in leadership. Recruiting women leaders has even been a challenge for DVULI cohorts; there are often only two or three women in a cohort of 12. In an article about gender, power, and leadership in the church, Everist points out that systems that oppress often do so by refusing to share power or by using power to exclude. This can be done in both intentional and unintentional ways by ignoring, trivializing, or even ridiculing the ideas of those who are without power (Everist, 2002). The implications of acknowledging and using power in a positive way are critical to successful collaboration (Mattessich et al. 2001; Turning Point 2006c).

A simple explanation for why men collaborated more often than women in this study may be that there are still by far more men in leadership in the Christian community making it is easier for men to find opportunities to collaborate. However, it is also possible that women in leadership in a church or ministry setting are not taken 
seriously as collaborators. As a result, they may not be invited to the table or, they may lack the self-confidence to seek partnerships with others.

Each subset of the CLSA survey concluded with two open-ended questions asking what participants felt they did well in that skill-set and what they could improve upon. It was interesting to note in reviewing the comments in the subset of Sharing Power and Influence that some women commented that they did not feel heard, needed selfconfidence in this area, did not speak up as often as they should, and did not step forward to lead as often as they should when it comes to collaboration. It is even more interesting to note that not one male respondent left similar comments.

In order for healthy collaboration to take place, the formerly powerful and the newly powerful need to listen to each other and each must declare the power that they bring to the table (Winer \& Ray, 1994). Leaders convening to collaborate need to seek out women in leadership and encourage them to share their unique perspective. As Everist (2002) explains, women who have entered previously all-male institutions need to speak up or they will be guilty of allowing their own leadership to be de-valued.

\section{Age}

Survey participants were asked to give their age at the time of taking the survey. In order to compare alumni at different ages, their responses were divided into four groups roughly based on decades. Using the one-way analysis of variance, it was found that there was no significant effect of age on collaboration activity at the $p<.05$ level, $\left[F_{(201,3)}=.43, p=.73\right]$. Analysis was also run in five year groupings with the same result, no significant effect of age on collaboration activity. 


\section{Education Level}

In order to compare alumni with different levels of education, their responses were divided into three groups: no college degree, college degree, and graduate degree. Using the one-way analysis of variance, results indicated that on average those with no college degree report collaboration activity more often $(M=7.40, S D=-2.92)$ than those with a college degree $(M=6.43, S D=2.92)$ or a graduate degree $(M=5.98, S D=2.94)$. Performing a post hoc comparison revealed there is a significant difference between those with no college degree and those with a graduate degree $[F(2,202)=3.25, p=.04]$.

This result is counter-intuitive to the literature researched for this study which implied that the more a practitioner knows about the benefits of collaboration, the more likely they would value and pursue collaboration (Getha-Taylor \& Morse, 2013; O'Leary et al., 2012; Pillsbury et al., 2009). Why would those with no college degree report more collaboration activity than those with a graduate degree? Perhaps those who have no college degree seek others for support or to accomplish a goal together because they feel less confident in their own leadership. Perhaps those with a graduate degree feel that they do not need to collaborate with others as often because they see themselves as experts. Perhaps those with a graduate degree feel embarrassed to ask for help because others see them as experts. There could be a danger that those who are more highly educated will be less likely to seek collaboration with others.

The literature on collaborative leadership is in agreement that collaborative skills can be learned (Huxham \& Vangen, 2005; Turning Point, 2006a; Getha-Taylor \& Morse, 2013). Assumptions that the DVULI and other collaborative leadership development programs make include the key points that diverse leaders who come together to create a 
learning community of peers will build relationships of trust with each other and that collaborative leadership skills will be nurtured in that environment. The finding that leaders with a higher level of education are collaborating less often may imply that they do not consider others to be peers and partners in ministry.

\section{Ethnicity}

Survey participants were asked to indicate racial or ethnic heritage. Using oneway analysis of variance that grouped ethnicities by Black, Hispanic, White, and Other, it was found that there was no significant effect of ethnicity on collaboration activity at the $p<.05$ level, $\left[F_{(3,202)}=.14, p=.94\right]$.

The information on ethnicity gathered for this study was of interest to the DVULI program. For recruiting purposes, they stated that preference should be made for candidates that represent the ethnic demographics of the city where the training is taking place (DeVos Urban Leadership Initiative, 2017d). However, it should be noted that gathering accurate data regarding race or ethnicity is a challenge in a multi-cultural society. The U.S. government has undertaken a study to research how it asks about race and ethnicity in reaction to a growing percentage of people who find it difficult to "find themselves" in categories offered by the U.S. census bureau making it difficult to draw conclusions about this result (Krogstad \& Cohn, 2014).

\section{Denomination}

A case can be made, based on doctrine and historical patterns that some denominational traditions are more likely to be open to collaborating than others. Also, it seems likely that churches in the same denomination would look for opportunities to collaborate with their sister churches. This study asked participants an open-ended 
question, "What is your denomination or faith tradition?" Some chose not to respond (13\%), another $41.1 \%$ said they were non-denominational. The remaining $45.9 \%$ gave a variety of responses. Those responses were grouped into seven categories based on an analysis of 400 families of religious groups found on the website of ARDA (Association of Religion Data Archives, 2017). The next largest reported denominational groups were Baptists with $15.4 \%$ and Pentecostals at $11.7 \%$.

It was difficult to make a decision on how to run and interpret the analysis on denominational data gathered. Recent work in sociology has challenged traditional religious categorization. According to Steensland et al, the most widely used classification system for religious data in the U.S. overlooks significant new trends in religious affiliation, specifically, it does not provide for a way to classify those who selfidentify as non-denominational. Instead, Steensland et al. propose a measure based on affiliation rather than ideology that would make a case for grouping denominations into two dominant religious traditions: mainline Protestantism and evangelical Protestantism (Steensland et al., 2000).

Another challenge with the denominational data was that the selection process for the DVULI training is designed to recruit participants who are likely to partner with others, so leaders who are not interested in working collaboratively would not be likely to apply. Senior leaders (pastors) who do not support collaboration would be less likely to nominate or give permission to their youth leader to participate in a program that encourages collaboration between organizations.

In light of this, one-way analysis of variance was performed by grouping the denominational data into two groups, those who reported themselves as non- 
denominational and those who affiliated with a denomination. There was no significant effect on collaboration activity at the $p<.05$ level, $\left[F_{(1,181)}=1.77, p=.19\right]$. Analysis was also run by grouping the reported denominations into three groups based generally on religious tradition: non-denominational; Pentecostal-Holiness-Methodist; BaptistReformed. Results also showed no effect on reported collaboration activity.

An area for further research would be understanding how gender, ethnic culture and denominational affiliation impact identifying and recruiting leaders for the DVULI training. Some demographic groups which exist (based on census data) including women, certain denominations, and ethnic leaders, have low representation in the DVULI cohorts. DVULI recently contracted with an outside organization to conduct focus groups with first and second generation Hispanic immigrant churches to learn if it is possible for the DVULI recruitment process to be more inclusive of leaders from these churches. It should be kept in mind that part of the Theory of Change for the DVULI is building bridges between diverse groups of Christian believers and not everyone in Christian ministry leadership will be interested in that goal.

\section{Conclusions}

This study began with a desire to evaluate the current program processes and content of a leadership development program as it relates to the specific goal of developing collaborative leadership skills that lead to collaboration activity. Six leadership skills are identified in the DVULI program Logic Model that are thought to contribute to the development of a more collaborative leader: Self-Reflection; Building Trust; Developing People; Assessing the Environment; Creating Clarity-Visioning and 
Mobilizing; and Sharing Power and Influence. Based on findings, data analysis and review of the literature, there are several conclusions that can be drawn.

Conclusion 1. Despite reporting that they do not participate in formal networks with other youth leaders, DVULI alumni are reaching out to connect and work together with others. Ninety three percent (93\%) of DVULI alumni reported some collaboration activity within the past twelve months.

Conclusion 2. All six skills are contributing to alumni growth as collaborative leaders. The strength of the relationship between each skill and collaboration activity varied with the lowest predictor being Self-Reflection and the highest predictor being Creating Clarity-Visioning and Mobilizing, and all six collaborative leadership skills together were a significant predictor of collaboration activity.

Conclusion 3. Although women are generally thought to embrace a more collaborative leadership style, based on the data revealed in this study, the women serving urban at-risk youth through Christian ministry organizations were not as likely as men to be engaged in collaboration activity. Understanding this result may be important to supporting women in leadership during and after participation in the training.

Conclusion 4. Education matters, but in the reverse of what one might expect. According to this study, those with no college degree participated in more collaboration activity than those with a graduate degree.

\section{Recommendations for DVULI}

The following recommendations are offered to DVULI based on the findings of this study related to the six collaborative leadership skills included in the curriculum. 
Recommendation 1. There is evidence that the six collaborative leadership skills are working together to strengthen the collaborative leadership skills of the training participants. There is no need to eliminate any of the skills. All of the skills showed a positive, significant correlation to collaboration activity.

Recommendation 2. The program should consider ways that can provide practical tools for setting goals and developing action plans, helping participants to understand what it takes to implement a plan and mobilize people around a shared vision. From one participant's survey, "I struggle with the time demands of doing for my community as opposed to the ministry teams I lead." From another, "My most important area for improvement is executing the details needed to move the project forward." These quotes represent the frustration of many of the survey participants and an acknowledgment that the desire to collaborate alone is not enough. The ability to develop action steps and mobilize people around them is vital to collaboration.

In addition, several recommendations related to other program features of DVULI should be considered:

Recommendation 3. Make collaboration a more visible expectation of the program. While it appears on the application and is incorporated into the interview process, it is not as visible in program marketing materials, the mentoring materials, and is only touched on in the orientation that is provided for the pastor/supervisor at the beginning of the training. The final plans that the participants write at the end of the program should require a section that addresses opportunities for networking or working together in some way, however small, with others in their city who share a passion for youth. 
Recommendation 4. Burke et al. (1997) and O’Donnell (2017) explained that a decision was made early on in the development stage of DVULI not to require collaboration as part of the training. However, almost 20 years of experience have shown how challenging it is to develop a collaborative mindset given the barriers to be overcome. DVULI might benefit from providing opportunities to practice collaboration among the cohorts as part of the training. For instance, collaborative learning activities could serve as models for collaboration throughout the program. Or perhaps participation in progressively more collaborative events or projects during the program with debriefing of the experiences could provide practical experience in collaboration. This would allow participants to work on overcoming the barriers to collaboration while still in the program.

Recommendation 5. Consider post-training evaluation of collaboration done by the city liaison. Have each alumnus complete the YMCAS every two years for as long as the alumnus stays involved in youth ministry to get a better understanding of the types of collaboration in which alumni are involved.

It is excellent that the program includes ongoing support for leadership and ministry development through the City Liaison after graduation. Day (2001) discusses the high leverage value of coaching and mentoring as a tool for developing leadership skills, DVULI could position the city liaison as a collaboration coach for groups of alumni who have natural connections through their ministry work with youth and want to develop successful partnerships with others. The YMCAS could be part of a results based measurement for the city liaison that could indicate where an alumnus has need of continued support. Liaisons might also encourage peer to peer accountability and support, 
affirming the value of working together with others who share the same passion for youth.

\section{Recommendation for Further Research}

This study provided much needed quantitative information about the collaboration activity of alumni of DVULI and developed the first ever measurement of collaboration among youth ministry leaders working in urban communities of poverty. What it did not provide was answers about alumni who are not seeking to collaborate. Questions 6, 8 and 9 on the YMCAS had low frequency rates, indicating that collaboration may not be supported at the organizational level. Information about the types of collaboration that people are participating in would be helpful. For those who indicated that they had been a part of a more complex collaboration project, what motivated them to do so and what was the larger outcome? A qualitative or mixed-method study would provide more in-depth information that could be useful to DVULI and to other leadership development programs that have collaboration as an end goal.

More extensive research needs to be conducted on the influence of gender on collaboration as it relates to women in leadership roles in the church. Do men intentionally or unintentionally exclude women as collaborative partners? Do women seek out collaboration as a problem-solving tool and as a way to share vision with others? Again, qualitative interviews can explore the why behind the results found in this study.

Results that those with advanced degrees collaborated significantly less than those with no college degree also provide an opportunity for qualitative study. This results seemed to contrast the literature on learning collaborative leadership skills which said that these skills can be learned and developed with practice. 
In the area of denominational background as an influence on collaboration, Steensland et al. (2002) recommended that surveys ask for the specific name of the church that the respondent attends. While requiring more time to categorize responses on the part of the researcher, that question would provide valuable information that can be used to clarify ambiguous responses to denominational affiliation such as Christian, or I follow Jesus.

Steensland et al. asserted that, "Social commentators now widely acknowledge that Americans are more religious than citizens in most other industrialized nations, and research has demonstrated that religious worldviews shape social and political attitudes in ways that cannot be reduced to social class, educational attainment, or other more traditional sociological factors" (Steensland et al., 2000, p. 292). They propose a useful scheme for approaching religious classification. The results of this study did not provide trustworthy data for analysis of denominational worldviews because many of the responses implied that the participant did not understand the information the study was seeking. For example, non-denominational churches, which was one of the most frequent responses, still have historic ties to a particular faith tradition that could be determined by the doctrinal statement of faith.

\section{Final Thoughts}

Studies on the long-term outcomes of leadership development programs are rare. This study was able to draw on the long-term relationship of a training program with its graduates to measure the amount of collaboration activity they engage in after the passing of time. The creation of a measurement for collaboration activity provided an opportunity 
to study the influence of various collaborative leadership skills as predictors of collaboration activity.

Investing time, money, and relationships in building the capacity of urban youth leaders to collaborate has been a worthwhile investment for DVULI. Collaborative leaders are able to share knowledge and resources, build supportive relationships, and create a shared vision for young people and their communities. Ultimately, working together for the common good demonstrates the love of Jesus to a divided world and provides a catalyst for change. Leaders in DVULI are learning the skills necessary to navigate the complexity of working together to make a positive difference for youth in their communities. 
APPENDIX A

SURVEY INSTRUMENT 


\section{Kooreman Dissertation Survey}

\section{Consent to Participate in Online Survey Research}

A study of the collaborative skills of graduates of the DeVos Urban Leadership Initiative Person Responsible for Research: Eileen Kooreman. The purpose of this research study is to explore to what extent graduates of the DeVos Urban Leadership Initiative use collaborative leadership skills. The study will be conducted with a self-assessment survey called the Collaborative Leadership Self-Assessment questionnaire (CLSA) used with permission from the Robert Wood Johnson Foundation. In addition to the CLSA, participants will be asked to respond to questions that measure their current collaboration practices. Approximately 540 subjects will be invited to participate in this study. If you agree to participate, you will be asked to complete an online survey that will take approximately 25 minutes to complete. The questions will ask about behaviors in six areas that have been identified as important to leaders who practice collaboration. Collection of data and survey responses using the internet involves the same risks that a person would encounter in everyday use of the internet, such as breach of confidentiality. While the researcher has taken every reasonable step to protect your confidentiality, there is always the possibility of interception or hacking of the data by third parties that is not under the control of the researcher. Should you choose to participate, your survey will be identified with a code that matches the benchmark survey ID you completed at the start of the DeVos Urban Leadership training program. Identifying information will be collected for research purposes only. Data will be retained on the Qualtrics website server. Any data transferred from the survey site will be saved in an encrypted format for a maximum of 7 years. Only Eileen Kooreman and staff at the Calvin Center for Social Research will have access to the data collected by this study. All study results will be reported without identifying information so that no one viewing the results will ever be able to match you with your responses. Your participation in this study is voluntary. You may choose to not answer any of the questions or withdraw from this study at any time without penalty. For more information about the study or study procedures, contact: Erich Baumgartner, PhD; 269-471-2523; baumgart@andrews.edu: Dissertation Chair, Eileen Kooreman; 616-540-3020 eileenk@dvuli.org, researcher By entering this survey, you are indicating that you have read the consent form, you are age 18 or older, and that you voluntarily agree to participate in this research study. Thank you!

Please indicate your consent decision:

I voluntarily agree to take this survey. (1)

I do not wish to take this survey. (2)

If I do not wish to take this ... is selected, then skip to end of survey 


\section{SELF REFLECTION}

\begin{tabular}{|c|c|c|c|c|c|c|c|}
\hline $\begin{array}{l}\text { Please indicate how often } \\
\text { you exhibit each of the } \\
\text { behaviors listed below. }\end{array}$ & $\begin{array}{l}\text { Never } \\
\text { (1) }\end{array}$ & $\begin{array}{l}\text { Rarely } \\
\text { (2) }\end{array}$ & $\begin{array}{l}\text { Some- } \\
\text { times } \\
(3)\end{array}$ & $\begin{array}{l}\text { About } \\
\text { half of } \\
\text { the } \\
\text { time (4) }\end{array}$ & $\begin{array}{l}\text { Often } \\
(5)\end{array}$ & $\begin{array}{l}\text { Most of } \\
\text { the } \\
\text { time (6) }\end{array}$ & $\begin{array}{l}\text { Always } \\
\text { (7) }\end{array}$ \\
\hline $\begin{array}{l}\text { I recognize the effect of } \\
\text { my emotions on work } \\
\text { performance. (1) }\end{array}$ & $O$ & 0 & 0 & 0 & O & 0 & 0 \\
\hline $\begin{array}{l}\text { I recognize the effect of } \\
\text { my emotions on } \\
\text { relationships. (2) }\end{array}$ & 0 & 0 & 0 & 0 & O & 0 & 0 \\
\hline $\begin{array}{l}\text { I recognize my personal } \\
\text { impact on group } \\
\text { dynamics. (3) }\end{array}$ & 0 & 0 & 0 & 0 & O & 0 & 0 \\
\hline $\begin{array}{l}\text { I can describe my } \\
\text { strengths realistically. (4) }\end{array}$ & 0 & 0 & 0 & 0 & O & 0 & 0 \\
\hline $\begin{array}{l}\text { I can describe my } \\
\text { weaknesses realistically. } \\
\text { (5) }\end{array}$ & 0 & 0 & 0 & 0 & O & O & 0 \\
\hline $\begin{array}{l}\text { I work to understand } \\
\text { others' perspectives. (6) }\end{array}$ & 0 & 0 & 0 & 0 & $O$ & 0 & $\mathrm{O}$ \\
\hline $\begin{array}{l}\text { I read the dynamics of } \\
\text { groups. (7) }\end{array}$ & 0 & 0 & 0 & 0 & O & 0 & 0 \\
\hline $\begin{array}{l}\text { I listen to others actively, } \\
\text { checking to ensure my } \\
\text { understanding. ( } 8 \text { ) }\end{array}$ & 0 & 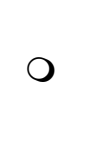 & 0 & 0 & $O$ & 0 & 0 \\
\hline $\begin{array}{l}\text { I read non-verbal } \\
\text { communication } \\
\text { accurately. (9) }\end{array}$ & 0 & $O$ & 0 & 0 & O & 0 & $\mathrm{O}$ \\
\hline $\begin{array}{l}\text { I use self-assessment } \\
\text { tools such as personality } \\
\text { inventories to inform my } \\
\text { self reflections. (10) }\end{array}$ & 0 & 0 & 0 & 0 & O & 0 & 0 \\
\hline $\begin{array}{l}\text { I seek feedback from all } \\
\text { relevant constituencies } \\
\text { about my behavioral } \\
\text { impact. (11) }\end{array}$ & 0 & 0 & $O$ & 0 & O & 0 & 0 \\
\hline
\end{tabular}

What do you think are your strengths in self-reflection as a collaborative leader?

What do you think are your most important areas for improvement in self-reflection 
BUILDING TRUST

\begin{tabular}{|c|c|c|c|c|c|c|c|}
\hline $\begin{array}{l}\text { Please indicate how often you } \\
\text { exhibit each of the behaviors listed } \\
\text { below. }\end{array}$ & $\begin{array}{l}\text { Never } \\
\text { (1) }\end{array}$ & $\begin{array}{l}\text { Rarely } \\
\text { (2) }\end{array}$ & $\begin{array}{c}\text { Some- } \\
\text { times (3) }\end{array}$ & $\begin{array}{c}\text { About } \\
\text { half of } \\
\text { the time } \\
\text { (4) }\end{array}$ & Often (5) & $\begin{array}{l}\text { Most of } \\
\text { the time } \\
\text { (6) }\end{array}$ & $\begin{array}{l}\text { Always } \\
\text { (7) }\end{array}$ \\
\hline $\begin{array}{l}\text { I build communication processes } \\
\text { that make it safe for people to say } \\
\text { what is on their minds. (1) }\end{array}$ & 0 & 0 & O & 0 & 0 & 0 & 0 \\
\hline $\begin{array}{l}\text { I refuse to engage in "rigged" } \\
\text { processes. (2) }\end{array}$ & 0 & O & O & 0 & 0 & 0 & 0 \\
\hline $\begin{array}{l}\text { I protect the group from those who } \\
\text { would wield personal power over } \\
\text { the collaborative process. (3) }\end{array}$ & 0 & 0 & 0 & 0 & 0 & 0 & 0 \\
\hline $\begin{array}{l}\text { I create credible processes for } \\
\text { collaborating. (4) }\end{array}$ & 0 & O & 0 & 0 & 0 & O & O \\
\hline $\begin{array}{l}\text { I ensure that processes for } \\
\text { exercising collaborative leadership } \\
\text { are open to all stakeholders. (5) }\end{array}$ & 0 & 0 & 0 & 0 & 0 & O & O \\
\hline $\begin{array}{l}\text { I ensure that the processes for } \\
\text { collaborative leadership are } \\
\text { transparent to all stakeholders. (6) }\end{array}$ & 0 & O & 0 & 0 & 0 & O & 0 \\
\hline $\begin{array}{l}\text { During the first stage of creating } \\
\text { collaborative relationships, I } \\
\text { establish the common ground } \\
\text { among the stakeholders. (7) }\end{array}$ & 0 & O & 0 & 0 & 0 & 0 & 0 \\
\hline $\begin{array}{l}\text { I approach collaboration by relying } \\
\text { heavily on building trust among } \\
\text { stakeholders. (8) }\end{array}$ & 0 & 0 & O & 0 & 0 & O & O \\
\hline $\begin{array}{l}\text { I "walk the talk," i.e., I do what I } \\
\text { say I will do. (9) }\end{array}$ & 0 & O & 0 & 0 & 0 & O & O \\
\hline $\begin{array}{l}\text { I demonstrate to my peers that I } \\
\text { believe that trust is the foundation } \\
\text { for successful collaboration. (10) }\end{array}$ & 0 & O & 0 & 0 & 0 & 0 & 0 \\
\hline
\end{tabular}

What do you think are your strengths in building trust as a collaborative leader? What do you think are your most important areas for improvement in building trust? 


\section{DEVELOPING PEOPLE}

\begin{tabular}{|c|c|c|c|c|c|c|c|}
\hline $\begin{array}{l}\text { Please indicate how often you } \\
\text { exhibit each of the behaviors } \\
\text { listed below. }\end{array}$ & $\begin{array}{l}\text { Never } \\
(1)\end{array}$ & $\begin{array}{l}\text { Rarely } \\
\text { (2) }\end{array}$ & $\begin{array}{l}\text { Some- } \\
\text { times } \\
(3)\end{array}$ & $\begin{array}{l}\text { About } \\
\text { half of } \\
\text { the } \\
\text { time } \\
(4)\end{array}$ & $\begin{array}{l}\text { Often } \\
(5)\end{array}$ & $\begin{array}{l}\text { Most } \\
\text { of the } \\
\text { time } \\
(6)\end{array}$ & $\begin{array}{c}\text { Always } \\
\text { (7) }\end{array}$ \\
\hline $\begin{array}{l}\text { I take seriously my responsibility } \\
\text { for coaching and mentoring } \\
\text { others. (1) }\end{array}$ & 0 & 0 & 0 & 0 & 0 & 0 & 0 \\
\hline $\begin{array}{l}\text { I invest adequate amounts of time } \\
\text { doing people development. (2) }\end{array}$ & 0 & 0 & 0 & 0 & 0 & 0 & 0 \\
\hline $\begin{array}{l}\text { I define my role when serving as } \\
\text { coach. (3) }\end{array}$ & 0 & 0 & 0 & 0 & 0 & 0 & 0 \\
\hline $\begin{array}{l}\text { I am committed to developing } \\
\text { people from diverse segments of } \\
\text { the population. (4) }\end{array}$ & 0 & 0 & 0 & 0 & 0 & 0 & 0 \\
\hline $\begin{array}{l}\text { I create opportunities for people } \\
\text { to assess their leadership skills. } \\
\text { (5) }\end{array}$ & 0 & 0 & 0 & 0 & 0 & 0 & 0 \\
\hline $\begin{array}{l}\text { I help people take advantage of } \\
\text { opportunities to learn new skills. } \\
\text { (6) }\end{array}$ & 0 & 0 & 0 & 0 & 0 & 0 & 0 \\
\hline $\begin{array}{l}\text { I look for ways to help others } \\
\text { become more successful at their } \\
\text { jobs. (7) }\end{array}$ & 0 & 0 & 0 & 0 & 0 & 0 & 0 \\
\hline $\begin{array}{l}\text { I help people to take advantage of } \\
\text { opportunities for new } \\
\text { experiences. (8) }\end{array}$ & 0 & 0 & 0 & 0 & 0 & 0 & 0 \\
\hline $\begin{array}{l}\text { I establish my expectations for the } \\
\text { people I mentor. (9) }\end{array}$ & 0 & 0 & 0 & 0 & 0 & 0 & 0 \\
\hline $\begin{array}{l}\text { I ask the people I mentor to define } \\
\text { their expectations. (10) }\end{array}$ & 0 & 0 & 0 & 0 & 0 & 0 & 0 \\
\hline $\begin{array}{l}\text { I create a mutually agreed-upon } \\
\text { coaching plan, including criteria } \\
\text { for success. (11) }\end{array}$ & 0 & 0 & 0 & 0 & 0 & 0 & 0 \\
\hline
\end{tabular}

What do you think are your strengths in developing people as a collaborative leader? What do you think are your most important areas for improvement in developing people? 


\section{ASSESSING THE ENVIRONMENT}

\begin{tabular}{|c|c|c|c|c|c|c|c|}
\hline $\begin{array}{l}\text { Please indicate how often you } \\
\text { exhibit each of the behaviors } \\
\text { listed below. }\end{array}$ & $\begin{array}{l}\text { Never } \\
\text { (1) }\end{array}$ & $\begin{array}{l}\text { Rarely } \\
\text { (2) }\end{array}$ & $\begin{array}{l}\text { Some- } \\
\text { times } \\
\text { (3) }\end{array}$ & $\begin{array}{l}\text { About } \\
\text { half of } \\
\text { the } \\
\text { time } \\
\text { (4) }\end{array}$ & $\begin{array}{l}\text { Often } \\
(5)\end{array}$ & $\begin{array}{l}\text { Most of } \\
\text { the } \\
\text { time (6) }\end{array}$ & $\begin{array}{l}\text { Always } \\
\text { (7) }\end{array}$ \\
\hline $\begin{array}{l}\text { I use assessment tools in order to } \\
\text { systematically learn the needs of } \\
\text { the community. (1) }\end{array}$ & 0 & 0 & 0 & O & 0 & 0 & 0 \\
\hline $\begin{array}{l}\text { I ensure that an assessment tool } \\
\text { is a good fit for the information } \\
\text { that needs to be collected. (2) }\end{array}$ & 0 & 0 & 0 & 0 & 0 & 0 & 0 \\
\hline $\begin{array}{l}\text { I undertake an appropriate } \\
\text { analysis of the data. (3) }\end{array}$ & 0 & 0 & 0 & 0 & 0 & 0 & 0 \\
\hline $\begin{array}{l}\text { I ensure responsible } \\
\text { interpretation of the data. (4) }\end{array}$ & 0 & 0 & 0 & 0 & 0 & 0 & 0 \\
\hline $\begin{array}{l}\text { I gather information before } \\
\text { taking action. (5) }\end{array}$ & 0 & 0 & 0 & 0 & 0 & 0 & 0 \\
\hline $\begin{array}{l}\text { I encourage people to act on } \\
\text { information rather than } \\
\text { assumptions. (6) }\end{array}$ & 0 & 0 & 0 & 0 & 0 & 0 & 0 \\
\hline $\begin{array}{l}\text { I clarify the problem before } \\
\text { planning solutions. (7) }\end{array}$ & 0 & 0 & 0 & 0 & O & O & 0 \\
\hline $\begin{array}{l}\text { I seek culturally different views } \\
\text { of the problem. (8) }\end{array}$ & 0 & 0 & 0 & 0 & 0 & 0 & 0 \\
\hline $\begin{array}{l}\text { I use a systems perspective to } \\
\text { understand the community. (9) }\end{array}$ & 0 & O & 0 & 0 & 0 & O & 0 \\
\hline $\begin{array}{l}\text { I look at the perceived problem } \\
\text { from different angles before } \\
\text { proceeding. (10) }\end{array}$ & 0 & 0 & 0 & O & 0 & 0 & 0 \\
\hline
\end{tabular}

What do you think are your strengths in assessing the environment as a collaborative leader?

What do you think are your most important areas for improvement in assessing the environment? 


\section{CREATING CLARITY-VISIONING AND MOBILIZING}

\begin{tabular}{|c|c|c|c|c|c|c|c|}
\hline $\begin{array}{l}\text { Please indicate how often you } \\
\text { exhibit each of the behaviors listed } \\
\text { below. }\end{array}$ & Never (1) & $\begin{array}{l}\text { Rarely } \\
\text { (2) }\end{array}$ & $\begin{array}{c}\text { Some- } \\
\text { times (3) }\end{array}$ & $\begin{array}{l}\text { About } \\
\text { half of the } \\
\text { time (4) }\end{array}$ & Often (5) & $\begin{array}{c}\text { Most of } \\
\text { the } \\
\text { time (6) }\end{array}$ & $\begin{array}{l}\text { Always } \\
\text { (7) }\end{array}$ \\
\hline $\begin{array}{l}\text { I can describe a personal vision for } \\
\text { my community that offers a future } \\
\text { achievable with the assets available. } \\
\text { (1) }\end{array}$ & 0 & O & 0 & 0 & 0 & 0 & 0 \\
\hline $\begin{array}{l}\text { I facilitate an effective process for } \\
\text { exploring the diverse aspirations } \\
\text { among community stakeholders. (2) }\end{array}$ & 0 & 0 & 0 & 0 & 0 & 0 & 0 \\
\hline $\begin{array}{l}\text { I facilitate the development of a } \\
\text { shared community vision that is } \\
\text { influenced by the views of diverse } \\
\text { stakeholders. (3) }\end{array}$ & 0 & O & 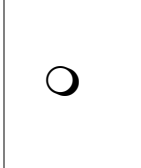 & 0 & 0 & 0 & 0 \\
\hline $\begin{array}{l}\text { I communicate the shared vision } \\
\text { broadly. (4) }\end{array}$ & 0 & 0 & 0 & 0 & 0 & 0 & 0 \\
\hline $\begin{array}{l}\text { I create a framework for action using } \\
\text { systems thinking. (5) }\end{array}$ & 0 & O & 0 & 0 & 0 & 0 & 0 \\
\hline $\begin{array}{l}\text { I facilitate stakeholder teaming to } \\
\text { develop strategic action plans. (6) }\end{array}$ & 0 & 0 & 0 & 0 & 0 & 0 & 0 \\
\hline $\begin{array}{l}\text { I create the conditions for } \\
\text { brainstorming the strategic issues } \\
\text { and actions. (7) }\end{array}$ & 0 & O & 0 & $\mathrm{O}$ & 0 & 0 & 0 \\
\hline $\begin{array}{l}\text { I build an action plan with time lines } \\
\text { and assigned responsibilities to } \\
\text { enable the community vision to be } \\
\text { achieved. (8) }\end{array}$ & 0 & $\mathrm{O}$ & 0 & 0 & 0 & 0 & 0 \\
\hline $\begin{array}{l}\text { I facilitate achieving buy-in to the } \\
\text { action plans and next steps. (9) }\end{array}$ & 0 & 0 & 0 & 0 & 0 & 0 & 0 \\
\hline $\begin{array}{l}\text { I follow up on action plans to ensure } \\
\text { completion. (10) }\end{array}$ & 0 & 0 & 0 & 0 & 0 & 0 & 0 \\
\hline $\begin{array}{l}\text { I seek innovative solutions for } \\
\text { persistent problems encountered } \\
\text { while mobilizing to achieve the } \\
\text { vision. (11) }\end{array}$ & 0 & 0 & 0 & 0 & 0 & 0 & 0 \\
\hline
\end{tabular}

What do you think are your strengths in creating clarity as a collaborative leader?

What do you think are your most important areas for improvement in creating clarity? 


\section{SHARING POWER AND INFLUENCE}

\begin{tabular}{|c|c|c|c|c|c|c|c|}
\hline $\begin{array}{l}\text { Please indicate how often you exhibit } \\
\text { each of the behaviors listed below. }\end{array}$ & $\begin{array}{l}\text { Never } \\
(1)\end{array}$ & $\begin{array}{l}\text { Rarely } \\
\text { (2) }\end{array}$ & $\begin{array}{l}\text { Some- } \\
\text { times (3) }\end{array}$ & $\begin{array}{l}\text { About } \\
\text { half of } \\
\text { the time } \\
\text { (4) }\end{array}$ & $\begin{array}{l}\text { Often } \\
(5)\end{array}$ & $\begin{array}{l}\text { Most of } \\
\text { the } \\
\text { time (6) }\end{array}$ & $\begin{array}{c}\text { Always } \\
\text { (7) }\end{array}$ \\
\hline I use my personal power responsibly. (1) & O & O & $\mathrm{O}$ & $\mathrm{O}$ & $\mathrm{O}$ & O & O \\
\hline $\begin{array}{l}\text { I share power as a means for increasing } \\
\text { power. ( } 2 \text { ) }\end{array}$ & O & O & $\mathrm{O}$ & O & 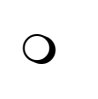 & O & O \\
\hline $\begin{array}{l}\text { I share power with others whenever } \\
\text { possible. (3) }\end{array}$ & $\mathrm{O}$ & $\mathrm{O}$ & $\mathrm{O}$ & $\mathrm{O}$ & $\mathrm{O}$ & O & O \\
\hline $\begin{array}{l}\text { I offer people an active role in decision } \\
\text { making about matters that affect them. } \\
\text { (4) }\end{array}$ & $\mathrm{O}$ & $\mathrm{O}$ & O & $\mathrm{O}$ & $\mathrm{O}$ & O & $\bigcirc$ \\
\hline $\begin{array}{l}\text { When exercising leadership, I rely } \\
\text { significantly on peer problem-solving. } \\
\text { (5) }\end{array}$ & O & $\bigcirc$ & $\mathrm{O}$ & O & O & O & O \\
\hline I promote self-confidence in others. (6) & O & O & O & O & $\mathrm{O}$ & O & O \\
\hline $\begin{array}{l}\text { I create processes that ensure } \\
\text { stakeholders an equal say in decision } \\
\text { making. (7) }\end{array}$ & O & $\mathrm{O}$ & O & O & $\mathrm{O}$ & O & $\mathrm{O}$ \\
\hline $\begin{array}{l}\text { I encourage others to act together to } \\
\text { change circumstances that affect them. } \\
\text { (8) }\end{array}$ & O & $\mathrm{O}$ & $\mathrm{O}$ & 0 & 0 & 0 & 0 \\
\hline $\begin{array}{l}\text { I express confidence in the capabilities } \\
\text { of others. (9) }\end{array}$ & 0 & 0 & 0 & 0 & 0 & 0 & 0 \\
\hline $\begin{array}{l}\text { I use influence to produce results } \\
\text { whenever possible. (10) }\end{array}$ & 0 & 0 & 0 & 0 & 0 & 0 & 0 \\
\hline $\begin{array}{l}\text { I am open to being influenced by others. } \\
\text { (11) }\end{array}$ & 0 & 0 & 0 & 0 & 0 & 0 & 0 \\
\hline
\end{tabular}

What do you think are your strengths in sharing power and influence as a collaborative leader?

What do you think are your most important areas for improvement in sharing power and influence?

Copyright 2006. Robert Wood Johnson Foundation. Used with permission from the Robert Wood Johnson Foundation. 


\section{WORKING WITH OTHER YOUTH-SERVING ORGANIZATIONS}

Which of the following things have you done in the past 12 months? Please check all that apply.

$\square$ Communicated with youth leaders outside of my organization for personal connections, encouragement, or support. (1)

$\square$ Communicated with youth leaders outside of my organization to discuss a specific concern, issue, or event. (2)

$\square$ Posted an event on a calendar that people outside my organization can access. (3)

口 Participated in a youth leader network in my city. (4)

$\square$ Shared information about training or funding opportunities with youth leaders outside of my organization. (5)

$\square$ Worked with youth leaders outside of my organization to implement events or trainings. (6)

$\square$ Directed youth to other programs in my community. (7)

$\square$ Received approval from my organization to work with other youth-serving organizations. (8)

$\square$ Worked with another organization to establish a new entity that achieves a common goal. (9)

$\square$ Received full commitment and resources from my organization to work with other youth-serving organizations. (10)

If response is Yes to activity - How many times in the past 12 months?

\section{Your Comments}

Please use the space below to provide any other comments you may have that are relevant to this survey. 
What is your gender?

O Male (1)

Female (2)

Prefer not to answer (3)

How old are you?

O 20-24 (1)

O 25-29(2)

O $30-34$ (3)

O $35-39$ (4)

O $40-44(5)$

O $45-49$ (6)

O $50-54$ (7)

O $55-59$ (8)

O 60-64 (9)

O 65 or older (10)

Prefer not to answer (11)

What is your level of education?

Less than high school (1)

High school graduate (2)

Some college (3)

O 2 year degree (4)

O 4 year degree (5)

O Professional degree (6)

Doctorate (7)

Prefer not to answer (8)

What is your racial and ethnic heritage? Check all that apply.

O American Indian or Alaska Native (1)

O Asian or Asian American (2)

Black or African American (3)

Hispanic or Latino/Latina (4)

O Native Hawaiian or Pacific Islander (5)

O White or Caucasian (6)

Other (please specify) (7)

Prefer not to answer (8)

\section{What is your denomination or faith tradition?}

\section{Almost Done!}

If you would like to go back and review your answers, press the "BACK" button. If you are ready to submit your survey, press the "SUBMIT!" button now. 
APPENDIX B

YOUTH MINISTRY COLLABORATION ACTIVITY SCALE 


\section{Youth Ministry Collaboration Activity Scale}

\section{Working with Other Youth-Serving Organizations}

Which of the following things have you done in the past 12 months? Please check all that apply.

$\square$ Communicated with youth leaders outside of my organization for personal connections, encouragement, or support. (1)

$\square$ Communicated with youth leaders outside of my organization to discuss a specific concern, issue, or event. (2)

P Posted an event on a calendar that people outside my organization can access. (3)

$\square$ Participated in a youth leader network in my city. (4)

$\square$ Shared information about training or funding opportunities with youth leaders outside of my organization. (5)

$\square$ Worked with youth leaders outside of my organization to implement events or trainings. (6)

$\square$ Directed youth to other programs in my community. (7)

$\square$ Received approval from my organization to work with other youth-serving organizations. (8)

$\square$ Worked with another organization to establish a new entity that achieves a common goal. (9)

$\square$ Received full commitment and resources from my organization to work with other youth-serving organizations. (10)

If response is Yes to activity - How many times in the past 12 months?

\section{Your Comments}

Please use the space below to provide any other comments you may have that are relevant to this survey. 
APPENDIX C

DVULI PROGRAM LOGIC MODEL 


\section{DeVos Urban Leadership Initiative 2006-2007 Evaluation Plan}

(Working Document)

This Evaluation Plan has been developed from data generated from the evaluation planning process conducted in the summer of 2005 with DVULI staff. It is the Initiatives' first-attempt at incorporating staff understandings of activities and aligning them with Initiative goals for the purpose of developing an evaluation framework. It is being offered as a working document for reaction and feedback. The plan's aim is to facilitate reflective dialogue, and clarification toward meaning making and the refinement of a workable evaluation plan for the Initiative.

The Evaluation Plan has taken into consideration the following design goals:

- The achievement of triangulation (i.e., corroborative measurements through multiple methods);

- reduced reliance on participant self-report;

- reusability of existing evaluative instruments

- intentional links to program generated data and natural opportunities to collect data; and

- formalization through rubrics of current practices, hunches, knowings, and the like.

Further, the plan has been informed by the profound lessons learned in the 2002 research study Evaluating Outcomes and Impacts: A Scan of 55 Leadership Development Programs conducted by the W.K. Kellogg Foundation. It is strongly recommended that further refinements to the evaluation strategy be informed by this and other emerging efforts specifically focused on leadership development and the specific challenges It poses in evaluating transformation.

It is hoped that this document serves as a transition document for new Evaluation staff. 


\section{Preliminary Change Theory Model}

\begin{tabular}{|c|c|c|c|}
\hline Symptoms & Problem Statement & Change Theory & Change Strategy \\
\hline $\begin{array}{l}\text { - High burnout rates; } \\
\text { - } \quad \text { High turnover rates; and } \\
\text { - } \quad \text { Tendency to work harder } \\
\text { rather than smarter }\end{array}$ & $\begin{array}{l}\text { Youth ministry leaders experience } \\
\text { high burnout rates resulting in high } \\
\text { turnover rates. There is a tendency for } \\
\text { them to work in low leveraged } \\
\text { inefficient ways that have little } \\
\text { capacity to wade through the } \\
\text { complexity of urban ministry and } \\
\text { affect sustained change }\end{array}$ & $\begin{array}{l}\text { Equip leaders for sustained } \\
\text { time in ministry with } \\
\text { influence over youth }\end{array}$ & $\begin{array}{l}\text { Develop a valuing for and } \\
\text { incorporation of personal and } \\
\text { spiritual disciplines including: } \\
\text { account6ability, balance, } \\
\text { empowerment, interdependence, } \\
\text { and leverage. }\end{array}$ \\
\hline $\begin{array}{l}\text { - Underdeveloped ministry; } \\
\text { - Under-resourced ministries; } \\
\text { and } \\
\text { - Under-supported in } \\
\text { ministry }\end{array}$ & $\begin{array}{l}\text { Due to the complexities of the urban } \\
\text { environment, the typical emerging } \\
\text { youth ministry leader is } \\
\text { underdeveloped, under-resourced and } \\
\text { under-supported to effectively } \\
\text { negotiate the complexity. }\end{array}$ & $\begin{array}{l}\text { Foster the development of } \\
\text { healthy and supportive } \\
\text { ministry organizations. }\end{array}$ & $\begin{array}{l}\text { Increase emerging leaders' } \\
\text { knowledge of tools and skills } \\
\text { effective urban ministry } \\
\text { including: asset mapping, } \\
\text { resource networking, scenario } \\
\text { planning, and systems thinking. }\end{array}$ \\
\hline $\begin{array}{l}\text { - } \\
\text { - } \quad \text { Lhortage of leaders; } \\
\text { - } \quad \text { Perceived threat of } \\
\text { competition }\end{array}$ & $\begin{array}{l}\text { There is a shortage of youth ministry } \\
\text { leaders. Disproportionately, urban } \\
\text { youth leaders work as lone rangers } \\
\text { often influenced by a perceived threat } \\
\text { of competition. }\end{array}$ & $\begin{array}{l}\text { Promote replication of } \\
\text { equipped youth leaders } \\
\text { inside and outside of } \\
\text { ministry. }\end{array}$ & $\begin{array}{l}\text { Increase emerging leaders } \\
\text { understanding of the value of } \\
\text { replication; increase knowledge } \\
\text { of tools and skills for urban } \\
\text { ministry. }\end{array}$ \\
\hline $\begin{array}{l}\text { - Feelings of isolation; and } \\
\text { - Lack of support system }\end{array}$ & $\begin{array}{l}\text { The staffing patterns of urban youth } \\
\text { ministry characteristically include few } \\
\text { staff working voluntarily or bi- } \\
\text { vocationally. As such, youth ministry } \\
\text { workers tend to find themselves } \\
\text { lacking a support system and } \\
\text { experiencing feelings of isolation. }\end{array}$ & $\begin{array}{l}\text { Encourage working with } \\
\text { others who have a passion } \\
\text { for youth. }\end{array}$ & $\begin{array}{l}\text { Develop relationships with others } \\
\text { who have a passion for youth; } \\
\text { develop a shared vision for } \\
\text { collectively reaching youth. }\end{array}$ \\
\hline
\end{tabular}




\section{Program Logic Model}

\begin{tabular}{|c|c|c|c|}
\hline Resources & Activities & Outputs & Outcomes \\
\hline $\begin{array}{l}\text { Instructors } \\
\text { Books/articles/program } \\
\text { materials } \\
\text { Food } \\
\text { Lodging } \\
\text { Travel } \\
\text { Staff } \\
\text { Consultants } \\
\text { Technology } \\
\text { Curriculum } \\
\text { Money } \\
\text { Supplies/equipment } \\
\text { Office space }\end{array}$ & $\begin{array}{l}\text { Critical activities } \\
\text { Training/workshops } \\
\text { National conferences } \\
\text { Group dialogues } \\
\text { Home work } \\
\text { Breakthrough planning } \\
\text { Learning reflection and } \\
\text { journaling } \\
\text { City coordination } \\
\text { Curriculum design } \\
\text { Curriculum publishing } \\
\text { Event planning } \\
\text { Group recreation } \\
\text { Coaching } \\
\text { PR/New City Development } \\
\text { Graduation } \\
\text { Follow-up } \\
\text { Reunion events } \\
\text { Web management } \\
\text { Evaluation }\end{array}$ & $\begin{array}{l}\text { Attendance at local workshops } \\
\text { Attendance at group dialogues } \\
\text { Attendance at national } \\
\text { conferences } \\
\text { Completion of homework } \\
\text { assignments } \\
\text { Completion of learning journals } \\
\text { Completion of breakthrough plan } \\
\text { Completion of initiative } \\
\text { Selection and meetings with } \\
\text { mentor } \\
\text { Attendance at curriculum design } \\
\text { meetings } \\
\text { No. of urban experienced } \\
\text { instructors, city coordinators, } \\
\text { coaches, and staff } \\
\text { Relevant quality material on the } \\
\text { web } \\
\text { No. of completed satisfaction } \\
\text { survey } \\
\text { No. of completed session } \\
\text { feedback forms }\end{array}$ & $\begin{array}{l}\text { Initiative participants will } \\
\text { increase the sustained time in } \\
\text { ministry where they have } \\
\text { influence over youth. } \\
\text { Initiative participants will } \\
\text { increase knowledge and ability to } \\
\text { develop healthy and supportive } \\
\text { ministry organizations. } \\
\text { Initiative participants will } \\
\text { increase knowledge and ability to } \\
\text { develop themselves and others for } \\
\text { ministry to youth. } \\
\text { Initiative participants will } \\
\text { increase relationships with others } \\
\text { who have a passion for youth. }\end{array}$ \\
\hline
\end{tabular}




\section{Outcome Measurement Framework and Goal Alignment}

\begin{tabular}{|c|c|c|c|}
\hline \multicolumn{4}{|c|}{ Goal 1: To equip participants for sustained work in ministry } \\
\hline Outcome & Indicator(s) & Data Source & Data Collection Method \\
\hline $\begin{array}{l}\text { Initial: To improve level of } \\
\text { accountability }\end{array}$ & $\begin{array}{l}\text { Number and percent of participants with } \\
\text { improved accountability indicators (i.e., have a } \\
\text { mentor, openness to feedback, journal as a } \\
\text { practice using formal methods) }\end{array}$ & Participant self report & $\begin{array}{l}\text { Benchmarks of participant } \\
\text { questionnaire }\end{array}$ \\
\hline $\begin{array}{l}\text { Intermediate: To incorporate } \\
\text { with intentionality other } \\
\text { disciplines (i.e., balance } \\
\text { empowerment, interdependence, } \\
\text { leverage) in personal and work- } \\
\text { life. }\end{array}$ & $\begin{array}{l}\text { Number and percent of participants with } \\
\text { improved ratings on other disciplines } \\
\text { Balance: balance rating, use of time consistent } \\
\text { with importance } \\
\text { Empowerment: mentoring key subordinates, } \\
\text { providing leadership opportunities; directing } \\
\text { versus doing } \\
\text { Interdependence: activities with others, level } \\
\text { of involvement including shared visioning and } \\
\text { decision-making, formal agreements } \\
\text { Leverage: extent of sharing with people } \\
\text { groups; count of sharing with people }\end{array}$ & $\begin{array}{l}\text { Participant self report } \\
\text { Mentor }\end{array}$ & $\begin{array}{l}\text { Benchmarks of participant } \\
\text { Questionnaire } \\
\text { Benchmarks of Mentor } \\
\text { Questionnaire }\end{array}$ \\
\hline $\begin{array}{l}\text { Intermediate: To change } \\
\text { participant's values and beliefs } \\
\text { regarding effective activities and } \\
\text { strategies for negotiating the } \\
\text { complexity of urban ministry }\end{array}$ & $\begin{array}{l}\text { Number and percent of participants exhibiting } \\
\text { value and belief shifts regarding effective } \\
\text { activities and strategies for negotiating the } \\
\text { complexity of urban ministry }\end{array}$ & $\begin{array}{l}\text { Program-Generated } \\
\text { Data }\end{array}$ & $\begin{array}{l}\text { Rating based on rubric of } \\
\text { Breakthrough Plan or } \\
\text { Learning Journal }\end{array}$ \\
\hline $\begin{array}{l}\text { Long-term: to increase longevity } \\
\text { in ministry }\end{array}$ & $\begin{array}{l}\text { Count of years in ministry with influence on } \\
\text { well-being of youth } \\
\text { Attrition rate }\end{array}$ & Initiative records & $\begin{array}{l}\text { Survey's through web log- } \\
\text { ons, reunion events, P4 } \\
\text { Benchmark of participant } \\
\text { questionnaire }\end{array}$ \\
\hline
\end{tabular}




\section{Outcome Measurement Framework and Goal Alignment}

\begin{tabular}{|c|c|c|c|}
\hline \multicolumn{4}{|c|}{ Goal 2: To equip participants to develop healthy and supportive ministry organizations } \\
\hline Outcome & Indicator(s) & Data Source & Data Collection Method \\
\hline $\begin{array}{l}\text { Initial: To increase the level } \\
\text { of empowering leadership }\end{array}$ & $\begin{array}{l}\text { Number and percent of participants with improved } \\
\text { empowerment indicators: mentoring key subordinates, } \\
\text { shifts from doing to directing, coaching, or supporting }\end{array}$ & $\begin{array}{l}\text { Participants Self } \\
\text { Report }\end{array}$ & $\begin{array}{l}\text { Benchmarks of } \\
\text { Participant } \\
\text { Questionnaire }\end{array}$ \\
\hline $\begin{array}{l}\text { Initial: To increase use of } \\
\text { organizational effectiveness } \\
\text { tools and skills including } \\
\text { planning, resource } \\
\text { networking, systems } \\
\text { thinking, and asset mapping. }\end{array}$ & $\begin{array}{l}\text { Number and percent of participants with increased use of } \\
\text { ministry organization tools and skills including: } \\
\text { Resource networking: securing non-financial resources; } \\
\text { Scenario Planning: use of formal methods to plan for a } \\
\text { range (worst-to-best case) ministry futures; } \\
\text { Systems thinking: frequency examining assumptions, } \\
\text { beliefs, mental images, structures and how they contribute } \\
\text { to organizational problems; (add team learning - measure } \\
\text { communication modalities with } 10 \text { pt. scale), shared vision } \\
\text { - eval of members change potential); } \\
\text { Asset Mapping: increased availability of resource units } \\
\text { (i.e., people/orgs.) }\end{array}$ & $\begin{array}{l}\text { Participant self } \\
\text { report } \\
\text { Mentor }\end{array}$ & $\begin{array}{l}\text { Benchmarks of } \\
\text { participant } \\
\text { Questionnaire } \\
\text { Benchmarks of Mentor } \\
\text { Questionnaire }\end{array}$ \\
\hline $\begin{array}{l}\text { Intermediate: To improve } \\
\text { areas of ministry } \\
\text { organization toward greater } \\
\text { alignment between strategy, } \\
\text { capacity and relationships }\end{array}$ & $\begin{array}{l}\text { Number and percent of improved ratings on ministry } \\
\text { assessment }\end{array}$ & $\begin{array}{l}\text { Participant Self } \\
\text { Report }\end{array}$ & $\begin{array}{l}\text { Pre and Post Survey of } \\
\text { Ministry Assessment }\end{array}$ \\
\hline $\begin{array}{l}\text { Intermediate/Long-term: } \\
\text { to improve contribution to } \\
\text { organizational health and } \\
\text { supports }\end{array}$ & $\begin{array}{l}\text { Number and percent of improved participant leadership } \\
\text { effectiveness ratings by organizational staff, volunteers, or } \\
\text { youth }\end{array}$ & $\begin{array}{l}\text { Supervisor, } \\
\text { Colleagues, or } \\
\text { Volunteers (maybe } \\
\text { youth leaders) }\end{array}$ & $\begin{array}{l}360 \text { degree assessment } \\
\text { of leadership } \\
\text { effectiveness in creating } \\
\text { healthy and supportive } \\
\text { organizations }\end{array}$ \\
\hline
\end{tabular}




\section{Outcome Measurement Framework and Goal Alignment}

\begin{tabular}{|l|l|l|l|}
\hline \multicolumn{4}{|c|}{ Goal 3: To equip participants to reproduce themselves and develop others for leadership with youth } \\
\hline \multicolumn{1}{|c|}{ Outcome } & \multicolumn{1}{|c|}{ Indicator(s) } & \multicolumn{1}{c|}{ Data Source } & \multicolumn{1}{c|}{ Data Collection Method } \\
\hline $\begin{array}{l}\text { Initial: To increase activities } \\
\text { aimed at equipping others to } \\
\text { lead }\end{array}$ & $\begin{array}{l}\text { Number and percent of participants } \\
\text { with improved rating on subordinate } \\
\text { mentoring } \\
\text { Number and percent of participants } \\
\text { with improved rating on subordinate } \\
\text { leadership skill development }\end{array}$ & Participant self report & $\begin{array}{l}\text { Benchmarks of participant } \\
\text { questionnaire }\end{array}$ \\
\hline $\begin{array}{l}\text { Initial: To increase the depth } \\
\text { of sharing and assignment of } \\
\text { work to others }\end{array}$ & $\begin{array}{l}\text { Number and percent of participants } \\
\text { with improved rating on assignment } \\
\text { of work of subordinates } \\
\text { Leverage: extent of sharing with } \\
\text { people groups; count of sharing with } \\
\text { people groups }\end{array}$ & Participant Self Report & $\begin{array}{l}\text { Benchmarks of participant } \\
\text { Questionnaire }\end{array}$ \\
\hline $\begin{array}{l}\text { Intermediate: To change } \\
\text { participant's values and beliefs } \\
\text { regarding replication of } \\
\text { leaders }\end{array}$ & $\begin{array}{l}\text { Number and percent of participants } \\
\text { exhibiting value and belief shifts } \\
\text { regarding replication, empowerment, } \\
\text { or youth leadership development }\end{array}$ & Program-Generated Data & $\begin{array}{l}\text { Rating based on rubric of } \\
\text { Breakthrough Plan or Learning } \\
\text { Journal }\end{array}$ \\
\hline $\begin{array}{l}\text { Long-term: to increase } \\
\text { number and quality of youth } \\
\text { leadership programs }\end{array}$ & $\begin{array}{l}\text { Number and quality of youth } \\
\text { development programs being } \\
\text { established among participants }\end{array}$ & Participant Self Report & Survey \\
\hline
\end{tabular}




\section{Outcome Measurement Framework and Goal Alignment}

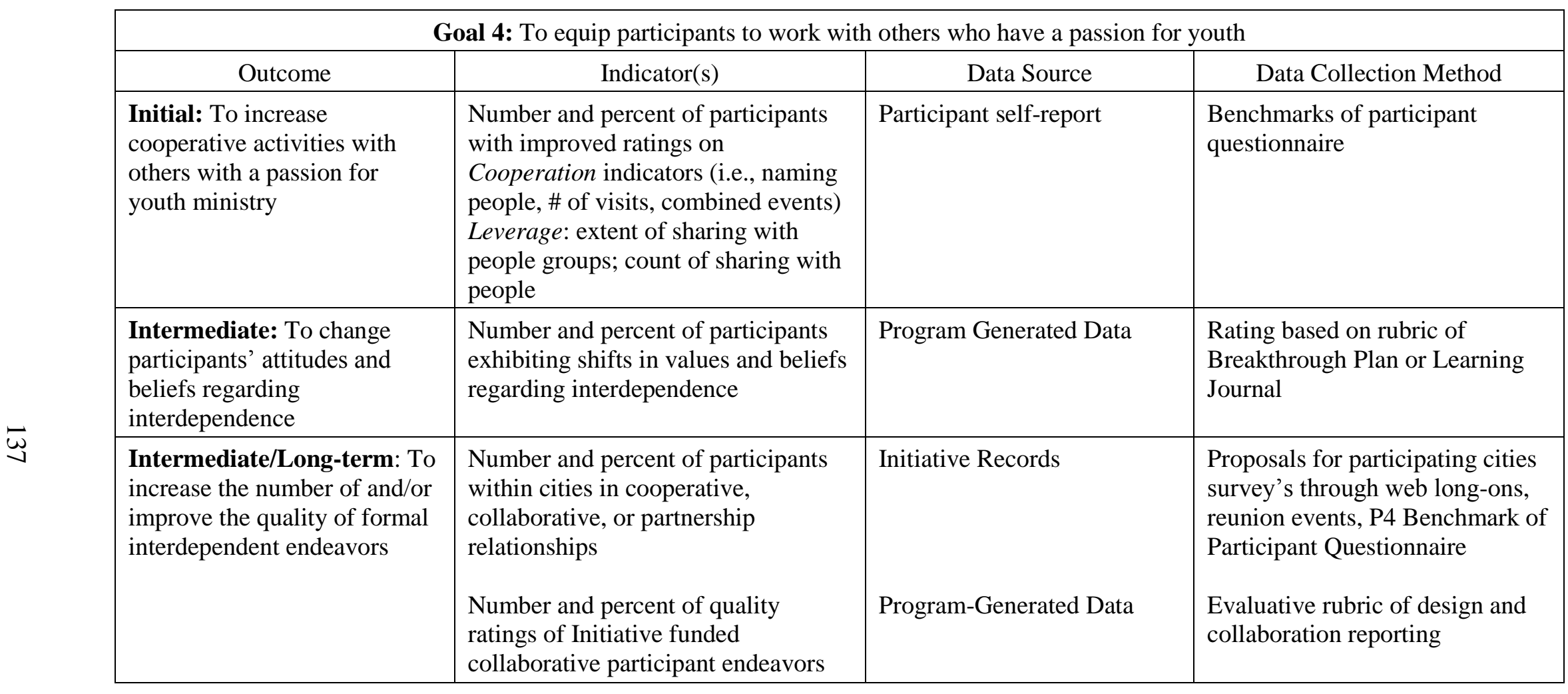




\section{APPENDIX D}

DVULI COLLABORATIVE LEADERSHIP SKILLS INTEGRATION 


\section{Collaborative Leadership Skills and Their Integration into the DeVos Urban Leadership Initiative}

Self-Reflection

Collaborative leaders are personally mature. They use self-reflection to understand their own values and think about whether their behaviors are congruent with their values. Good collaborative leaders have the ability to both reflect and adjust their behavior based on how it impacts others.
DVULI focus on self-reflection begins with the scripture passage of Romans 12:2, be transformed by the renewing of your mind. Program application points include:

- required journaling

- Core value of accountability - growth requires feedback from others

- personal assessments to identify personality traits, skills and abilities, leadership style, personal mission statement

- The ladder of inference

- Leadership and self-deception, blind spots

- Required mentor for learning journey

- Required written plan identifying leverage points for personal and ministry change

- Understanding that every leader has blind spots

- Understanding leadership and self-deception

- two live case studies presented by leaders who stumbled because they were not self-reflective and accountable

\section{Building trust}

The ability to build trust is an important part of the collaborative process. If stakeholders do not experience trust they will likely lose interest and may not be willing to share their ideas. The opportunity for surfacing creative solutions will be missed.
DVULI efforts to build trust among the cohort are based on the Biblical principle of unity and diversity. I Corinthians 12:7 says that all believers are given gifts to build each other up for the common good.

Program application is modeled through:

- selecting diverse participants that bring different perspectives to the cohort

- participants are required to room together

- time is provided for fun and social interaction

- participants worship together

- they attend dialogue meetings in between trainings with the city cohort

- A paid contracted local leader is responsible for convening and caring for the group

- a communication contract is established for the cohort at the first meeting

- group ground rules are established at the first meeting

- concepts presented include communication models, Systems thinking concept of mental model, the core values of Interdependence and accountability

In 2 Timothy 2:2 the apostle Paul tells Timothy to entrust what he has learned to reliable people who will be qualified to teach others. DVULI is both developing the participants in the
Developing people

Committing to the development of people as 
your key asset through mentoring and coaching.

program and teaching them that we are called to develop others through the following application points:

- Core Value - Empowerment

- Personal assessments: DiSC, Unique abilities

- Situational Leadership - Understanding how to adapt leadership style to the need of the follower

- Positive youth development; 40 developmental assets

- Community Youth Development; youth/adult partnership

- Resource networking, people are the most valuable resource

- DVULI models valuing people; Trainers are required to be available to participants for one on one consultation during meals and free time at workshops

- a live case study about youth who made an impact in their community

- Each participant is required to have a mentor

- Each mentor is required to attend an orientation to the program to help facilitate learning for the mentee

- Each supervisor/pastor is required to attend an orientation to understand the goals for the participant and provide support

Assessing the environment A collaborative leader understands the need to recognize common interests, purpose and values. This also involves being able to set priorities and identify obstacles and barriers.
The Bible reminds us in I Chronicles 12 that David chose leaders from Issachar who understood the times and the culture. An important part of leadership involves assessing the environment to make wise decisions. Program application points include:

- Being part of a learning community exposure to diverse perspectives

- Ministry assessment model

- Core Value - Interdependence

- Asset mapping; John McKnight

- Betterment to Development, James Lofquist

- Identifying youth as future community leaders

- Model of youth discipleship - Transformational Discipleship

- Resource Networking

- Systems thinking, understanding your role in connected systems

- Golding Game, Making Change Game; the importance of gathering information before beginning any initiative

- Approaching collaboration by scanning the community for like-minded people and organizations

- Scenario planning, preparing for alternative futures

- a live case study about youth who made an impact in their community

Creating ClarityVisioning and Mobilizing
Christian leaders understanding that they are but a small part of God's greater mission. They not only cast vision but also know 
Having clear values allows the collaborative leader to commit to a cause that transcends the self. In addition, committing to a process or way of doing things allows the leader to share the cause with others and help people develop the confidence to act.

how to inspire and mobilize people to work in their passion and strengths to implement the vision. Program application points include:

- Systems concept of shared vision

- Systems concept of alignment

- Interdependence with others who share a vision

- partnering together to avoid duplication of services

- Understanding how to adapt leadership style to the need of the follower (Situational Leadership)

- Understanding social change theory

- Common challenges to implementation of vision

- Pilot group model of change

- After Action Review

- Knowledge café

- DiBono's Six Thinking Hats

- The importance of networking to connect with others who share the same vision

- Empowerment as a tool to mobilize others for leadership

\section{Sharing power and} influence

This is an uncommon skill among leaders in western individualized countries. To work collectively, leaders need to feel empowered to share their experience and expertise as part of the decision-making process
Using Romans 12 as a foundation, DVULI believes that the community has many parts and God can use any of the parts to accomplish His mission. No one should think too highly of themselves or that they don't need others.

Program application points include:

- Learning together as peers in a cohort

- Wilder Foundation principles of collaboration

- Well Connected by Phill Butler, Biblical principles of collaboration

- Personal assessments and teaching on spiritual gifts

- Systems Thinking shared vision and alignment

- Leadership and self-deception

- 5 easy pieces exercise - the importance of not duplicating efforts and sharing resources

- The Web of life exercise

- Trainers who are practitioners

- Trainers who are skilled at drawing out the experience and expertise of the training participants as part of the learning format 
APPENDIX E

PERMISSION TO USE SURVEY 


\section{memo}

Date: December 16, 2015

To: Eileen Kooreman, DeVos Urban Leadership Initiative

From: Kristin Silvani, Production Coordinator, RWJF

Subject: Reprint permission

Thank you for your request dated $12 / 8 / 15$ to reproduce the document, Collaborative Leadership Self-Assessment Questionnaires, 2006.

RWJF is pleased to grant a non-exclusive, royalty-free license to you to reprint, publish, and distribute this work. Please ensure the following credit notice appears identifying RWJF as the copyright owner:

"Copyright 2006. Robert Wood Johnson Foundation. Used with permission from the Robert Wood Johnson Foundation."

RWJF does NOT grant permission for the graphics or text to be edited or modified in any way. Please reprint the infographic in its entirety.

As I am sure you will understand, RWJF reserves all rights not expressly granted to you in this letter and this license does not give you or anyone other than RWJF the right to allow others to publish the work without our express written consent. If anyone expresses an interest in using materials from this publication, have them get in touch with me and I would be happy to discuss granting permission.

Thank you,

Kristin Silvani 


\section{Kooreman, Eileen (RDV Corp - Foundations)}

$\begin{array}{ll}\text { From: } & \text { Silvani, Kristin <ksilvani@rwjf.org > } \\ \text { Sent: } & \text { Thursday, March 17, 2016 8:52 AM } \\ \text { To: } & \text { Kooreman, Eileen (RDV Corp - Foundations) } \\ \text { Cc: } & \text { ReprintPermission } \\ \text { Subject: } & \text { RE: Collaborative Leadership Questionnaire }\end{array}$

$\mathrm{Hi}$, Eileen. Thanks for reaching out. RWJF agrees to allow you to modify the format (but not the content) of the survey so that it may be used in your electronic platform.

Kristin Silvani

From: Eileen Kooreman [mailto:eileenk@dvuli.org]

Sent: Wednesday, March 16, 2016 4:22 PM

To: Silvani, Kristin <ksilvani@rwjf.org>

Subject: Collaborative Leadership Questionnaire

Hello Kristin,

I am returning to you again to clarify a few things about the permission you granted for using the collaborative leadership survey from Turning Point.

The letter that you provided states that I have to use the survey in its original format. "RWJF does NOT grant permission for the graphics or text to be edited or modified in any way. Please reprint the infographic in its entirety."

I'm sure that you can understand I was hoping to be able to send the survey to our study participants electronically since email is so much easier than collecting data on paper. We experimented with moving the survey into Qualtrics and found that if you will allow us to use it that way, it will also be necessary to make a few modifications to the original. For example, the original includes a way to self-score the assessment after each section. Since we will be compiling the results of the survey for those who participate, we would like to eliminate the information about how to self-score. Would you be able to grant me permission to make such modifications so that I can proceed with using the survey electronically?

If you would like to be able to see the survey in the electronic format, you should be able to access it here by copying and pasting this URL into your web browser:

https://calvin.co1.qualtrics.com/ife1/preview/SV bQvHiuJfGgqgLeB

Sincerely,

Eileen Kooreman

From: Silvani, Kristin [mailto:ksilvani@rwif.org]

Sent: Wednesday, December 16, 2015 1:57 PM

To: Kooreman, Eileen (RDV Corp - Foundations)

Subject: RE: Collaborative Leadership Questionnaire

$\mathrm{Hi}$, Eileen. Please find our approval letter attached. 


\section{APPENDIX F}

ALTERNATE VIEW OF DATA (GROUPING BY COOPERATION, COORDINATION, AND COLLABORATION

WITH ACTIVITY COUNT) 
Pearson Correlation using Cooperation, Coordination, and Collaboration Activity Count

\begin{tabular}{|c|c|c|c|c|c|c|c|c|c|c|}
\hline \multicolumn{11}{|c|}{ Correlations } \\
\hline & & $\begin{array}{l}\text { CooperationA } \\
\text { ctivityPercent }\end{array}$ & $\begin{array}{l}\text { Coordination } \\
\text { ActivityPercent }\end{array}$ & $\begin{array}{l}\text { Collaboration } \\
\text { ActivityPercent }\end{array}$ & $\begin{array}{l}\text { Self } \\
\text { Reflection } \\
\text { Average }\end{array}$ & $\begin{array}{l}\text { Building Trust } \\
\text { Average }\end{array}$ & $\begin{array}{l}\text { Developing } \\
\text { People } \\
\text { Average }\end{array}$ & $\begin{array}{l}\text { Assessing } \\
\text { the } \\
\text { Environment } \\
\text { Average }\end{array}$ & $\begin{array}{l}\text { Visioning and } \\
\text { Mobilizing } \\
\text { Average }\end{array}$ & $\begin{array}{c}\text { Sharing } \\
\text { Power and } \\
\text { Influence } \\
\text { Average }\end{array}$ \\
\hline \multirow{3}{*}{$\begin{array}{l}\text { CooperationActivityPerce } \\
\mathrm{nt}\end{array}$} & Pearson Correlation & 1 & $.671^{m \pi}$ & $.501^{n \pi}$ & $.151^{n}$ & $.196^{12}$ & $.221^{\mathrm{m}}$ & $.241^{n \pi}$ & $.308^{m+2}$ & $.233^{\mathrm{mm}}$ \\
\hline & Sig. (2-tailed) & & .000 & .000 & .030 & .005 & .001 & .000 & .000 & .001 \\
\hline & $\mathrm{N}$ & 215 & 215 & 215 & 207 & 206 & 206 & 207 & 206 & 205 \\
\hline \multirow{3}{*}{$\begin{array}{l}\text { CoordinationActivityPerce } \\
\mathrm{nt}\end{array}$} & Pearson Correlation & $.671^{\pi \times}$ & 1 & $.574^{\mathrm{nx}}$ & $.137^{x}$ & .121 & $.192^{\text {nN }}$ & $.154^{*}$ & $.233^{\mathrm{kn}}$ & $.220^{x *}$ \\
\hline & Sig. (2-tailed) & .000 & & .000 & .049 & .084 & .006 & .027 & .001 & .002 \\
\hline & $\mathrm{N}$ & 215 & 215 & 215 & 207 & 206 & 206 & 207 & 206 & 205 \\
\hline \multirow{3}{*}{$\begin{array}{l}\text { CollaborationActivityPerce } \\
\text { nt }\end{array}$} & Pearson Correlation & $.501^{\pi \times}$ & $.574^{\mathrm{Nx}}$ & 1 & $.198^{\mathrm{ma}}$ & $.278^{1 \times}$ & $.223^{m x}$ & $.160^{\circ}$ & $.305^{2 \times}$ & $.293^{2 \times}$ \\
\hline & Sig. (2-tailed) & .000 & .000 & & .004 & .000 & .001 & .022 & .000 & .000 \\
\hline & $\mathrm{N}$ & 215 & 215 & 215 & 207 & 206 & 206 & 207 & 206 & 205 \\
\hline \multirow[t]{3}{*}{ Self Reflection Average } & Pearson Correlation & $.151^{*}$ & $.137^{*}$ & $.198^{n \times}$ & 1 & $.575^{\mathrm{nx}}$ & $.563^{\mathrm{nx}}$ & $.453^{\mathrm{nx}}$ & $.395^{2 \times}$ & $.519^{\mathrm{nx}}$ \\
\hline & Sig. (2-tailed) & .030 & .049 & .004 & & .000 & .000 & .000 & .000 & .000 \\
\hline & $\mathrm{N}$ & 207 & 207 & 207 & 207 & 206 & 206 & 207 & 206 & 205 \\
\hline \multirow[t]{3}{*}{ Building Trust Average } & Pearson Correlation & $.196^{\prime \prime}$ & .121 & $.278^{n \times}$ & $.575^{\mathrm{kn}}$ & 1 & $.607^{m+1}$ & $.488^{2 *}$ & $.473^{\text {nx }}$ & $.658^{2 \times}$ \\
\hline & Sig. (2-tailed) & .005 & .084 & .000 & .000 & & .000 & .000 & .000 & .000 \\
\hline & $\mathrm{N}$ & 206 & 206 & 206 & 206 & 206 & 206 & 206 & 205 & 205 \\
\hline \multirow{3}{*}{$\begin{array}{l}\text { Developing People } \\
\text { Average }\end{array}$} & Pearson Correlation & $.221^{\pi \times}$ & $.192^{\mathrm{kn}}$ & $.223^{\text {nx }}$ & $.563^{\mathrm{nx}}$ & $.607^{\text {nx }}$ & 1 & $.575^{2 \times}$ & $.568^{\mathrm{xx}}$ & $.577^{\mathrm{Nx}}$ \\
\hline & Sig. (2-tailed) & .001 & .006 & .001 & .000 & .000 & & .000 & .000 & .000 \\
\hline & $\mathrm{N}$ & 206 & 206 & 206 & 206 & 206 & 206 & 206 & 205 & 205 \\
\hline \multirow{3}{*}{$\begin{array}{l}\text { Assessing the } \\
\text { Environment Average }\end{array}$} & Pearson Correlation & $.241^{n x}$ & $.154^{*}$ & $.160^{*}$ & $.453^{\mathrm{nn}}$ & $.488^{\text {nx }}$ & $.575^{2 n}$ & 1 & $.658^{\text {nk }}$ & $.506^{12}$ \\
\hline & Sig. (2-tailed) & .000 & .027 & .022 & .000 & .000 & .000 & & .000 & .000 \\
\hline & $\mathrm{N}$ & 207 & 207 & 207 & 207 & 206 & 206 & 207 & 206 & 205 \\
\hline \multirow{3}{*}{$\begin{array}{l}\text { Visioning and Mobilizing } \\
\text { Average }\end{array}$} & Pearson Correlation & $.308^{\text {nx }}$ & $.233^{\text {nk }}$ & $.305^{1 \times x}$ & $.395^{\mathrm{xk}}$ & $.473^{\text {nx }}$ & $.568^{\mathrm{kN}}$ & $.658^{\mathrm{Nm}}$ & 1 & $.527^{\mathrm{nm}}$ \\
\hline & Sig. (2-tailed) & .000 & .001 & .000 & .000 & .000 & .000 & .000 & & .000 \\
\hline & $\mathrm{N}$ & 206 & 206 & 206 & 206 & 205 & 205 & 206 & 206 & 204 \\
\hline \multirow{3}{*}{$\begin{array}{l}\text { Sharing Power and } \\
\text { Influence Average }\end{array}$} & Pearson Correlation & $.233^{\text {nx }}$ & $.220^{m+n}$ & $.293^{n \times}$ & $.519^{\mathrm{Nn}}$ & $.658^{m \times}$ & $.577^{m \times}$ & $.506^{\prime \prime}$ & $.527^{\mathrm{nn}}$ & 1 \\
\hline & Sig. (2-tailed) & .001 & .002 & .000 & .000 & .000 & .000 & .000 & .000 & \\
\hline & $\mathrm{N}$ & 205 & 205 & 205 & 205 & 205 & 205 & 205 & 204 & 205 \\
\hline
\end{tabular}

**. Correlation is significant at the 0.01 level (2-tailed).

*. Correlation is significant at the 0.05 level (2-tailed). 


\section{REFERENCE LIST}

Abele, J. (2011). Bringing minds together. Harvard Business Review, 89(7-8), 86-93, 164.

Altschuld, J. W. K., David Devraj. (2010). Needs assessment: An overview. Thousand Oaks, CA: Sage.

Ardichvili, A., \& Manderscheid, S. V. (2008). Emerging practices in leadership development. Advances in Developing Human Resources, 10(5), 619-631.

Association of Religion Data Archives. (2017). Religious groups: Profiles. Retrieved April 4, 2017, from http://www.thearda.com/denoms/families/groups.asp

Avolio, B. J., \& Gardner, W. L. (2005). Authentic leadership development: Getting to the root of positive forms of leadership. The Leadership Quarterly, 16(3), 315-338.

Benson, P., Scales, P., Hamilton, S., Sesma, A., Jr., Hong, K., \& Roehlkepartain, E. (2006). Positive youth development so far. Search Institute Insights \& Evidence, $3(1)$.

Black, A. M., \& Earnest, G. W. (2009). Measuring the outcomes of leadership development programs. Journal of Leadership \& Organizational Studies, 16(2), 184-196.

Bourda, T. B. (2014). Developing leaders in the nonprofit sector: Evaluating the influence of executive leadership training on collaboration (Doctoral Dissertation). Available from ProQuest Dissertations \& Theses Global. (UMI No. 3645206)

Burke, M. (1997). DeVos Urban Leadership Foundation preliminary research and design report. Available upon request from DVULI.

Burke, M., Galvin, J., O'Donnell, P., VanderHart, V., \& VanPatten, D. (1997). DVULI Development Documents. Available upon request from DVULI.

Butler, P. (2006). Well connected: Releasing power and restoring hope through kingdom partnerships. Federal Way, WA: Authentic.

Carter, H., \& Rudd, R. (2000). Evaluation of the florida leadership program for agriculture and natural resources. Journal of Southern Agricultural Research, 50(1), 193-199. 
Chien, N., Blasberg, A., Daneri, P., Halle, T., King, C., M., Z., . . Dwyer, K. (2013). Conceptualizing and measuring collaboration in the context of early childhood care and education (OPRE Research Brief). Washington D.C.: Office of Planning, Research and Evaluation, Administration for Children and Families, U.S. Department of Health and Human Services.

Chrislip, D. (2002). The collaborative leadership fieldbook. San Francisco, CA: Wiley.

Chrislip, D., \& Larson, C. (1994). Collaborative leadership: How citizens and civic leaders can make a difference (Vol. 24). San Francisco, CA: Jossey-Bass.

Chrislip, D. D., Larson, C. E., \& American Leadership Forum. (1994). Collaborative leadership: How citizens and civic leaders can make a difference (1st ed.). San Francisco, CA: Jossey-Bass.

Cohen, M. A., Piquero, A. R., \& Jennings, W. G. (2010). Estimating the Costs of Bad Outcomes for At-Risk Youth and the Benefits of Early Childhood Interventions to Reduce Them. Criminal Justice Policy Review, 21(4), 391-434. doi: $10.1177 / 0887403409352896$

Collins, J. C., \& Collins, J. (2006). Good to great and the social sectors. New York, NY: Random House.

Cooksy, L. J., Gill, P., \& Kelly, P. A. (2001). The program logic model as an integrative framework for a multimethod evaluation. Evaluation and Program Planning, 24(2), 119-128. doi:10.1016/S0149-7189(01)00003-9

Creswell, J. W. (2012). Educational research: Planning, conducting, and evaluating quantitative and qualitative research (4 ed.). New York, NY: Pearson.

Creswell, J. W. (2014). Research design: Qualitative, quantitative, and mixed method approaches (4th ed.). Thousand Oaks, CA: Sage.

Cross, J. E., Dickmann, E., Newman-Gonchar, R., \& Fagan, J. M. (2009). Using mixedmethod design and network analysis to measure development of interagency collaboration. American Journal of Evaluation, 30(3), 310-329. doi: $10.1177 / 1098214009340044$

Day, D. V. (2001). Leadership development: A review in context. The Leadership Quarterly, 11(4), 581-613. doi:10.1016/S1048-9843(00)00061-8

Dedrick, R., \& Greenbaum, P. (2011). Multilevel confirmatory factor analysis of a scale measuring interagency collaboration of children's mental health agencies. National Institute of Health Public Access, 19(1), 27-40. doi: $10.1177 / 1063426610365879$

DeVos Urban Leadership Initiative. (2017a). City Coordinator Handbook. Available upon request from DVULI. 
DeVos Urban Leadership Initiative. (2017b). City coordinator training 1 facilitation notes. Available upon request from DVULI.

DeVos Urban Leadership Initiative. (2017c). Core values. Retrieved April 17, 2011, from http://www.dvuli.org/content/core-values-healthy-change-3

DeVos Urban Leadership Initiative. (2017d). Goals. Retrieved January 10, 2017, from http://www.dvuli.org/the-program/description/goals

DeVos Urban Leadership Initiative. (2017e). Local workshop facilitation guide: Introduction. Available upon request from DVULI.

DeVos Urban Leadership Initiative. (2017f). Mission. Retrieved November 18, 2011, from http://www.dvuli.org/the-program/mission

DeVos Urban Leadership Initiative. (2017g). Partnerships. Retrieved December 12, 2016, from http://www.dvuli.org/content/partnerships

Duff, A. J. (2013). Performance management coaching: Servant leadership and gender implications. Leadership \& Organization Development Journal, 34(3), 204-220.

Edwards, G., \& Turnbull, S. (2013). Special issue on new paradigms in evaluating leadership development. Advances in Developing Human Resources, 15(1), 3-9. doi:10.1177/1523422312467147

Edwards, O. W., Mumford, V. E., \& Serra-Roldan, R. (2007). A positive youth development model for students considered at-risk. School Psychology International, 28(1), 29-45. doi:10.1177/0143034307075673

Eriksson, C., Shin, H., Walling, S., Lee, H., \& Montgomery, C. (2007). Risk and resilience in urban ministry: Stress, spirituality, and support. Report of General Findings. Pasadena, CA: Fuller Youth Institute (formerly Center for Youth and Family Ministry), Fuller Theological Seminary.

Eriksson, C., Tiersma-Watson, J., \& Powell, K. (2007). Stress in the city: A new study of youth workers. Retrieved from http://fulleryouthinstitute.org/articles/stress-in-thecity

Evans, G. W., \& Kutcher, R. (2011). Loosening the link between childhood poverty and adolescent smoking and obesity: The protective effects of social capital. Psychological Science, 22(1), 3-7. doi:10.1177/0956797610390387

Everist, N. C. (2002). Gender, power and leadership. Journal of Religious Leadership, 1(2), 67.

Fleischmann, P. (2014). Better together: Discovering the dynamic results of cooperation. Oviedo, FL: HigherLife Publishing \& Marketing. 
Freed, S. A., Covrig, D. M., \& Baumgartner, E. W. (2011). Learning while leadering: The andrews university leadership program. Journal of Applied Christian Leadership, 5(1), 27-56.

Frey, B. B., Lohmeier, J. H., Lee, S. W., \& Tollefson, N. (2006). Measuring collaboration among grant partners. American Journal of Evaluation, 27(3), 383-392. doi:10.1177/1098214006290356

Getha-Taylor, H., \& Morse, R. S. (2013). Collaborative leadership development for local government officials: Exploring competencies and program impact. Public Administration Quarterly, 37(1).

Gipson, A. N., Pfaff, D. L., Mendelsohn, D. B., Catenacci, L. T., \& Burke, W. W. (2017). Women and leadership. The Journal of Applied Behavioral Science, 53(1), 32-65. doi:10.1177/0021886316687247

Granner, M. L., \& Sharpe, P. A. (2004). Evaluating community coalition characteristics and functioning: A summary of measurement tools. Health Education Research, 19(5), 514-532.

Grant, H. M., \& Crutchfield, L. R. (2007). Creating high impact non-profits. Stanford Social Innovation Review, 5(4), 32-41.

Gray, B. (1989). Collaborating: Finding common ground for multiparty problems. San Francisco, CA: Jossey-Bass.

Greenleaf, R. K., \& Spears, L. C. (2002). Servant leadership: A journey into the nature of legitimate power and greatness (25th anniversary ed.). New York: Paulist Press.

Hankins, K., \& Walter, A. (2012). 'Gentrification with Justice': An Urban Ministry Collective and the Practice of Place-making in Atlanta's Inner-city Neighbourhoods. Urban Studies, 49(7), 1507-1526. doi:10.1177/0042098011415434

Hannum, K., Martineau, J., \& Reinelt, C. (2007). The handbook of leadership development evaluation (1st ed.). San Francisco: Jossey-Bass.

Harris, E. (2005). An introduction to theory of change. the Evaluation Exchange, 11(2).

Hibbert, P., \& Huxham, C. (2010). The past in play: Tradition in the structures of collaboration. Organization Studies, 31(5), 525-554. doi:10.1177/0170840610372203

Hsieh, J. Y., \& Liou, K. T. (2016). Collaborative leadership and organizational performance: Assessing the structural relation in a public service agency. Review of Public Personnel Administration. doi:10.1177/0734371x15623619 
Hughes, R. L., Ginnett, R., \& Curphy, G. (2012). Leadership: Enhancing the lessons of experience (7th ed.). New York, NY: McGraw-Hill.

Huxham, C., \& Vangen, S. (2005). Managing to collaborate: The theory and practice of collaborative advantage. New York, NY: Routledge.

Jameson, J. (2007). Investigating collaborative leadership for communities of practice in learning and skills. Lancaster University UK. Retrieved from http://citeseerx.ist.psu.edu/viewdoc/download?doi=10.1.1.301.6654\&rep=rep1\&t ype $=$ pdf

Kania, J., Hanleybrown, F., \& Juster, J. S. (2014, Fall). Essential mindset shifts for collective impact. Stanford Social Innovation Review, 12, S2-S5.

Kania, J., \& Kramer, M. (2011). Collective impact. Stanford Social Innovation Review, 9, $36-41$.

Kania, J., \& Kramer, M. (2013, January 21). Embracing emergence: How collective impact addresses complexity [Web log message]. Retrieved from http://ssir.org/articles/entry/

embracing_emergence_how_collective_impact_addresses_complexity

Keating, K. H. (2011). Training civic bridge builders: Outcomes of community leadership development programs (Doctoral Dissertation). Available from ProQuest Dissertations \& Theses Global. (UMI No. 3479113)

Kennedy, F., Carroll, B., \& Francoeur, J. (2013). Mindset not skill set: Evaluating in new paradigms of leadership development. Advances in Developing Human Resources, 15(1), 10-26. doi: 10.1177/1523422312466835

Kouzes, J. M., \& Posner, B. Z. (2007). The leadership challenge. 4th. San Francisco, CA: John Wiley \& Sons.

Kretzmann, J. P., \& McKnight, J. L. (1993). Building communities from the inside out. Chicago, IL: ACTA.

Krogstad, J. M., \& Cohn, D. V. (2014). U.S. Census looking at big changes in how it asks about race and ethnicity. Retrieved February 25, 2017, from http://www.pewresearch.org/fact-tank/2014/03/14/u-s-census-looking-at-bigchanges-in-how-it-asks-about-race-and-ethnicity/

Leavitt, M., \& McKeown, R. (2013). Finding allies, building alliances: 8 elements that bring--and keep--people together. San Francisco, CA: John Wiley \& Sons.

Lerner, R. M., \& Benson, P. (2003). Developmental assets and asset-building communities: Implications for research, policy, and practice (Vol. 1): New York, NY: Kluwer Academic/Plenum. 
Lerner, R. M., Lerner, J. V., Almerigi, J. B., Theokas, C., Phelps, E., Gestsdottir, S., . . von Eye, A. (2005). Positive youth development, participation in community youth development programs, and community contributions of fifth-grade adolescents: Findings from the first wave of the 4-H study of positive youth development. The Journal of Early Adolescence, 25(1), 17-71. doi: $10.1177 / 0272431604272461$

London, S. (2011, March 26). The power of informal networks. Retrieved from http://www.scottlondon.com/blog/archives/287

Main, B. (2005). Zip codes and a rolodex: Increasing the social capital of urban youth. Journal of Youth Ministry, 3(2), 25-36.

Mark, M. (2005). Evaluation theory: What are evaluation methods for? The Evaluation Exchange, 11(2), 2-5.

Mast, R. (2011). Best youth ministry ever! The Banner. Retrieved October 7, 2011, from https://thebanner.org/features/2011/10/best-youth-ministry-ever

Mattessich, P. W., Murray-Close, M., Monsey, B. R., \& Amherst H. Wilder Foundation. (2001). Collaboration--what makes it work (2nd ed.). Saint Paul, MN: Amherst H. Wilder Foundation.

McIntyre Hall, L., \& Kennedy, S. S. (2008). Public and nonprofit management and the "new governance". The American Review of Public Administration, 38(3), 307321. doi: 10.1177/0275074007309153

Meehan, D., \& Reinelt, C. (2007). Accelerating learning about leadership development The Handbook of Leadership Development Evaluation (pp. 511-535). San Francisco, CA: J. Wiley \& Sons.

Misner, I., \& Morgan, D. (2000). Masters of Networking. Marietta, GA: Bard Press.

Morgan, G. A., Leech, N. L., Gloeckner, G. W., \& Barrett, K. C. (2013). IBM SPSS for introductory statistics use and interpretation (5 ed.). New York, NY: Routledge.

Morrison, M., \& Arthur, L. (2013). Leadership for inter-service practice: Collaborative leadership lost in translation? An exploration. Educational Management Administration \& Leadership, 41(2), 179-198.

Mumford, M. D., Zaccaro, S. J., Harding, F. D., Jacobs, T. O., \& Fleishman, E. A. (2000). Leadership skills for a changing world: Solving complex social problems. The Leadership Quarterly, 11(1), 11-35. doi: http://dx.doi.org/10.1016/S10489843(99)00041-7

National Network of Youth Ministries. (2015). Youth Ministry Network Online Survey conducted in 2011 by OneHope. Received via attachment [E-mail to the author]. (2015, November 18). 
Nouwen, H. (1995). From solitude to community to ministry. Leadership Journal, Spring. Retrieved from http://www.christianitytoday.com/le/1995/spring/51280.html

O'Donnell, P. (2017). Research background for dissertation. [E-mail to the author]. (2017, August 12).

O'Leary, R., Choi, Y., \& Gerard, C. M. (2012). The skill set of the successful collaborator. Public Administration Review, 72(s1), S70-S83. doi: 10.1111/j.1540-6210.2012.02667.x

Pillsbury, J. D., Goddard-Truitt, V., \& Littlefield, J. (2009). Cross-sector performance accountability: Making aligned contributions to improve community well-being Retrieved from ngcg.org website: http://www.ngcg.org/resources/_reports/CrossSector\%20Performance\%20Accountability\%20-\%20Making\%20Aligned\%20 Contributions\%20to\%20Improve\%20Community\%20Well-Being.pdf

Pittman, K. J., Irby, M., Tolman, J., Yohalem, N., \& Ferber, T. (2011). Preventing problems, promoting development, encouraging engagement. Proceedings of the 2011 Conference. Washington, DC: Forum for Youth Investment.

Putnam, R. D. (2015). Our kids. New York, NY: Simon \& Schuster.

Ruben, B. D., \& Gigliotti, R. A. (2016). Leadership as social influence: An expanded view of leadership communication theory and practice. Journal of Leadership \& Organizational Studies, 23(4), 467-479.

Rubin, H. (2002). Collaborative leadership: Developing effective partnerships in communities and schools. Thousand Oaks, CA: Corwin.

Russon, C., \& Reinelt, C. (2004). The results of an evaluation scan of 55 leadership development programs. Journal of Leadership \& Organizational Studies, 10(3), 104-107. doi: 10.1177/107179190401000309

RWJF. (2012). Robert wood johnson foundation survey guidelines. Retrieved May 22, 2015, from http://www.rwjf.org/en/library/research/2012/07/robert-woodjohnson-foundation-survey-guidelines.html

Scales, P. (2007). Early spirituality and religious participation linked to later adolescent well-being. Retrieved June 14, 2014, from http://www.searchinstitute.org/system/ files/a/Early-Spirituality-Religious-Participation.pdf

Sinha, J. W. (2013). Examining pros and cons of collaboration with small to midsized, grassroots, and strongly faith-based partners. Journal of Leadership Studies, 7(1), 61-69.

Stearns, R. (2013). Unfinished: Filling the hole in our gospel. Nashville, TN: Thomas Nelson. 
Steensland, B., Park, J. Z., Regnerus, M. D., Robinson, L. D., W. Bradford Wilcox, \& D.Woodberry, R. (2000). The measure of American religion: Toward improving the state of the art. Social Forces, 79(1), 291-318.

Taplin, D., \& Clark, H. (2012). Theory of change basics: A primer on theory of change. New York, NY: ActKnowledge.

Taylor, C. S., Smith, P. R., Taylor, V. A., von Eye, A., Lerner, R. M., Balsano, A. B., . . . Almerigi, J. B. (2005). Individual and ecological assets and thriving among african american adolescent male gang and community-based organization members: A report from wave 3 of the "overcoming the odds" study. The Journal of Early Adolescence, 25(1), 72-93. doi: 10.1177/0272431604271771

Thompson, L. S., \& Lerner, R. M. (2000). Pursuing policies promoting healthy youth development: The role of university-community collaborations. Policy, Politics, \& Nursing Practice, 1(1), 68-75. doi: 10.1177/152715440000100114

Thomson, A. M., Perry, J. L., \& Miller, T. K. (2009). Conceptualizing and Measuring Collaboration. Journal of Public Administration Research and Theory: 19(1), 2356.

Trulear, H. D. (2000). Faith based institutions and high risk youth: First report to the field. Retrieved from http://ppv.issuelab.org/advanced_search/results

Turning Point Leadership Development National Excellence Collaborative. (2006a). Collaborative leadership: Introduction, overview, and resources. $\mathrm{http} / / /$ socialmarketingcollaborative.org/smc/toolkit/pdf/CL_Introduction.pdf

Turning Point Leadership Development National Excellence Collaborative. (2006b). Collaborative leadership self-assessment questionnaires. Retrieved from http://www.collaborativeleadership.org/pages/pdfs/ CL_selfassessments

Turning Point Leadership Development National Excellence Collaborative. (2006c). Fundamental concepts facilitator's guide. http://socialmarketingcollaborative.org/smc/toolkit/pdf/CL_fund_concepts_ manual.pdf

Van De Valk, L. J. (2008). Leadership development and social capital: Is there a relationship? Journal of Leadership Education, 7(1), 47-64.

Van De Valk, L. J., \& Constas, M. A. (2011). A methodological review of research on leadership development and social capital: Is there a cause and effect relationship? Adult Education Quarterly, 61(1), 73-90.

VanderWaal, C. (2005). 2006-2007 Evaluation plan [Working document]. Available upon request from DVULI. 
VanderWaal, C., Carlson, N., Cain, C., Trecartin, S., Ichoya, C., Bishop, R., \& Louis, M. (2008). Achieving the Dream. Research Report. Andrews University.

Weiss, C. H. (1998). Have we learned anything new about the use of evaluation? American Journal of Evaluation, 19(1), 21.

Wenger, E. (1998). Communities of practice: Learning as a social system. The Systems Thinker, 9(5), 1-5.

Wheeler, W. (2006). A circle of place: Engaging institutions in shared values and actions to serve youth in crises. Retrieved August 19, 2017 from http://www.theinnovationcenter.org/news-events/articles-and-publications

Winer, M., \& Ray, K. (1994). Collaboration handbook. St. Paul, MN: Wilder.

Wolff, T. (2010). The power of collaborative solutions. San Francisco CA: Jossey-Bass.

Woodland, R. H., \& Hutton, M. S. (2012). Evaluating organizational collaborations: Suggested entry points and strategies. American Journal of Evaluation, 33(3), 366-383. doi: 10.1177/1098214012440028 


\section{Vita}

\section{Eileen R. Kooreman \\ 27 Library St. NE Unit 601 \\ Grand Rapids, MI 49503}

\section{EDUCATION}

2018 Ph.D. Leadership Studies, School of Education

Andrews University, Berrien Springs, MI

2003 M.B.A., Business Administration

Grand Valley State University, Grand Rapids, MI

1983 B.A., Business Administration

Rutgers University, Camden, NJ

\section{WORK EXPERIENCE}

1996-Present Director of Operations, DeVos Urban Leadership Initiative, Grand Rapids, MI

1992-1996 Computer Specialist/Pharmacy, Town \& Country Pharmacy Ridgewood, NJ

1988-1989 Account Representative, Comstock \& Theakston, Oradell, NJ

1986-1988 Production Planner, F. G. Montabert, Midland Park, NJ

1983-1985 Office Manager, Fischer Woods, Inc., Linwood, NJ

\section{PROFESSIONAL MEMBERSHIPS}

Phi Kappa Phi Honor Society

Association of Youth Ministry Educators 